\title{
Homogeneidad geoquímica de la alteración hidrotermal del cinturón de oro orogénico del NW de Sonora, México: Estudio de balance de masas en rocas encajonantes de la mineralización
}

\author{
Aldo Izaguirre ${ }^{1, *}$, Alexander Iriondo ${ }^{1,2}$, Juan Antonio Caballero-Martínez ${ }^{3}$, \\ Francisco Moreira-Rivera ${ }^{3}$, Enrique Espinosa-Arámburu ${ }^{3}$ \\ ${ }^{1}$ Centro de Geociencias, Universidad Nacional Autónoma de México, Campus Juriquilla, Boulevard Juriquilla 3001, Juriquilla, \\ 76230, Querétaro, México \\ ${ }^{2}$ Department of Geological Sciences, Jackson School of Geosciences, The University of Texas at Austin, Austin, 78712, Texas, EUA \\ ${ }^{3}$ Servicio Geológico Mexicano, Boulevard Felipe Ángeles km 93.50-4, Colonia Venta Prieta Pachuca, 42080, Hidalgo, México \\ *aldoizapo@gmail.com
}

\section{Resumen}

Un estudio geoquímico de balance de masas, combinado con otros de carácter multidisciplinario (petrografía, correlación geoquímica bivariable de $\mathrm{Au}$ y Ag e inclusiones minerales en pirita y oro nativo) en rocas encajonantes alteradas y en vetas de cuarzo presentes a lo largo del Cinturón de Oro Orogénico Caborca (COOC), permitieron evaluar el grado de homogeneidad geoquímica de los fluidos que generaron la alteración hidrotermal y las vetas auríferas que componen la mineralización en el NW de Sonora, México.

Los resultados del estudio de balance de masas, realizado mediante el método de isocona combinando geoquímica de roca fresca y alterada de 20 localidades del COOC, muestran que la mayoría de las rocas encajonantes ( $>50 \%)$ se enriquecieron en los compuestos y elementos $\mathrm{K}_{2} \mathrm{O}, \mathrm{W}, \mathrm{Cu}, \mathrm{Pb}, \mathrm{Mo}, \mathrm{Tl}, \mathrm{Be}, \mathrm{Zn}, \mathrm{V}, \mathrm{Sb}, \mathrm{Ag}, \mathrm{Sn}, \mathrm{SiO}_{2}$, Se, Ni y FeO. Por lo contrario, el balance de masas muestra un empobrecimiento en los elementos $\mathrm{Ca}, \mathrm{Y}, \mathrm{Na}, \mathrm{Ho}, \mathrm{Co}, \mathrm{Sr}, \mathrm{Yb}, \mathrm{Mn}, \mathrm{Dy}$, Er y Tb. Este consistente patrón de enriquecimiento y empobrecimiento encontrado en las muestras recolectadas en toda la extensión del COOC ( 400 km de largo y $\sim 60-80 \mathrm{~km}$ de ancho) sugiere un alto grado de homogeneidad de la alteración originada por los fluidos mineralizantes.

Los estudios petrográfícos de las rocas encajonantes frescas y alteradas sugieren que la alteración hidrotermal consistió principalmente en silicificación, sericitización, cloritización, epidotización y piritización. El estudio geoquímico bivariable de Au y Ag, realizado en vetas de cuarzo, indica una estrecha correlación (positiva) con los elementos que sufrieron mayor enriquecimiento en el estudio de balance de masas. De esta manera, estos pudieran proporcionar una guía geoquímica útil en la exploración mineral de Au en la región.

Por otro lado, en cristales de pirita y oro nativo de vetas de cuarzo se encontraron múltiples inclusiones minerales de oro y plata nativos, galena, covelita, esfalerita, molibdenita, scheelita y turmalina que explicarían, mineralógicamente, los enriquecimientos elementales detectados por los métodos geoquímicos empleados en este estudio.

Finalmente, la homogeneidad geoquímica del fluido mineralizante sugerida en este estudio permitiría proponer un evento coetáneo de mineralización de gran envergadura para gran parte del NW de Sonora (vetas de cuarzo con oro de tipo orogénico) durante el periodo compresivo laramídico que se desarrolló durante el Cretácico tardío al Terciario temprano.

Palabras clave: Balance de masas, homogeneidad, alteración hidrotermal, mineralización, oro orogénico, Sonora, México, método de isocona, vetas de cuarzo, microscopia electrónica, correlación bivariable.

\footnotetext{
Abstract

A geochemical mass balance study, combined with petrography, bivariate Au and Ag geochemical analysis, and inclusion study
} 
in pyrites and native gold, was performed on a suite of hydrothermally altered host rocks and contemporaneous quartz veins from the Caborca Orogenic Gold Belt in NW Sonora, Mexico (COOC; by its abbreviations in Spanish: Cinturón de Oro Orogénico Caborca). These combined studies helped evaluating the geochemical homogeneity of the mineralizing fluids that formed the alteration envelopes and the auriferous quartz veins in the entire area occupying the COOC ( 400 km long and $\sim 60-80 \mathrm{~km}$ wide belt).

The isocon statistical technique used in the mass balance study was applied on 20 pairs of mayor and trace element geochemical data of altered and fresh rock samples. The results show that the majority (>50\%) of the altered host rocks are enriched in $K_{2} O, W$, $\mathrm{Cu}, \mathrm{Pb}, \mathrm{Mo}, \mathrm{Tl}, \mathrm{Be}, \mathrm{Zn}, \mathrm{V}, \mathrm{Sb}, \mathrm{Ag}, \mathrm{Sn}, \mathrm{SiO}$, Se, $\mathrm{Ni}$ and $\mathrm{FeO}$, and are clearly depleted in $\mathrm{Ca}, \mathrm{Y}, \mathrm{Na}, \mathrm{Ho}, \mathrm{Co}, \mathrm{Sr}, \mathrm{Yb}, \mathrm{Mn}, \mathrm{Dy}, \mathrm{Er}$ and $\mathrm{Tb}$. The similar pattern of enrichment and depletion was shown by most of the studied samples suggesting a high degree of geochemical homogeneity of the mineralizing fluids.

Petrography on both the altered and fresh rocks indicates that the hydrothermal alteration primarily consisted of silicification, sericitization, chloritization, epidotization and pyritization. The bivariate Au and Ag geochemical studies, done in auriferous quartz veins, show a strong positive correlation between these two elements and the enriched elements shown by the mass balance study on the altered host rocks. Therefore, these elements could be utilized as a geochemical exploration guide to targeting orogenic gold deposits in the region. Multiple inclusions of native gold and silver, galena, covellite, sphalerite, molybdenite, scheelite and tourmaline were encapsulated in pyrite and native gold grains in the quartz veins. Presence of these mineral occurrences explains most of the elemental anomalies obtained geochemically on the quartz veins and altered host rocks.

In conclusion, the geochemical homogeneity of the mineralizing fluid, proposed in this study, implies that the mineralization (Aurich quartz veins) and associated alteration assemblages were part of a large-scale event synchronous with the Laramide orogeny when compressional tectonism was active during Late Cretaceous to Early Tertiary time.

Keywords: Mass balance, homogeneity, hydrothermal alteration, mineralization, orogenic gold, Sonora, México, isocon method, quartz veins, electron microscopy, bivariate correlaction.

\section{Introducción}

El siguiente trabajo presenta un estudio geoquímico de balance de masas de la alteración hidrotermal presente en las rocas encajonantes del Cinturón de Oro Orogénico Caborca (COOC), zona localizada al NW de Sonora, México (Figura 1). La denominación de COOC se presenta en este trabajo para comunicar y facilitar el manejo cuando se refiere a la mineralización aurífera de tipo oro orogénico en el NW de Sonora. El objetivo principal de este estudio ha sido el evaluar la hipótesis que asume una homogeneidad geoquímica de los fluidos hidrotermales mineralizantes durante la génesis de la mineralización de tipo orogénico a largo del COOC. Dicha homogeneidad será evaluada por medio de (1) un estudio geoquímico de balance de masas, (2) un análisis de correlación bivariable de los elementos químicos de las vetas de cuarzo del COOC, (3) petrografía de las rocas encajonantes frescas y alteradas (Figuras 2, 3 y 5; Tabla 1), y (4) la caracterización de microscopía electrónica de barrido con espectroscopía de energía dispersiva (SEM-EDS) de inclusiones minerales encapsuladas en granos de pirita y oro nativo.

Otro objetivo de este estudio de balance de masas es determinar la proporción de enriquecimiento, empobrecimiento e inmovilidad de elementos mayores, traza y preciosos de las muestras encajonantes de la mineralización utilizando pares de roca fresca y alterada. Esto se logra calculando los incrementos y decrementos en las concentraciones de cada elemento de la roca fresca (original) con respecto a la roca alterada por el proceso hidrotermal mineralizante. Para encontrar dichos cambios se usó el concepto de diagramas de isocona propuesto por Grant (1986) y que se presentará en este trabajo.

\section{Estudios previos de la mineralización de tipo orogénico en el NW de Sonora}

Los primeros estudios publicados en relación con el área que abarca el Cinturón de Oro Orogénico Caborca (COOC) fueron de carácter regional, con poco detalle, y consistieron en un reconocimiento de la geología estructural y geoquímica de la mineralización que sirvieron para delimitar la extensión y relaciones de $\mathrm{Au}-\mathrm{Ag}$ entre las expresiones minerales de este cinturón (Silberman et al., 1987, 1988). Sin embargo, en estos estudios se incluyeron depósitos epitermales u otras tipologías de yacimientos dentro de una inmensa área, mucho mayor a la actualmente propuesta en este estudio (Figura 1). Albinson (1989) realizó un estudio regional de inclusiones fluidas determinando que las vetas de cuarzo con Au son de tipo mesotermal, tipología que actualmente se conoce como oro orogénico. Estudios más recientes y de más detalle han permitido caracterizar temporal y geoquímicamente algunas zonas mineralizadas del COOC con el objetivo de contextualizar la mineralización y proponer su paragénesis. Estas zonas 


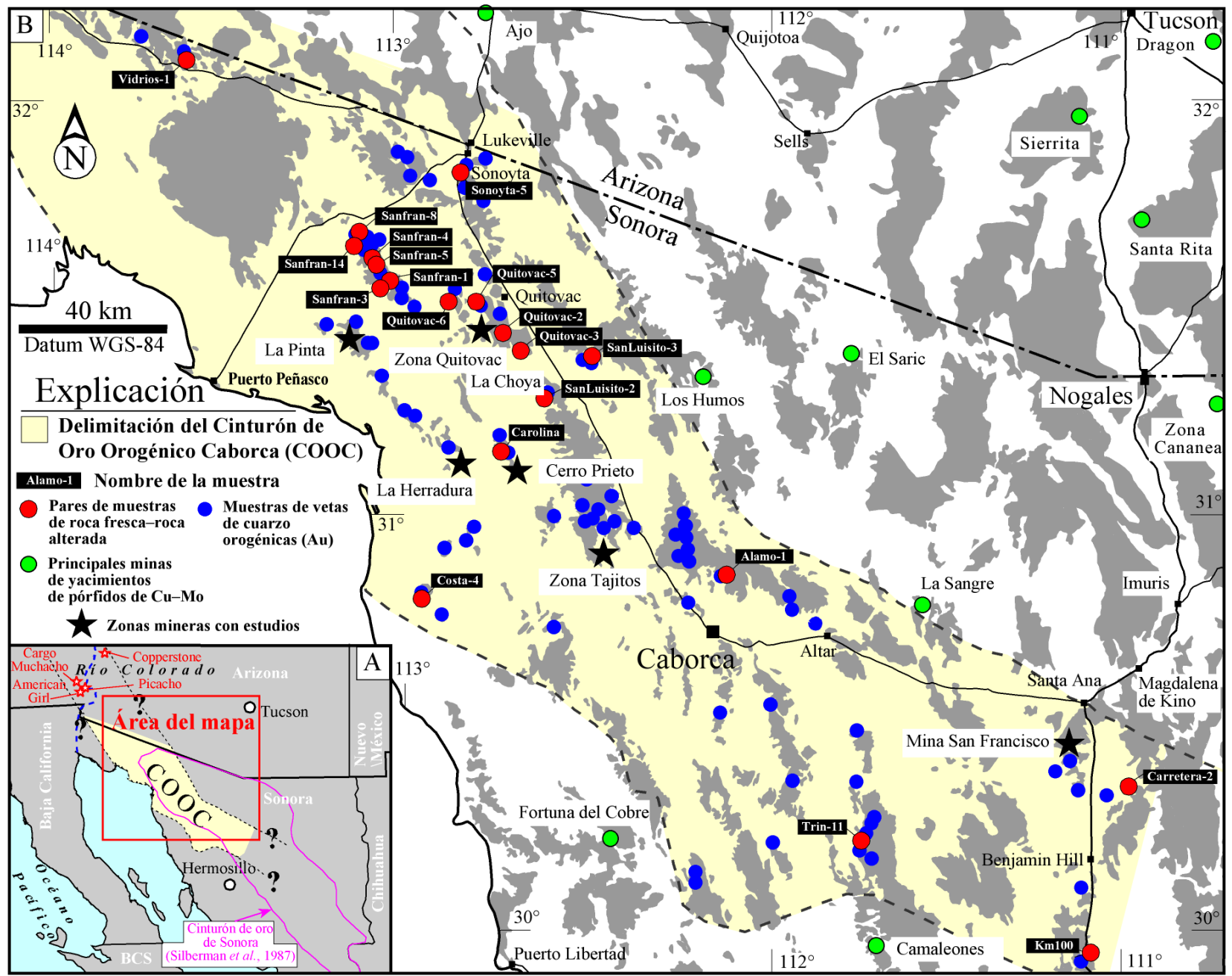

Figura 1. Localización de los pares de muestras de roca encajonante fresca y alterada para la realización del estudio de balance de masas en el Cinturón de Oro Orogénico Caborca (COOC), NW de Sonora, México. Afloramientos de cerros y sierras de roca firme en color gris y en blanco valles de sedimentos no consolidados. Polígonos del mapa tomados de Iriondo (2001).

mineralizadas (Figura 1) incluyen la Mina San FranciscoLlano (Changkuon, 1990; Pérez-Segura et al., 1996; AraizaMartínez, 1998; Poulsen et al., 2008), Zona Quitovac-La Choya (Durgin y Terán, 1996; Iriondo y Atkinson, 2000; Iriondo, 2001), Zona Tajitos (Noriega-Martínez, 2006), La Pinta (Araux-Sánchez, 2000) y La Herradura-Cerro Prieto (Quintanar-Ruíz, 2008; Ornelas-Macías y Verdugo-Noriega, 2009). Esta región mineralizada de $\mathrm{Au}$ (COOC) presenta las siguientes características:

1. Edades de mineralización del Cretácico tardíoTerciario temprano obtenidas por medio de estudios geocronológicos en sericita o mica blanca (K-Ar y Ar-Ar; Pérez-Segura et al., 1996; Iriondo y Atkinson, 2000; Araux-Sánchez, 2000; Iriondo, 2001) y magnetita o pirita (Re-Os; Quintanar-Ruíz, 2008).

2. El estudio de los fluidos mineralizantes, mediante la medición de inclusiones fluidas atrapadas en el cuarzo de las vetas, indican temperaturas medias de precipitación de $\sim 260-370^{\circ} \mathrm{C}$, salinidades bajas $(\sim 3 \%$ en peso equivalente de $\mathrm{NaCl})$ y contenidos altos en $\mathrm{CO}_{2}$ (p.e., Albinson, 1989; Pérez-Segura et al., 1996; Noriega-Martínez, 2006; QuintanarRuíz, 2008).

3. Cálculos termobarométricos sugieren presiones litostáticas de $\sim 1.1$ kbar que han permitido calcular profundidades medias de precipitación de las vetas de $3.5-4.5 \mathrm{~km}$ (Noriega-Martínez, 2006).

4. Las firmas isotópicas $(\mathrm{O}, \mathrm{H}, \mathrm{S}$ y $\mathrm{C})$ indican que los fluidos son de origen metamórfico, característico de la tipología de yacimientos minerales de oro orogénico (Quintanar-Ruíz, 2008).

En general, estos estudios también sugieren que este tipo de mineralización se precipitó, preferentemente, a lo largo de fallamientos y fracturas bien establecidas (zonas de debilidad). Por último, recientemente Iriondo y Premo (2010) sugirieron que los fluidos de mineralización de Au en el NW de Sonora se canalizaron precisamente por una zona de debilidad estructural que coincide espacialmente con los límites de la provincia de basamento paleoproterozoica 
Yavapai.

\section{Muestreo de las rocas encajonantes y vetas de cuarzo del COOC}

El muestreo consistió en colectar los pares de roca encajonate fresca y alterada y las vetas de cuarzo del Cinturón de Oro Orogénico Caborca (COOC) (Figura 1). Los puntos estratégicos a muestrear se seleccionaron empleando información de las publicaciones previas y las cartas geológico-mineras del Servicio Geológico Mexicano (SGM) a escala 1:250,000 del NW de Sonora. También los reportes en texto publicados por el SGM, donde se han ubicado minas o zonas mineralizadas con las características paragenéticas comunes del oro orogénico (vetas de cuarzo, carbonatos de calcio y/o hierro, sericita, mica blanca, clorita, epidota, pirita y galena, principalmente). Durante el muestreo se cubrió una proporción amplia de ocurrencias de la mineralización del $\mathrm{COOC}$, permitiendo un muestreo espacialmente representativo (Figura 1) colectando 20 pares de muestras de roca encajonante fresca y alterada, que fueran representativos de la mineralización. También se colectaron muestras en 102 vetas de cuarzo (Figura 1), que incluyeron algunos fragmentos de la roca encajonante alterada, como comúnmente se hace en el muestreo de tipo canal-esquirla. Las muestras de roca alterada se colectaron en los halos de alteración generados por los fluidos precursores de las vetas de Au del COOC. Las rocas frescas fueron colectadas alejadas de dicha zona alterada hasta encontrar roca visualmente fresca, que en promedio resultó comúnmente $\sim 10 \mathrm{~m}$ a partir del fin del halo de alteración generado por las vetas de cuarzo. Cabe aclarar que en algunos de estos puntos de muestreo existe cierto grado de enriquecimiento supergénico, producto, principalmente, del intemperismo de pirita. Este proceso pudo ser debido a variaciones del nivel freático, seguramente originadas durante procesos de oxidación-reducción en el periodo extensional (basculamientos) desde el Mioceno a la actualidad y que generó mineralogías secundarias como carbonatos y silicatos de cobre (p.e., malaquita, azurita, crisocola), wulfenita y óxidos de hierro (p.e., goethita).

Las observaciones de campo, realizadas durante el muestreo, permitieron trazar el perímetro aproximado que presenta geográficamente el Cinturón de Oro Orogénico Caborca (COOC; Figura 1). El COOC tiene dimensiones aproximadas de $400 \mathrm{~km}$ de largo y $60-80 \mathrm{~km}$ de ancho con una orientación NW-SE. El límite del muestreo, hacia la porción norte, fue la frontera política con los Estados Unidos (Arizona). Sin embargo, la mineralización de tipo orogénico aparentemente continúa, en dirección NW, hacia el estado de California, donde se han reportado ocurrencias de oro orogénico en la zona minera de Cargo Muchacho, American Girl y, posiblemente, Picacho y Copperstone (Branham, 1988; Figura 1A). El límite hacia el sureste del COOC se localiza a $\sim 50 \mathrm{~km}$ al SE del poblado de Benjamín
Hill donde terminan las ocurrencias de mineralización de esta tipología debido a la presencia de rocas volcánicas oligoceno-miocénicas que las cubren. Finalmente, hacia el NE y SW del cinturón, el límite está estimado por la presencia de otras tipologías de yacimientos (p.e., pórfidos cupríferos) con paragénesis minerales diferentes a las presentes en el COOC (Figura 1B).

\section{Técnicas analíticas}

\subsection{Preparación de las muestras}

La preparación de rocas encajonantes y vetas de cuarzo consistió en triturar $\sim 3 \mathrm{~kg}$ de muestra representativa de cada localidad a estudiar (Figura 1). Para el triturado se empleó una quebradora de gran capacidad marca Chipmuck que fue previamente limpiada con cada una de las muestras para evitar al máximo la contaminación entre muestras. Del material quebrado resultante se realizó un cuarteo para obtener $\sim 150$ g de gravilla que se utilizó en el proceso final de pulverizado usando el sistema de pulverizado Shatter Box con contenedores de alúmina para evitar contaminación metálica. Sin embargo, para el pulverizado de las muestras de vetas de cuarzo se utilizó un contenedor de carburo de tungsteno con anillo interno para agilizar el proceso. De cada muestra se obtuvieron $\sim 100 \mathrm{~g}$ de polvo con un tamaño de partícula inferior a las $\sim 74$ micras, el cual se envió para su análisis a los laboratorios del Centro Experimental Chihuahua pertenecientes al Servicio Geológico Mexicano.

Las muestras se analizaron por medio de diferentes técnicas analíticas para determinar las concentraciones de elementos mayores, traza y preciosos (Tablas A1 y A2 del Apéndice A). Se usaron las técnicas analíticas de espectrometría de emisión atómica con fuente de plasma de acoplamiento inductivo (ICP-AES, por sus siglas en inglés) para analizar $\mathrm{Al}, \mathrm{Al}_{2} \mathrm{O}_{3}, \mathrm{As}, \mathrm{Ba}, \mathrm{Be}, \mathrm{Bi}, \mathrm{CaO}, \mathrm{Co}$, $\mathrm{Cr}, \mathrm{Cu}, \mathrm{FeO}, \mathrm{Fe}_{2} \mathrm{O}_{3}, \mathrm{~K} 2 \mathrm{O}, \mathrm{MgO}, \mathrm{MnO}, \mathrm{Mo}, \mathrm{Na}_{2} \mathrm{O}, \mathrm{Ni}, \mathrm{P}_{2} \mathrm{O}_{5}$, $\mathrm{Pb}, \mathrm{Sb}, \mathrm{SiO}_{2}, \mathrm{Se}, \mathrm{Sn}, \mathrm{Sr}, \mathrm{Te}, \mathrm{TiO}_{2}, \mathrm{Tl}, \mathrm{V}, \mathrm{W}, \mathrm{Zn}$. También se empleó la espectrometría de masas con fuente de plasma de acoplamiento inductivo (ICP-MS, por sus siglas en inglés) para obtener Ag, Ce, Dy, Eu, Gd, Ho, Ir, La, Lu, Nd, Os, Pd, Pr, Pt, Rh, Ru, Sc, Sm, Tb, Th, Tm, U, Y, Yb. Por otro lado, la pérdida por calcinación (probablemente, y en mayor medida, se componga de $\mathrm{H}_{2} \mathrm{O}$, contenidos orgánicos, carbonato de calcio y dióxido de carbono) se obtuvo al calentar la muestra a $950^{\circ} \mathrm{C}$. Para el caso de la medición del Au se realizó copelación al fuego (fire assay) para obtener mejores resultados. Esto debido a que el oro de esta región se caracteriza por ser de grano fino, o criptocristalino, esta característica lo hace invisible, e inclusive cuando se emplea lupa de aumento.

\subsection{Método de balance de masas}

El estudio de balance de masas se elaboró utilizando 
el método de isocona propuesto por Grant $(1986,2005)$, técnica basada en los estudios pioneros de Gresens (1967). Esta consiste en emplear un simple gráfico binario " $\mathrm{x}-\mathrm{y}$ " donde, por costumbre universal, el eje " $x$ " es igual a la concentración de elementos químicos medidos en la roca fresca y el eje " $y$ " es igual a la concentración de elementos medidos en la roca alterada. Sobre este gráfico, se busca visualmente, o por medios estadísticos, una correlación entre los elementos que han tenido inmovilidad o que fueron inertes (argumento principal del método) durante el fenómeno geológico de alteración. De esta forma se elige la línea de isocona que se traza a través del origen $(0,0)$ y los elementos inertes elegidos (p.e., Figura 5). El campo por encima de la línea de isocona incluye o abarca los elementos que sufrieron enriquecimiento elemental, mientras que los del campo inferior a la isocona indican empobrecimiento. Este método ha sido útil en los estudios de balance de masas y de movilidad de elementos mayores, traza y preciosos en depósitos minerales de oro orogénico en Nueva Zelanda (Pitcairn et al., 2006) y China (Wei et al., 2001). En estos estudios, se han determinado los elementos característicos de la alteración hidrotermal que han servido como una guía de exploración y en el cálculo de predicción de volúmenes de roca mineralizada de Au. Así mismo, otras tipologías de yacimientos (p.e., skarn) también han sido estudiadas con este método, en donde se ha tratado de determinar los mismos aspectos antes mencionados (Lentz, 2005).

El estudio de balance de masas se realizó enteramente con el programa computacional GEOISO (Coelho, 2006) y se generaron gráficos binarios de la geoquímica de la roca fresca versus la roca alterada (Figura 5) para cada par de las muestras estudiadas. En la elaboración de estos gráficos, las concentraciones químicas de los elementos expresadas en diferentes unidades (p.e., ppm; \% en peso) se escalaron de forma arbitraria para conseguir treinta unidades en cada eje, multiplicando cada elemento por factores de normalización incluidos en el programa computacional. Cabe aclarar que cuando los valores de las concentraciones elementales de las muestras se encontraron por debajo del nivel de detección, se utilizó la mitad de ese valor (N.D.) para poder incluirlos en los diagramas de isocona (Tabla A1 del Apéndice A). Con ayuda de los algoritmos del programa se seleccionó la mejor isocona posible (línea de inmovilidad elemental), según los parámetros de correlación y error (Figura 5; línea en color verde). Por medio de estos algoritmos se obtuvieron las estimaciones de empobrecimiento, enriquecimiento e inmovilidad elemental que se muestran en las Figuras 6, 7, 8 y Tablas A3 a A5 del Apéndice A.

\subsection{Método de correlación geoquímica bivariable}

Con los datos geoquímicos obtenidos de las vetas se realizó un estudio de análisis de correlación geoquímica bivariable utilizando el paquete computacional Statistical Package for Social Sciencies (SPSS v19) para determinar el coeficiente de correlación " $r$ " entre el elemento clave
$\mathrm{Au}$ y los otros elementos traza y preciosos (Figura 9 y Tablas A6 del Apéndice A). Los coeficientes de correlación varían entre $-1 \mathrm{y}+1$, $\mathrm{y}$ cuando $\mathrm{r}=0$, significa una completa independencia entre dos elementos analizados; o bien, cuando $r=+1$, indica una relación funcional directa. Por último, cuando $r=-1$ representa una correlación funcional inversa (p.e., Davis, 1986). Cabe aclarar que al momento de realizar los cálculos para algunas de las muestras, se utilizó el valor del límite de detección de los elementos. Los valores de los límites de detección se encuentran listados en la Tabla A2 del Apéndice A.

\subsection{Técnica de SEM-EDS}

Los estudios de microscopía electrónica de barrido con detector de espectroscopía de rayos $\mathrm{X}$ de energía dispersiva (SEM-EDS, por sus siglas en inglés) se realizaron en granos milimétricos de pirita, oro y galena de algunas muestras de vetas de cuarzo del Cinturón de Oro Orogénico Caborca (COOC). El procedimiento consistió en la elaboración de probetas de resina epóxica, montando cristales de pirita y galena de algunas de las muestras estudiadas en cinta doble cara, para posteriormente verter la resina epóxica en un molde y capturar los granos. Después del endurecimiento de las probetas se desbastó y pulió hasta llegar aproximadamente a la mitad de los granos para obtener un área máxima de exposición de los mismos. Por otro lado, los granos de oro de las muestras observadas se adhirieron con pintura de carbón conductora de electrones en unas pequeñas pastillas metálicas que sirven para su transporte y análisis dentro del SEM.

Para la obtención de imágenes y espectros de energía dispersiva por medio de análisis puntual de las muestras de pirita y galena se utilizó un SEM-EDS de marca JEOL5800LV. Para las muestras de oro se empleó un FEI Quanta $450 \mathrm{FEG}$, ambos, equipos del laboratorio de microsonda y microscopia electrónica del U.S. Geological Survey, Federal Center, en Denver, Colorado, Estados Unidos. Los datos fueron reducidos con el paquete computacional NSS 2.3 Microbeam X-ray analysis de Thermo Scientific, del cual se obtuvieron espectros de elementos químicos y composiciones de los análisis puntuales realizados sobre las superficies de los minerales.

\section{Resultados}

5.1. Estudios petrográficos de luz transmitida en la roca encajonante

Mediante un estudio petrográfico de las 20 muestras de roca encajonante fresca y alterada se detectó que la alteración cuarzo-sericítica que solo se observa en algunas de las muestras megascópicamente, en el campo, se encuentra presente microscópicamente en la totalidad de las rocas estudiadas (Tabla 1 y Figuras 2 a 4). Algunos ejemplos 
Tabla 1. Resumen petrográfico de la mineralogía de las rocas encajonantes frescas y alteradas del Cinturón de Oro Orogénico Caborca, NW Sonora, México.

\begin{tabular}{|c|c|c|c|c|}
\hline $\begin{array}{l}\text { Muestra } \\
\text { Localidad } \\
\end{array}$ & Tipo de roca & Edad & $\begin{array}{c}\text { Roca fresca } \\
\text { Mineralogía primaria }\end{array}$ & $\begin{array}{c}\text { Roca alterada } \\
\text { Mineralogía de alteraración }\end{array}$ \\
\hline Alamo-1 & Arenisca & Jurásico temprano & $\mathrm{Qtz}+\mathrm{Pl}+\mathrm{Bt}$ & $\mathrm{Ser}+\mathrm{Ep}+\mathrm{Clr}$ \\
\hline Carolina-1 & Ortogneis & Paleoproterozoico & $\mathrm{Kfs}+\mathrm{Qtz}+\mathrm{Pl}+\mathrm{Bt}$ & Ser+Qtz \\
\hline Carretera-2 & Granito & Cretácico-Terciario & $\mathrm{Kfs}+\mathrm{Pl}+\mathrm{Qtz}+\mathrm{Bt} \pm \mathrm{Op}$ & $\mathrm{Ser} \pm \mathrm{Op}$ \\
\hline Costa-4 & Granito & Terciario temprano & $\mathrm{Kfs}+\mathrm{Pl}+\mathrm{Qtz}+\mathrm{Bt}$ & Ser+Qtz \\
\hline km100 & Ortogneis & Mesoproterozoico & $\mathrm{Kfs}+\mathrm{Pl}+\mathrm{Qtz}+\mathrm{Bt}$ & Ser $+Q t z \pm O p$ \\
\hline Quitovac-2 & Granito & Jurásico temprano & $\mathrm{Kfs}+\mathrm{Pl}+\mathrm{Qtz}+\mathrm{Bt} \pm \mathrm{Op}$ & Ser + Qtz \pm Op \\
\hline Quitovac-3 & Granito & Jurásico temprano & $\mathrm{Kfs}+\mathrm{Pl}+\mathrm{Qtz}+\mathrm{Bt} \pm \mathrm{Ttn} \pm \mathrm{Apt} \pm \mathrm{Op}$ & Ser + Qtz \pm Op \\
\hline Quitovac-5 & Granodiorita & Cretácico tardío & $\mathrm{Pl}+\mathrm{Kfs}+\mathrm{Qtz}+\mathrm{Bt}+\mathrm{Hbl} \pm \mathrm{Op}$ & Ser+Qtz $\pm \mathrm{Op}$ \\
\hline Quitovac-6 & Granito & Cretácico tardío & $\mathrm{Kfs}+\mathrm{Pl}+\mathrm{Qtz}+\mathrm{Bt}$ & Ser+Qtz \\
\hline Sanfran-1 & Granito & Cretácico tardío & $\mathrm{Kfs}+\mathrm{Pl}+\mathrm{Qtz}+\mathrm{Bt} \pm \mathrm{Apt} \pm \mathrm{Ttn}$ & $\mathrm{Ser}+\mathrm{Qtz}+\mathrm{Clr} \pm \mathrm{Op}$ \\
\hline Sanfran-3 & Granito & Cretácico tardío & $\mathrm{Kfs}+\mathrm{Pl}+\mathrm{Qtz}+\mathrm{Bt} \pm \mathrm{Apt} \pm \mathrm{Op}$ & Ser+Qtz $\pm \mathrm{Op}$ \\
\hline Sanfran-4 & Granito & Cretácico tardío & $\mathrm{Kfs}+\mathrm{Pl}+\mathrm{Qtz}+\mathrm{Bt} \pm \mathrm{Apt} \pm \mathrm{Op}$ & $\mathrm{Ser} \pm \mathrm{Op}$ \\
\hline Sanfran-5 & Granodiorita & Cretácico tardío & $\mathrm{Pl}+\mathrm{Kfs}+\mathrm{Qtz}+\mathrm{Bt} \pm \mathrm{Op}$ & Ser + Qtz \pm Op \\
\hline Sanfran-8 & Ortogneis & Paleoproterozoico & $\mathrm{Pl}+\mathrm{Qtz}+\mathrm{Kfs}+\mathrm{Hbl}+\mathrm{Bt}$ & Ser+Qtz \\
\hline Sanfran-14 & Ortogneis & Paleoproterozoico & $\mathrm{Pl}+\mathrm{Qtz}+\mathrm{Kfs}+\mathrm{Hbl}+\mathrm{Bt} \pm \mathrm{Op}$ & Ser+Qtz \pm Op \\
\hline Sanluisito-2 & Granito & Jurásico temprano & $\mathrm{Kfs}+\mathrm{Pl}+\mathrm{Qtz}+\mathrm{Bt} \pm \mathrm{Apt} \pm \mathrm{Op}$ & Ser+Qtz \pm Op \\
\hline Sanluisito-3 & Granodiorita & Jurásico temprano & $\mathrm{Pl}+\mathrm{Qtz}+\mathrm{Kfs}+\mathrm{Bt} \pm \mathrm{Ttn}$ & Ser+Qtz \\
\hline Sonoyta-5 & Granito & Cretácico tardío & $\mathrm{Kfs}+\mathrm{Pl}+\mathrm{Qtz}+\mathrm{Bt}$ & $\mathrm{Ser}+\mathrm{Qtz}+\mathrm{Ep}+\mathrm{Clr} \pm \mathrm{Op}$ \\
\hline Trin-11 & Ortogneis & Paleoproterozoico & $\mathrm{Kfs}+\mathrm{Pl}+\mathrm{Qtz}+\mathrm{Bt}$ & Ser+Qtz \\
\hline Vidrios-1 & Ortogneis & Paleoproterozoico & $\mathrm{Kfs}+\mathrm{Pl}+\mathrm{Qtz}+\mathrm{Bt} \pm \mathrm{Op}$ & $\mathrm{Ser}+\mathrm{Qtz} \pm \mathrm{Op}$ \\
\hline
\end{tabular}

$\mathrm{Ap}=$ apatito, $\mathrm{Bt}=$ biotita, $\mathrm{Clr}=$ clorita, $\mathrm{Ep}=$ epidota, $\mathrm{Hbl}=$ hornblenda, $\mathrm{Kfs}=$ feldespato, $\mathrm{Op}=$ opaco, $\mathrm{Pl}=\mathrm{plagioclasa}, \mathrm{Qtz}=\mathrm{cuarzo}, \mathrm{Ser}=\mathrm{sericita}(\mathrm{mica}$ blanca), Ttn = titanita. Signo +: Mineral componente, signo \pm : Mineral accesorio.

de los minerales de alteración hidrotermal (sericita, cuarzo, epidota, clorita y minerales opacos) se pueden apreciar en las fotografías de las figuras antes mencionadas. Así mismo, se pueden ver los fantasmas o relictos de mineral desaparecidos asociados a la pérdida (destrucción), principalmente de los minerales ferromagnesianos y plagioclasas en los ejemplares de roca alterada. Esta alteración no es propiamente homogénea ya que se observan, en la mayoría de las muestras, parches de sericita y mosaicos de cuarzo. En la Tabla 1 se presenta un resumen de la mineralogía primaria en la roca fresca (original) y de la mineralogía de alteración presente en la roca alterada como resultado del hidrotermalismo. También se señala una clasificación litológica general y la edad del protolito definida a partir de estudios geocronológicos y de correlaciones con otras rocas similares fechadas en otros lugares del NW de Sonora.

\subsection{Estudio geoquímico de balance de masas}

Los 20 pares de muestras de roca encajonante fresca y alterada por los fluidos mineralizantes del Cinturón de Oro Orogénico Caborca (Figuras 1 y 2; Tabla A1 del Apéndice A) se analizaron geoquímicamente para cuantificar las concentraciones de elementos mayores, traza y preciosos. De esta manera se pudo realizar un estudio de balance de masas usando la técnica de diagramas de isocona propuesta

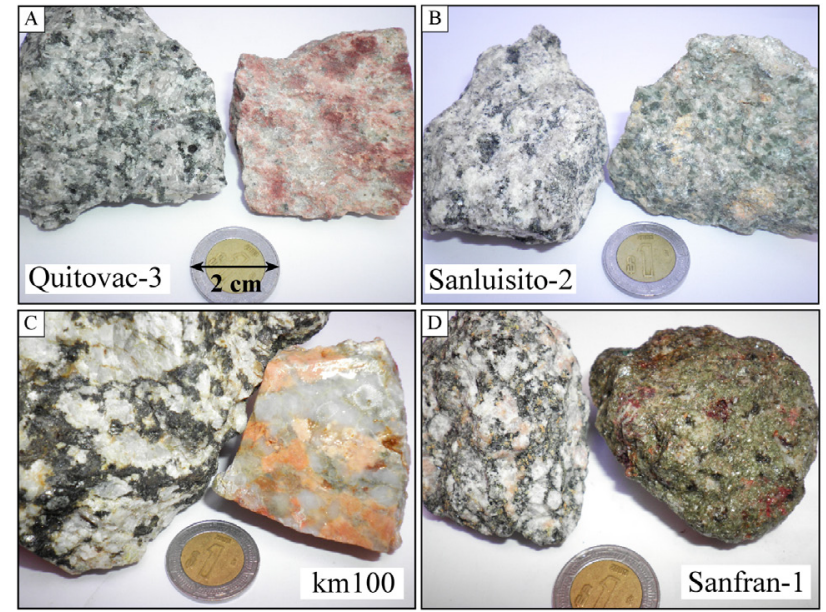

Figura 2. Fotografías de rocas encajonantes graníticas frescas (lado izquierdo de cada fotografía) y alteradas (lado derecho de cada fotografía) representativas del Cinturón de Oro Orogénico Caborca (COOC). En la fotografía A (muestra Quitovac-3) se puede observar una coloración rojiza de la roca alterada que indica la oxidación de los ferromagnesianos; también se observa mica blanca de color verde (sericita) que es producto de alteración mineral asociada al hidrotermalismo. En la fotografía B (muestra Sanluisito-2) se puede ver una coloración verdosa que indica la presencia de mica blanca, como mineral de alteración. En la fotografía $\mathrm{C}$ (muestra $\mathrm{km} 100$ ) se pueden ver, en la roca fresca, ferromagnesianos (oscuros) y feldespatos frescos (gris claro) y en contraparte alterados en el ejemplar de roca alterada. Finalmente, en la fotografía D (muestra Sanfran-1) se puede ver abundante mica blanca color verdosa en la muestra alterada comparando con su correspondiente ejemplar de roca fresca. 


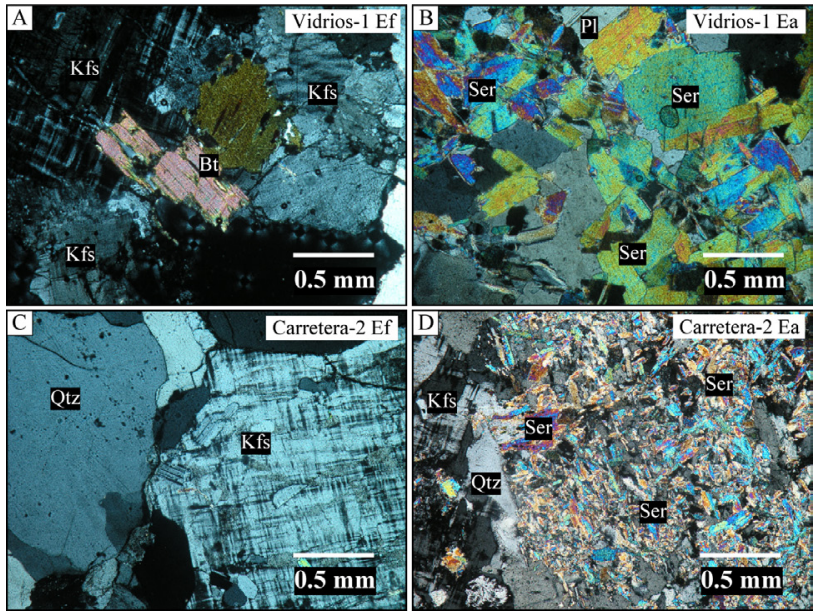

Figura 3. Fotomicrografías en luz polarizada analizada en sección delgada de rocas encajonantes frescas y alteradas por el hidrotermalismo en el Cinturón de Oro Orogénico Caborca (COOC). (A) Roca fresca gnéisica Vidrios-1 y (B) su contraparte alterada. (C) Roca fresca granítica Carretera-2 y (D) su contraparte alterada. $\mathrm{Bt}=$ biotita, $\mathrm{Kfs}=$ feldespato potásico (microclina), $\mathrm{Pl}=$ plagioclasa, $\mathrm{Qtz}=$ cuarzo, $\mathrm{Ser}=$ sericita $(\mathrm{mica}$ blanca).

por Grant (1986).

En la Figura 5A-D, se muestran 4 ejemplos representativos de estos diagramas de isocona con sus correspondientes diagramas de barras (Figuras 6A-D) con los elementos más útiles para evaluar el fenómeno de alteración hidrotermal en el COOC. En estos diagramas, los elementos que grafican por encima de la isocona (campo sombreado de color gris) indican que fueron enriquecidos durante el proceso de alteración hidrotermal. Los elementos y compuestos $\mathrm{K}_{2} \mathrm{O}, \mathrm{Cu}, \mathrm{W}, \mathrm{Mo}, \mathrm{Pb}, \mathrm{Be}, \mathrm{Ag}, \mathrm{Sb}, \mathrm{V}$ y Zn, y la pérdida por calcinación, señalados con una flecha punteada color rojo (Figura 5A), sufrieron un enriquecimiento de mayor envergadura en el total de las muestras del estudio. Por otro lado, los elementos que graficaron por debajo de la línea de isocona son los elementos que fueron empobrecidos durante el proceso de alteración hidrotermal, y están señalados con una línea punteada de color azul (Ca, Y, Na, Sr, Co, Mn y Dy).

El primer ejemplo de la Figura 5A corresponde a la muestra Sanfran-1 que es una roca granítica del Cretácico tardío (Tabla 1) que se localiza en la porción norte del COOC (Figura 1). En este ejemplo, la isocona se generó considerando los elementos $\mathrm{Al}_{2} \mathrm{O}_{3}, \mathrm{Pd}$ y $\mathrm{Sn}$ (elementos señalados en color verde como inmóviles) y forman un arreglo lineal con una muy buena correlación entre si (1.00 \pm 0.041; Tabla A3 del Apéndice A). La línea de isocona también coincide con la constante de aluminio, elemento que por su baja solubilidad se considera como un elemento básicamente inerte en los estudios de balance de masas (Baumgartner y Olsen, 1995; Grant, 1986) y que es ideal para trazar, incluso por sí solo, la línea de isocona a través del origen. Sin embargo, de la totalidad de las muestras de este estudio, solo en un $60 \%$ de los casos el $\mathrm{Al}_{2} \mathrm{O}_{3}$ muestra

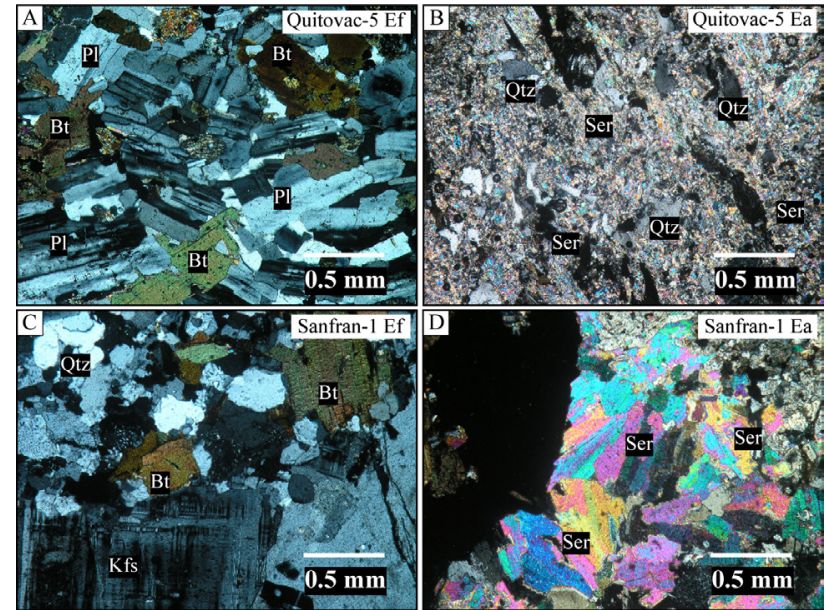

Figura 4. Fotomicrografías en luz polarizada analizada en sección delgada de rocas encajonantes frescas y alteradas por el hidrotermalismo en el Cinturón de Oro Orogénico Caborca (COOC). (A) Roca fresca microdiorítica Quitovac-5 y (B) su contraparte alterada. (C) Roca fresca granítica Sanfran-1 (D) su contraparte alterada. Bt = biotita, Kfs = feldespato potásico (microclina), $\mathrm{Pl}=$ plagioclasa, $\mathrm{Qtz}=$ cuarzo, $\mathrm{Ser}=$ sericita (mica blanca).

un comportamiento inerte, posiblemente debido a que la línea de isocona fue elegida por medios estadísticos, sin influencia del usuario, como sugieren Baumgartner y Olsen (1995) y Coelho (2006)

Los resultados de balance de masa indican que la muestra original (fresca) de la localidad Sanfran-1 tuvo una pérdida de masa de $21.3 \%$ en la zona alterada (Tabla A3 del Apéndice A). El óxido mayor $\mathrm{K}_{2} \mathrm{O}$ en la muestra Sanfran-1 se enriqueció y los fluidos incorporaron $\sim 2.48$ $\%$ de $\mathrm{K}_{2} \mathrm{O}$, lo que representa un incremento de $\sim 0.87$ veces o $\sim 87 \%$ su concentración con respecto al contenido en la roca fresca original (Tabla A3 del Apéndice A). El elemento $\mathrm{Cu}$ también fue enriquecido en $\sim 621 \mathrm{ppm}$, lo que representa $\sim 26$ veces la concentración original de la roca fresca (Figura 6A). En contrapartida, el óxido mayor $\mathrm{CaO}$ se empobreció en $2.37 \%$, lo que representa casi el doble ( $\sim 91 \%)$ del $\mathrm{CaO}$ presente en la roca original. El elemento Y se empobreció en 2.38 ppm representando un poco más de la mitad ( $\sim 54 \%)$ del contenido inicial en la roca fresca. Por otro lado, la inmovilidad geoquímica para los elementos inertes es expresada como cero (Tabla A3 del Apéndice A). Sin embargo, en algunos elementos (p.e., Os) puede que esta inmovilidad no sea representativa porque podría ser el resultado de la falta de precisión en las técnicas analíticas empleadas en su cuantificación. De esta manera, y sucesivamente, el empobrecimiento, enriquecimiento e inmovilidad se pueden leer con el resto de los elementos presentados en la Tabla A3 del Apéndice A.

La muestra granítica del Jurásico temprano Sanluisito-2 (Figuras 5B y 6B) se localiza hacia la zona centro del Cinturón de Oro Orogénico Caborca (Figura 1). De esta muestra se determinó estadísticamente una isocona con $\mathrm{FeO}, \mathrm{Sm} \mathrm{y} \mathrm{P}_{2} \mathrm{O}_{5}$ (señalados en color verde). Éstos forman 

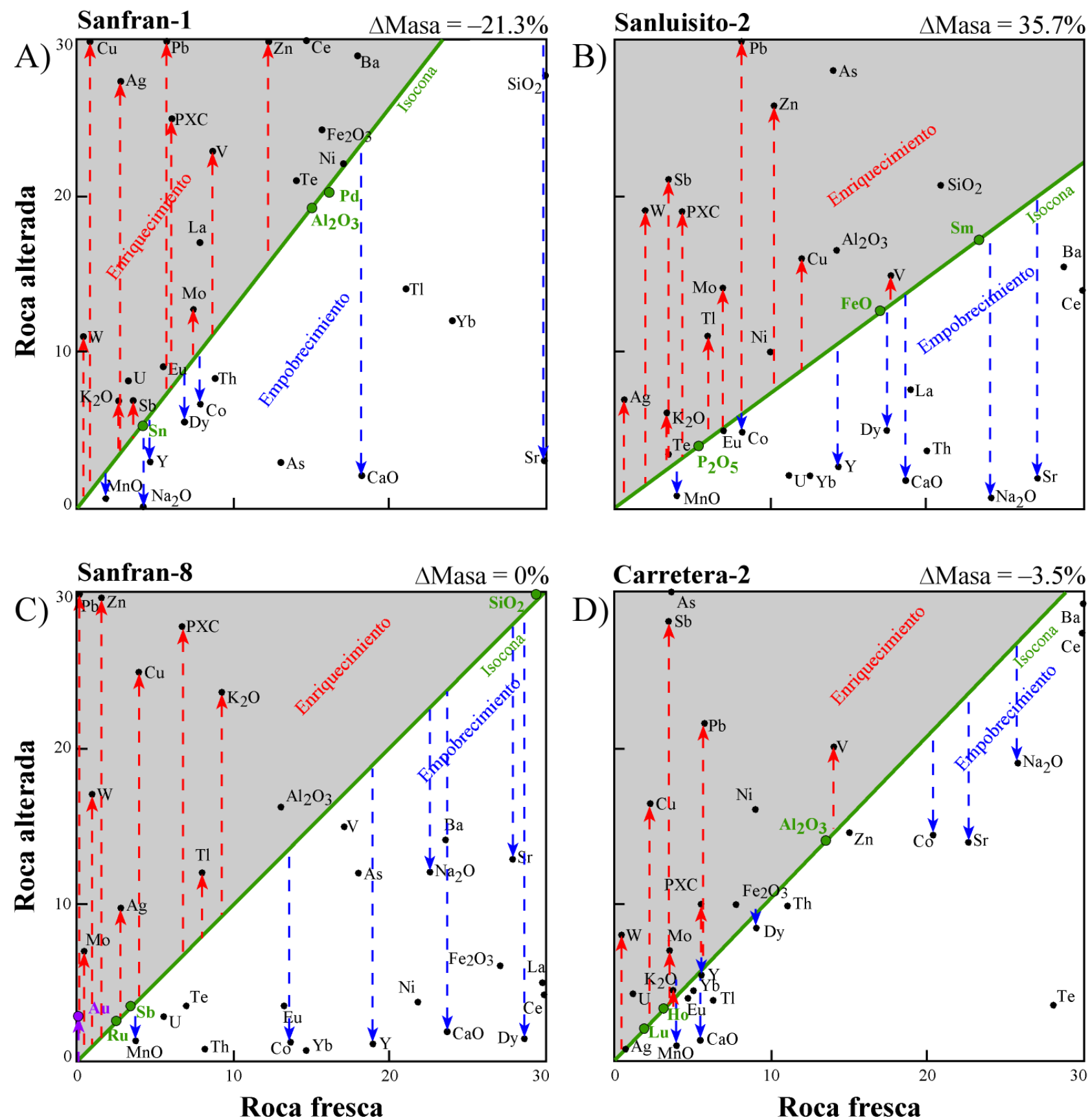

Figura 5. Diagramas de isocona de cuatro localidades representativas de zonas de alteración hidrotermal construidos a partir de elementos mayores y traza obtenidos en la roca encajonante fresca y alterada. La línea de isocona (línea de inmovilidad elemental en color verde) se encuentra dividiendo la tendencia de enriquecimiento (campo en gris) y empobrecimiento geoquímico (campo en blanco). Los elementos en verde fueron empleados para definir la línea de isocona. Las flechas rojas indican algunos de los elementos más característicos del enriquecimiento $\left(\mathrm{K}_{2} \mathrm{O}, \mathrm{W}, \mathrm{Cu}, \mathrm{Pb}, \mathrm{Mo}, \mathrm{Tl}, \mathrm{Zn}, \mathrm{V}, \mathrm{Sb}\right.$ y $\mathrm{Ag}$ ), y la pérdida por calcinación (PXC). Por otra parte, las flechas azules indican los elementos más característicos del empobrecimiento elemental a lo largo del $\mathrm{COOC}\left(\mathrm{CaO}, \mathrm{Na}_{2} \mathrm{O}, \mathrm{Sr}, \mathrm{Y}, \mathrm{Co}, \mathrm{Dy}, \mathrm{MnO}\right)$. El punto y la flecha morada en el diagrama $\mathrm{C}$ indican enriquecimiento en Au. Diagramas graficados con el programa computacional GEOISO (Coelho, 2006).

un arreglo lineal con un coeficiente de correlación de $1.00 \pm$ 0.003 (Tabla A3 del Apéndice A). En este caso, el aluminio no se comportó de forma inerte y presenta un pequeño grado de enriquecimiento que imposibilita usarlo en el cálculo de la isocona. De igual forma que en la descriptiva de la muestra anterior, se señalan con flechas punteadas en color rojo a los elementos que experimentaron una mayor proporción de enriquecimiento en el estudio, mientras que los elementos empobrecidos se señalan con flechas punteadas en color azul (Figura 5B). El elemento Tl se encuentra enriquecido ilustrándose que es uno de los elementos principales y representativos del enriquecimiento en las muestras del 

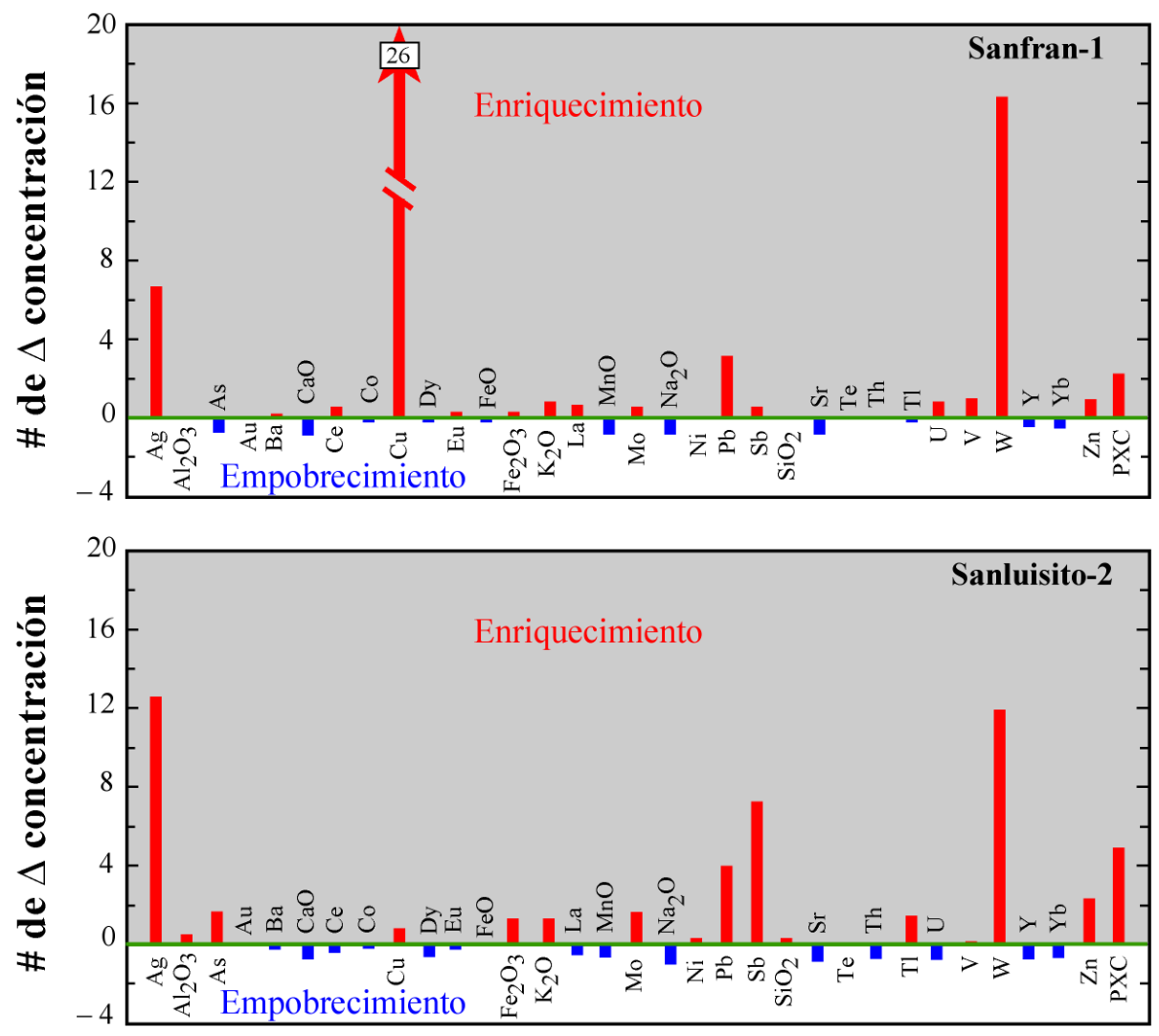

B)
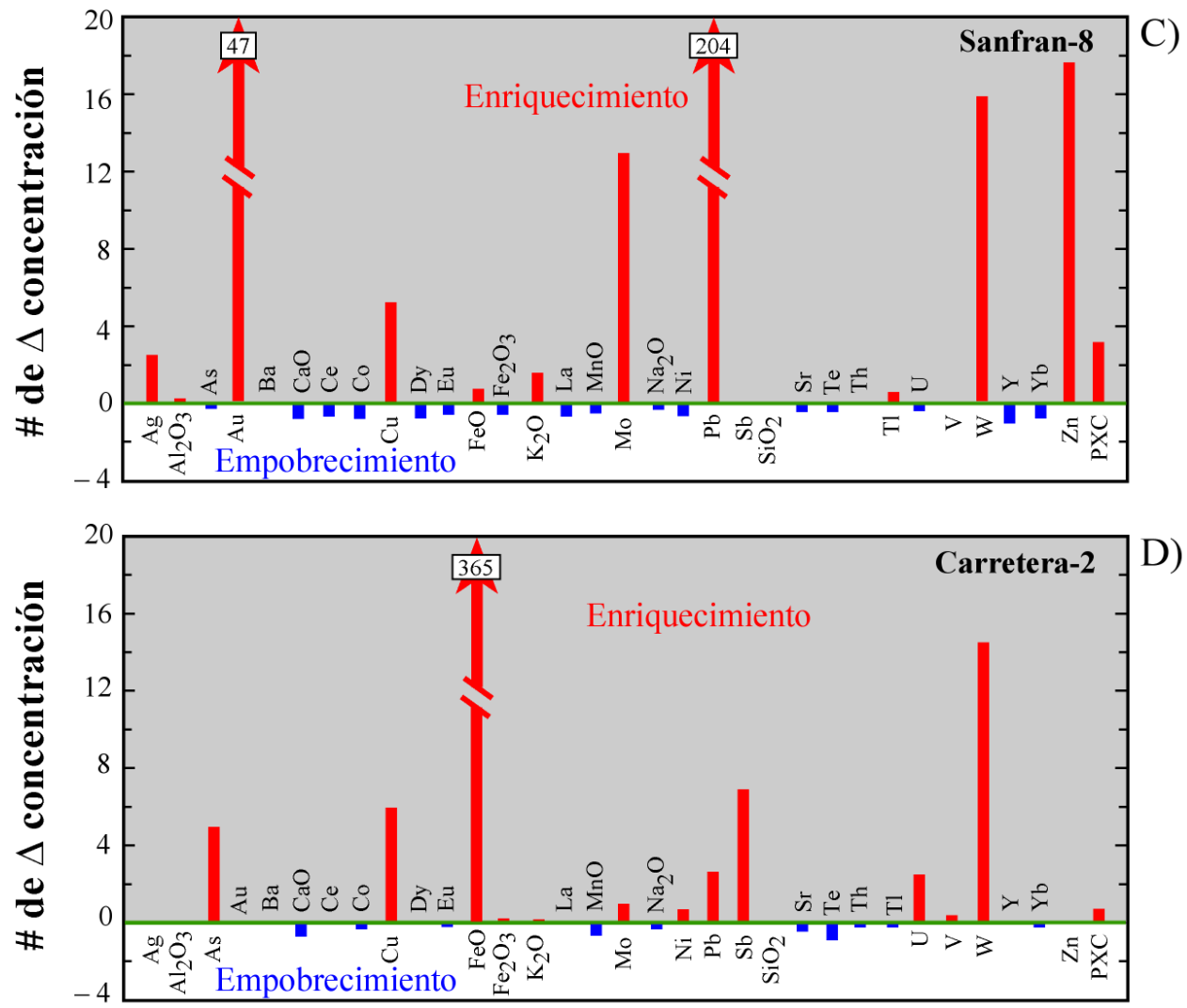

D)

Figura 6. Histogramas A, B, C y D, correspondientes a los cuatro diagramas de isocona de la Figura 5A, B, C y D, respectivamente. Estos diagramas fueron construidos con el programa computacional GEOISO (Coelho, 2006). \# de $\Delta$ concentración = número de veces que se enriqueció o empobreció cada elemento con respecto a su concentración original (roca fresca). Las barras con flecha roja indican el número de veces que se enriqueció ese elemento en particular. 
conjunto de este estudio. Esta muestra alterada presenta una ganancia de $35.7 \%$ con respecto al total de la masa de la roca fresca (Tabla A3 del Apéndice A). El óxido mayor $\mathrm{K}_{2} \mathrm{O}$ se enriqueció en una mayor proporción que en la muestra anterior; en el orden de $\sim 4.82 \%$, que implica $\sim 1.5$ veces $(141 \%)$ el contenido original en la roca (Figura 6B). En este caso, el enriquecimiento del $\mathrm{Cu}$ fue menor que en la muestra anterior ya que solo tuvo $9.71 \mathrm{ppm}$ de aumento, que representa casi el doble del contenido ( $~ 80 \%)$ en la roca fresca original. Por otra parte, el óxido mayor $\mathrm{CaO}$ se empobreció en $1.94 \%$, lo que representa $\sim 77 \%$ del $\mathrm{CaO}$ contenido en la roca fresca. También el Y se empobreció en 10.24 ppm, representando una disminución de $\sim 76 \%$ del contenido inicial.

La muestra Sanfran-8 (Figuras 5C y 6C) es una roca encajonante ortognéisica de edad paleoproterozoica localizada al norte del COOC (Figura 1) y de la cual se determinó una isocona con $\mathrm{Ru}, \mathrm{SiO}_{2}$ y Sb, con un coeficiente de correlación de $1.00 \pm 0.0003$ (Tabla A3 del Apéndice A). En esta muestra, el aluminio no se comportó de forma inerte presentando enriquecimiento, por lo que no fue seleccionado para formar parte de la isocona. También presenta enriquecimiento y empobrecimiento elemental en común con las otras muestras de este estudio (líneas punteadas en rojo y azul, respectivamente) y no presenta un cambio de masa considerable durante la alteración. Entre los elementos más enriquecidos se encuentran el $\mathrm{Pb}$, que se presenta $\sim 204$ veces (Figura 6C) más concentrado que en la roca fresca (Tabla A3 del Apéndice A), el Au con $\sim 47$ veces $(\sim 4700 \%)$ más de su concentración original, el Zn con $\sim 18$ veces más de su concentración original, y el $\mathrm{W}$ con 16 veces más de su concentración original. Por otro lado, los elementos más empobrecidos que presentó esta muestra fueron el Y, con un $97 \%$ de pérdida con respecto a la roca original, y el Er y Pt, con un $96 \%$ de pérdida con respecto a la roca original (fresca).

El último diagrama de isocona que se ejemplifica en la Figura 5 corresponde a la muestra Carretera-2 que es una muestra granítica de edad Cretácico tardío localizada al sur del Cinturón de Oro Orogénico Caborca (Figura 1). La línea de isocona de esta muestra se trazó con los elementos y compuestos con comportamiento inerte $\mathrm{Al}_{2} \mathrm{O}_{3}, \mathrm{Lu}$ y Ho, obteniendo un coeficiente de correlación de $1.00 \pm 0.003$ (Tabla A3 del Apéndice A). El aluminio, en este caso, se comportó como inerte y forma parte de la línea de isocona (Figura 5D). Esta muestra presenta un decremento de masa de $\sim 3.5 \%$ y un enriquecimiento y empobrecimiento elemental similar al de otras muestras de este estudio (líneas punteadas en rojo y azul, respectivamente). Entre los más enriquecidos se encuentran $\mathrm{FeO}, \mathrm{W}, \mathrm{Sb}, \mathrm{Cu}$ y As, y entre los más empobrecidos, $\mathrm{Te}, \mathrm{MnO}$ y $\mathrm{CaO}$ (Figura 6D).

Por su parte, en la Tabla 2 y Figura 7A se presenta un resumen de la totalidad de las muestras analizadas mediante este estudio geoquímico de balance de masas con un recuento semicuantitativo de la proporción de enriquecimiento, empobrecimiento e inmovilidad
Tabla 2. Resumen del balance de masas de la alteración hidrotermal en el Cinturón de Oro Orogénico Caborca, NW Sonora, México.

\begin{tabular}{|c|c|c|c|}
\hline Elemento & $\begin{array}{c}\text { Enriquecimiento } \\
\% \\
\end{array}$ & $\begin{array}{c}\text { Empobrecimiento } \\
\% \\
\end{array}$ & $\begin{array}{c}\text { Inmovilidad } \\
\% \\
\end{array}$ \\
\hline $\mathrm{K}_{2} \mathrm{O}$ & 90 & 10 & 0 \\
\hline PXC & 85 & 15 & 0 \\
\hline W & 85 & 15 & 0 \\
\hline $\mathrm{Cu}$ & 85 & 15 & 0 \\
\hline $\mathbf{P b}$ & 75 & 25 & 0 \\
\hline Mo & 75 & 15 & 10 \\
\hline Tl & 70 & 25 & 5 \\
\hline Be & 70 & 20 & 10 \\
\hline Zn & 60 & 40 & 0 \\
\hline V & 60 & 40 & 0 \\
\hline Sb & 60 & 25 & 15 \\
\hline $\mathrm{Ag}$ & 60 & 25 & 15 \\
\hline Sn & 55 & 35 & 10 \\
\hline $\mathrm{SiO}_{2}$ & 55 & 45 & 0 \\
\hline Se & 55 & 35 & 10 \\
\hline $\mathbf{N i}$ & 55 & 45 & 0 \\
\hline $\mathrm{FeO}$ & 55 & 35 & 10 \\
\hline $\mathbf{U}$ & 50 & 50 & 0 \\
\hline $\mathrm{TiO}_{2}$ & 50 & 35 & 15 \\
\hline Ir & 50 & 30 & 20 \\
\hline $\mathrm{Ce}$ & 50 & 45 & 5 \\
\hline Ba & 50 & 50 & 0 \\
\hline Th & 45 & 55 & 0 \\
\hline $\mathbf{T e}$ & 45 & 55 & 0 \\
\hline $\mathrm{Pr}$ & 45 & 55 & 0 \\
\hline MgO & 45 & 55 & 0 \\
\hline $\mathrm{Cr}$ & 45 & 55 & 0 \\
\hline $\mathbf{B i}$ & 45 & 35 & 20 \\
\hline As & 45 & 55 & 0 \\
\hline Ru & 40 & 40 & 20 \\
\hline $\mathbf{R h}$ & 40 & 40 & 20 \\
\hline La & 40 & 55 & 5 \\
\hline $\mathrm{Fe}_{2} \mathrm{O}_{3}$ & 40 & 60 & 0 \\
\hline Cd & 40 & 45 & 15 \\
\hline $\mathrm{Al}_{2} \mathrm{O}_{3}$ & 40 & 0 & 60 \\
\hline Sm & 35 & 55 & 10 \\
\hline Sc & 35 & 65 & 0 \\
\hline Pt & 35 & 50 & 15 \\
\hline Pd & 35 & 60 & 5 \\
\hline Nd & 35 & 55 & 10 \\
\hline Gd & 35 & 65 & 0 \\
\hline $\mathbf{P}_{2} \mathbf{O}_{5}$ & 30 & 55 & 15 \\
\hline Eu & 30 & 70 & 0 \\
\hline $\mathbf{Y b}$ & 25 & 75 & 0 \\
\hline $\mathbf{T m}$ & 25 & 60 & 15 \\
\hline Tb & 25 & 70 & 5 \\
\hline Lu & 25 & 65 & 10 \\
\hline MnO & 20 & 75 & 5 \\
\hline Dy & 20 & 75 & 5 \\
\hline Co & 20 & 80 & 0 \\
\hline Au & 20 & 25 & 55 \\
\hline $\mathbf{Y}$ & 15 & 85 & 0 \\
\hline $\mathrm{Sr}$ & 15 & 80 & 5 \\
\hline $\mathbf{N a}$ & 15 & 85 & 0 \\
\hline Ho & 15 & 85 & 0 \\
\hline $\mathbf{E r}$ & 15 & 5 & 80 \\
\hline $\mathrm{CaO}$ & 10 & 90 & 0 \\
\hline Os & 0 & 0 & 100 \\
\hline
\end{tabular}

Resumen porcentual obtenido con los resultados de $\Delta$ conc (Tabla A3 del Apéndice A).

* La inmovilidad elemental puede no ser representativa debido a las limitantes en las técnicas analíticas para la medición de la concentración de algunos elementos. Los datos sobre el área en color gris se pueden observar graficados en la Figura 7B. 


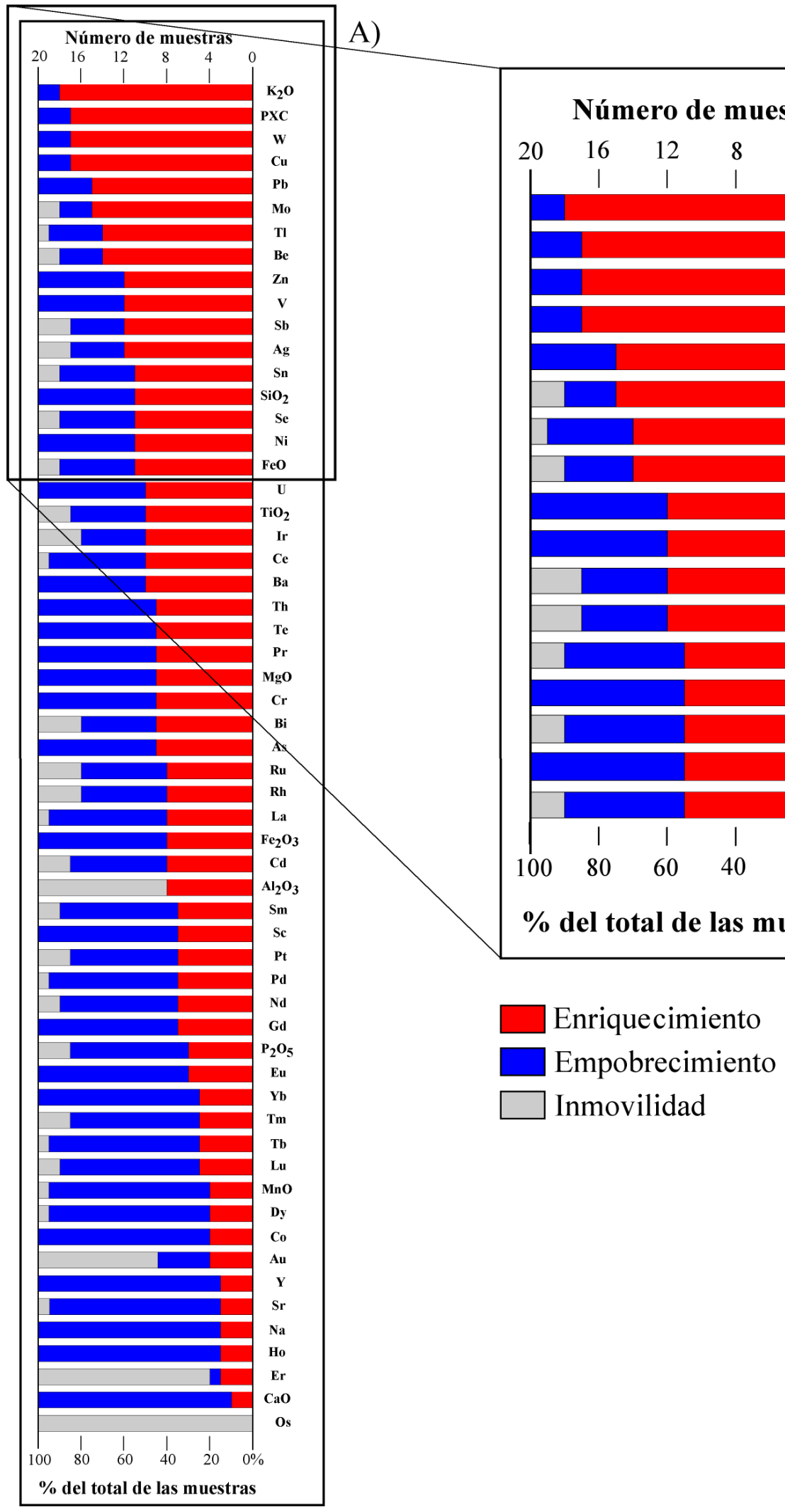

Figura 7. (A) Diagrama resumen del enriquecimiento, empobrecimiento e inmovilidad geoquímica obtenidos en el estudio de balance de masas de la totalidad de las rocas encajonantes frescas y alteradas estudiadas en el Cinturón de Oro Orogénico Caborca (COOC). (B) En este diagrama se enfatizan los elementos que sufrieron una mayor proporción o grado de enriquecimiento en las rocas encajonantes ( $>50 \%$; barras rojas). Estos diagramas se construyeron con los datos presentados en la Tabla 1. Nota: La inmovilidad elemental en algunos casos pudiera ser artefacto de las limitantes en las técnicas analíticas con las que se obtuvieron los resultados geoquímicos de las rocas (p.e., el Os). 
elemental. Estos conceptos indican qué elementos han sido modificados o han permanecido sin cambios en sus concentraciones de la roca fresca (original) con respecto a la roca alterada. Los elementos y compuestos con una proporción de enriquecimiento $>50 \%$ de la totalidad de las muestras, o mayormente enriquecidos en las rocas encajonantes alteradas, son el $\mathrm{K}_{2} \mathrm{O}, \mathrm{W}, \mathrm{Cu}, \mathrm{Pb}, \mathrm{Mo}, \mathrm{Tl}, \mathrm{Be}$, $\mathrm{Zn}, \mathrm{V}, \mathrm{Sb}, \mathrm{Ag}, \mathrm{Sn}, \mathrm{SiO}_{2}$, Se, Ni y FeO, y la pérdida por calcinación. Igualmente, los elementos con una proporción de empobrecimiento $>60 \%$ en las rocas encajonantes alteradas son el Ca, Y, Na, Ho, Co, Sr, Yb, Mn, Dy, Eu y $\mathrm{Tb}$ (Figura 7A). Cabe destacar que las concentraciones de $\mathrm{CO}_{2}, \mathrm{~S}, \mathrm{Cl}$ no han sido medidas para este estudio de balance de masas, pero sin duda estos elementos se encuentran presentes en los minerales de la paragénesis de la alteración de las rocas del COOC (p.e., carbonatos de calcio y/o hierro, $\mathrm{y}$ pirita). También el $\mathrm{S}$ y $\mathrm{Cl}$ deberían haber tenido un papel importante en la disolución, transporte y precipitación del $\mathrm{Au}$, en tanto en cuanto constituyen moléculas complejantes, como sugieren algunos estudios en yacimientos de oro orogénico (p.e., Mernagh y Bierlein, 2008). Por último, las Figuras $8 \mathrm{~A}$ y $8 \mathrm{~B}$ presentan a los elementos y compuestos más importantes que fueron enriquecidos hasta más de 200 $\%$ (barras en color rojo) y empobrecidos en más de $50 \%$ (barras en color azul) con respecto a la concentración de la roca fresca, respectivamente (Tablas A4 y A5 del Apéndice
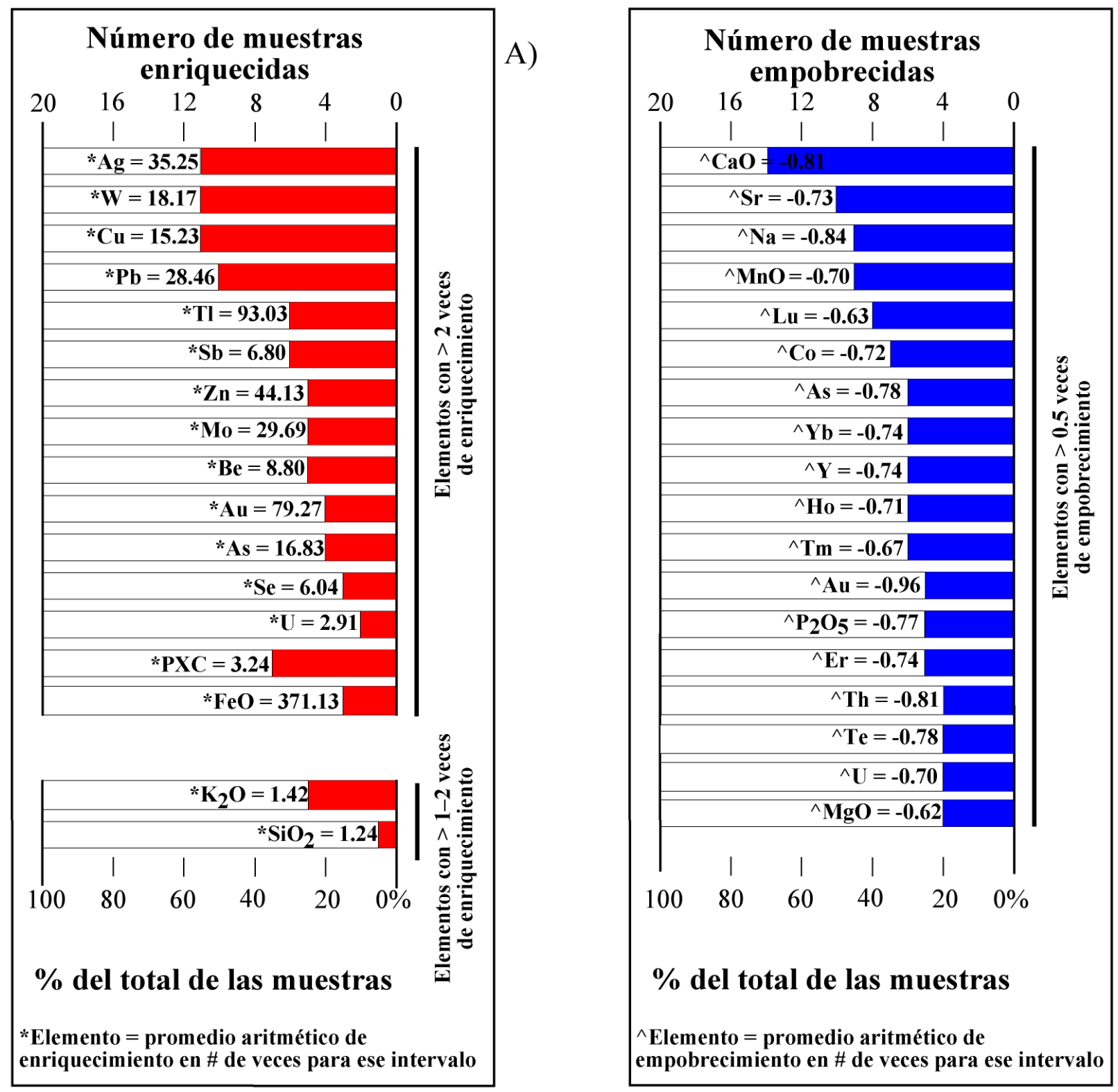

B)

Figura 8. Diagramas de elementos con el mayor empobrecimiento y enriquecimiento geoquímico por unidad de veces con respecto a la roca fresca (original). El resto de los elementos y compuestos se muestran en la Tabla A5 del Apéndice. Los valores de los elementos mayores de esta figura se obtuvieron basándose en unidades de \% en peso. Los valores de los elementos traza se obtuvieron usando unidades de partes por millón (ppm). 
A). En las barras de cada elemento se muestra la media aritmética del cambio de concentración en número de veces con respecto a la roca fresca original para cada elemento. Los datos que se muestran en las Tablas A4 y A5, del Apéndice $\mathrm{A}$, se obtuvieron al hacer un ordenamiento por rangos de los resultados de enriquecimiento y empobrecimiento que presenta cada elemento con respecto a la concentración original $\left(\Delta\right.$ conc- $\mathrm{C}^{\mathrm{A}}$, Tabla $\mathrm{A} 3$ del Apéndice $\left.\mathrm{A}\right)$.

5.3. Resultados del estudio geoquímico de correlación bivariable en vetas de cuarzo

En este estudio se analizaron 102 muestras de esquirlas de vetas de cuarzo representativas de la mineralización del Cinturón de Oro Orogénico Caborca para cuantificar las concentraciones de elementos traza y preciosos (Figura 1; Tabla A2 del Apéndice A). Cabe destacar que 20 de esas muestras coinciden con las 20 localidades del estudio de balance de masas presentado anteriormente.

Los resultados de este estudio de correlación geoquímica bivariable quedan ilustrados en un gráfico binario de coeficiente de correlación del Au vs. los elementos traza y elementos preciosos de las vetas de cuarzo (Figura 9A) dispuestos en orden de mayor a menor correlación. La correlación bivariable de la geoquímica de las vetas con el $\mathrm{Au}$ muestran que el $\mathrm{Pb}, \mathrm{Ag}, \mathrm{Zn}$ y Fe presentan una correlación positiva moderada (0.604 a 0.510). Los elementos $\mathrm{As}, \mathrm{Cu}, \mathrm{Ni}, \mathrm{Bi}, \mathrm{Cr}, \mathrm{Mo}, \mathrm{Sr}$ y $\mathrm{Sb}$ presentan una correlación positiva ( 0.377 a 0.225$)$ la cual se puede considerar baja. Por lo contrario, los elementos $\mathrm{Na}, \mathrm{Y}, \mathrm{Yb}$, Er y Pr presentan una correlación negativa muy baja ( -0.073 a -0.022), y de los elementos como el Dy y Ca es casi nula (0.001 a 0.017$)$.

La correlación geoquímica bivariable de Ag (Figura 9B) con la geoquímica de las vetas indica que el $\mathrm{Pb}$ presenta una correlación positiva alta (0.703), mientras que los elementos $\mathrm{Zn}, \mathrm{Au}, \mathrm{Sb}, \mathrm{As}$ y $\mathrm{Cu}$ presentan un correlación positiva moderada ( 0.565 a 0.432$)$. Una correlación positiva baja (0.305 a 0.219$)$ es representada por el Mo, Sr, Fe, Bi, Ba y Cr. Por lo contrario, los elementos $\mathrm{Na}, \mathrm{Ca}, \mathrm{Y}, \mathrm{Yb}, \mathrm{Dy}, \mathrm{Ti}$, $\mathrm{Mg}$, Th, Mn, Gd y Sm presentan correlación negativa muy baja (-0.173 a -0.004). Además, el elemento Er presenta una correlación negativa baja (-0.240), siendo más intensa que en el resto de los elementos.

\subsection{Resultados de SEM-EDS en piritas y oro nativo}

Granos milimétricos de pirita, galena y oro nativo de algunas muestras de vetas de cuarzo del COOC se seleccionaron para realizar estudios de microscopía electrónica de barrido con espectroscopía de energía dispersiva (SEM-EDS). El propósito es determinar los minerales incluidos y asociados a los sulfuros que pudieran explicar las anomalías geoquímicas elementales obtenidas en los estudios geoquímicos de las vetas de cuarzo. Esto, debido a que no se pudieron encontrar minerales en tamaños
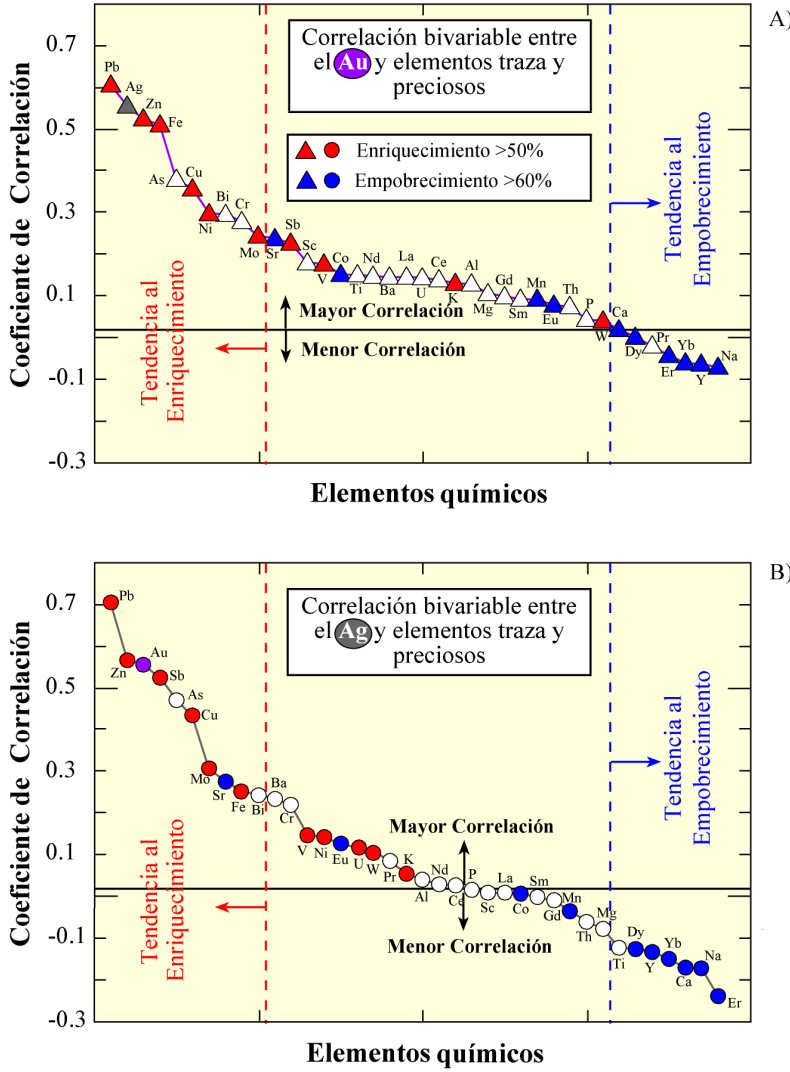

Figura 9. Coeficientes de correlación bivariable del $\mathrm{Au}$ (A) y Ag (B) con respecto a otros elementos traza y preciosos de 102 muestras de vetas de cuarzo del Cinturón de Oro Orogénico Caborca (COOC). Las muestras de vetas de cuarzo contenían, en algunos casos, parte del encajonante alterado por el hidrotermalismo. Las tendencias de enriquecimiento (triángulos y círculos en rojo) y de empobrecimiento (triángulos y círculos en azul) son las observadas a partir del estudio de balance de masas (Figura 6; Tabla A2 del Apéndice A).

megascópicos en los agregados de cuarzo que pudieran explicar dichas anomalías geoquímicas. De esta manera, se pretende interpretar mejor la presencia y origen de los elementos y compuestos geoquímicos analizados en el estudio de balance de masas de las rocas encajonantes de la mineralización del COOC.

Los resultados obtenidos consisten en imágenes SEM (Figuras 10, 11 y 12) con análisis puntuales espectrales EDS donde se obtuvo espectros de elementos y compuestos que sugieren un gran número de pequeñas inclusiones minerales $(\sim 10-50 \mu \mathrm{m})$ en los granos de pirita y oro nativo, resultando negativa la búsqueda en los granos de galena. Las inclusiones minerales encontradas en pirita mostraron en los espectros de energía dispersiva elementos como el $\mathrm{Au}, \mathrm{Ag}$, $\mathrm{Pb}, \mathrm{S}, \mathrm{Cu}, \mathrm{Zn}, \mathrm{Fe}, \mathrm{Mo}, \mathrm{Te}, \mathrm{Bi}, \mathrm{K}, \mathrm{W}$ y Ti. En la inspección de granos de $\mathrm{Au}$ se pudo encontrar inclusiones minerales con $\mathrm{W}$ y $\mathrm{Ca}$ los cuales se puede interpretar como scheelita $\left[\mathrm{CaWO}_{4}\right]$ (Figura 12). Mediante el análisis de pirita con un microscopio óptico se dedujo que las inclusiones minerales pueden corresponder a oro nativo, telururos de plata, galena, 


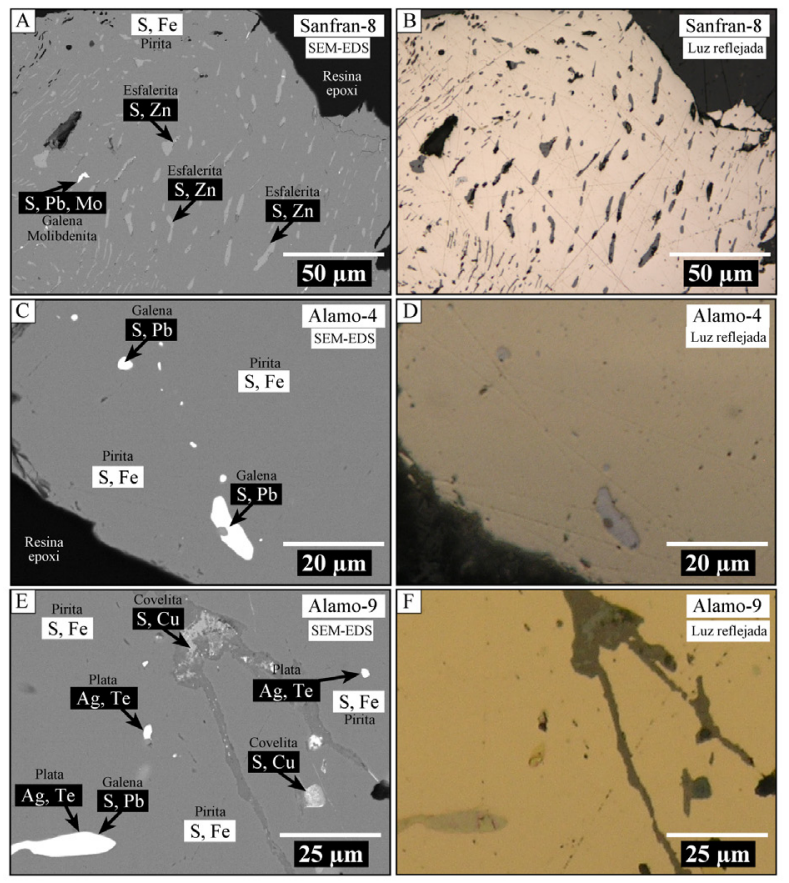

Figura 10. Microfotografías de piritas provenientes de vetas de cuarzo del Cinturón de Oro Orogénico Caborca (COOC). En el lado izquierdo se muestran imágenes de microscopio electrónico de barrido (SEM). Del lado derecho se pueden observar imágenes correspondientes a la misma área anterior pero obtenidas mediante un microscopio óptico de luz reflejada. Los elementos químicos señalados se obtuvieron mediante espectroscopía de energía dispersiva (EDS) conectado al SEM.

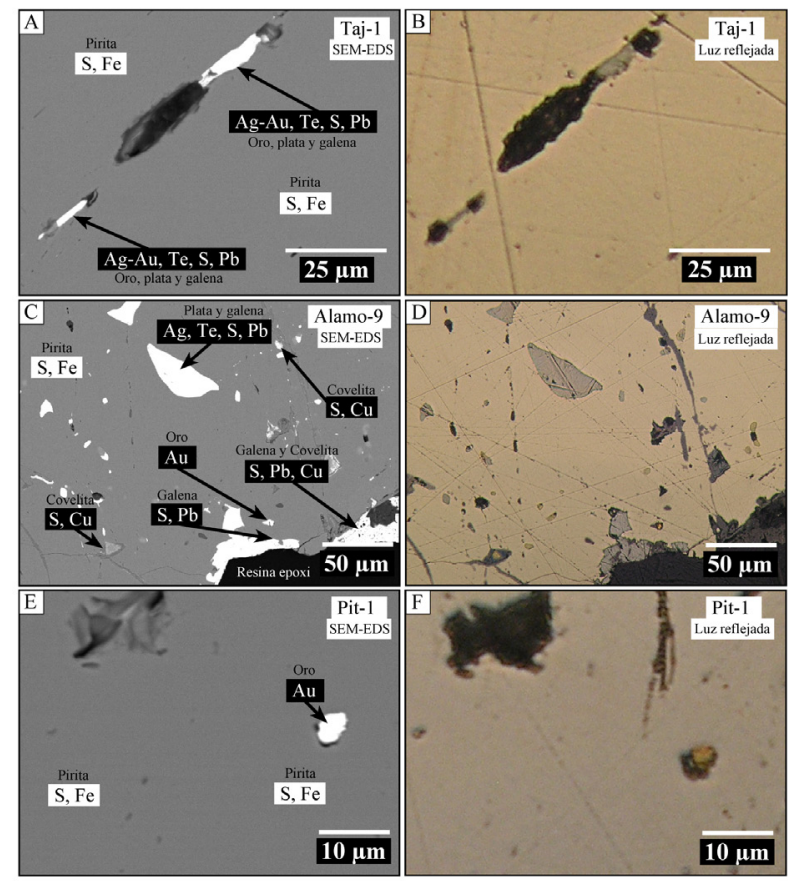

Figura 11. Fotomicrografías de muestras de pirita provenientes de vetas de cuarzo del Cinturón de Oro Orogénico Caborca (COOC). En el lado izquierdo se muestra nimágenes de microscopio electrónico de barrido (SEM). Del lado derecho se pueden observar imágenes correspondientes a la misma área anterior pero obtenidas mediante un microscopio óptico de luz reflejada. Los elementos químicos señalados se obtuvieron mediante espectroscopía de energía dispersiva (EDS) conectado al SEM.
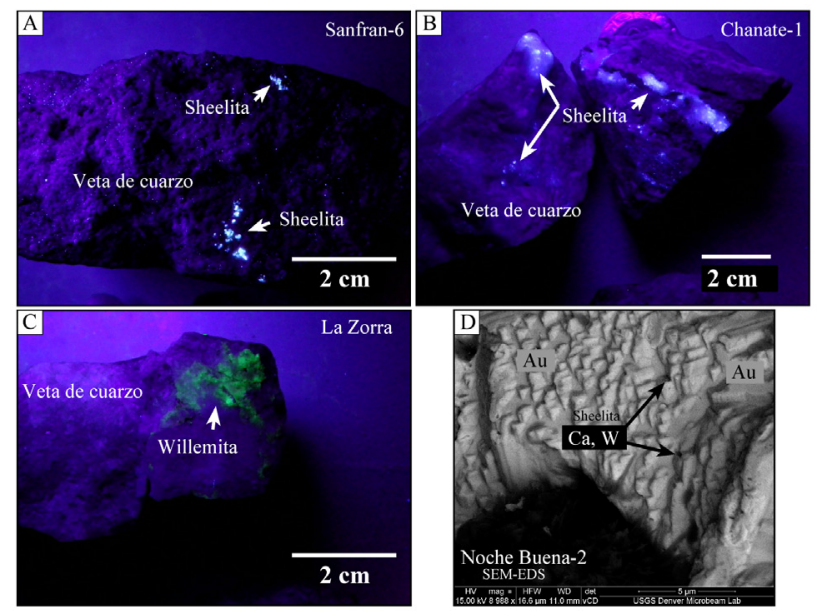

Figura 12. Fotografías de vetas de cuarzo con exposición de luz ultravioleta (A-C) e imagen de un grano de oro (D) obtenida con microscopio electrónico de barrido (SEM) en muestras del Cinturón de Oro Orogénico de Caborca (COOC). Las fotografías de vetas de cuarzo muestran los colores característicos de los minerales señalados (scheelita, azul, y willemita, verde). La imagen del grano de oro muestra elementos químicos que se obtuvieron con la técnica puntual de espectroscopía de energía dispersiva (EDS) conectado al SEM.

covelita, esfalerita, molibdenita y scheelita. Los posibles minerales de telururos, incluidos en las piritas, pudieran ser silvanita $\left[(\mathrm{Au}, \mathrm{Ag}) \mathrm{Te}_{2}\right]$, calaverita $\left[\mathrm{AuTe}_{2}\right]$ y altaíta $[\mathrm{PbTe}]$, como los encontrados en el depósito de tipo orogénico de San Francisco, en Estación Llano (Figura 1, Pérez-Segura et al., 1996). También con una lupa binocular se pudieron detectar inclusiones de turmalina dentro de algunos granos de pirita y, aplicando luz ultravioleta de onda corta en vetas de cuarzo, scheelita y willemita $\left[\mathrm{Zn}_{2} \mathrm{SiO}_{4}\right]$ (Figura 12).

\section{Discusión y conclusiones}

Los estudios petrográfícos de las rocas encajonantes alteradas en el COOC indican que la alteración hidrotermal generó silicificación, sericitización, cloritización, epidotización y piritización, aunque estas alteraciones no siempre son visibles megascópicamente. Por otra parte, la alteración presente no siempre es homogénea, y frecuentemente se observa formando parches; sin embargo, a pesar de tener una alteración hidrotermal heterogénea, los resultados del análisis de balance masas sugieren que existió una movilidad elemental considerable.

Los resultados del estudio de balance de masas (Tabla 2, Tabla A3 del Apéndice, Figura 7) permiten, de una manera semicuantitativa y rápida, la discriminación del cambio de masa total en la roca y del enriquecimiento, empobrecimiento e inmovilidad elemental asociado al proceso de mineralización hidrotermal a lo largo del COOC. El balance de masa total en cada roca encajonante, representadas mayormente por rocas graníticas, sugiere que las rocas que contienen más abundancia de feldespato 
potásico fueron más susceptibles a la alteración hidrotermal $\mathrm{y}$, en consecuencia, más susceptibles a cambiar su masa. Las muestras que aumentaron su masa en más de un $50 \%$ ( p.e., km100 y Quitovac 3) presentan un contenido elevado en $\mathrm{SiO}_{2}$ y alta pérdida por calcinación, lo que explicaría el aumento de volumen. Por otro lado, en las rocas que perdieron masa en más de un $10 \%$ (p.e., Sanfran-1 y Sanfran-3), la alteración mineral pudiera haber reducido su densidad.

Por su parte, el enriquecimiento elemental obtenido en este estudio indica que la mayoría de las rocas alteradas $\left(>50 \%\right.$ ) presentan un enriquecimiento en $\mathrm{K}_{2} \mathrm{O}, \mathrm{W}, \mathrm{Cu}, \mathrm{Pb}$, Mo, Tl, Be, Zn, V, Sb, Ag, Sn, $\mathrm{SiO}_{2}$, Se, Ni y FeO, y alta pérdida por calcinación, a una escala mucho mayor con respecto a los elementos en que éstas se empobrecieron, como se observa en la Figura 8A y 8B. Esto también coincide en los porcentajes altos de aumento de masa con respecto a los porcentajes bajos de disminución de masa total en la roca.

En la Figura 8A y B se puede observar que el cambio de concentración elemental ocurrido en el enriquecimiento (p.e., en $\mathrm{K}_{2} \mathrm{O}, \mathrm{Ag}, \mathrm{W}, \mathrm{Cu}$ y $\mathrm{Pb}$ ) y en el empobrecimiento (p.e., en $\mathrm{CaO}, \mathrm{Sr}, \mathrm{Na}, \mathrm{MnO}$ ), con respecto a la roca fresca, ha sido importante en número de veces o en porcentaje. De este modo, el enriquecimiento y empobrecimiento no es únicamente proporcional como se muestra en la Figura 7 e implica que los fluidos que originaron la alteración en el COOC tenían altas concentraciones en los elementos enriquecidos y capacidad de incorporar elementos de las rocas encajonantes.

Los resultados del estudio de correlación geoquímica bivariable realizados sobre las vetas de cuarzo del COOC sugieren que los elementos que presentaron una mayor proporción de enriquecimiento en el análisis de balance de masas ( $\mathrm{Pb}, \mathrm{Ag}, \mathrm{Zn}, \mathrm{Fe}, \mathrm{Cu}, \mathrm{Ni}$, Mo Sb y V) coinciden con los elementos de mayor coeficiente de correlación positiva (triángulos rojos). Por el contrario, los elementos que presentaron una mayor proporción de empobrecimiento $(\mathrm{Ca}$, $\mathrm{Y}, \mathrm{Na}, \mathrm{Yb}, \mathrm{Mn}$ y Dy; triángulos azules) coinciden con los elementos con coeficientes de correlación negativa o nula (Figura 9A). Sin embargo, existen excepciones con algunos elementos que no coinciden con este comportamiento, como son el W y K para el caso del enriquecimiento, y el $\mathrm{Sr}$ y Eu para el caso del empobrecimiento. Por su parte, este mismo agrupamiento general de enriquecimiento y empobrecimiento elemental con respecto al Au también se observa para el caso de la Ag (Figura 9B; Tabla A6 del Apéndice A). Esta observación explica que el análisis realizado sobre las vetas de cuarzo, en conjunto con los fragmentos de la roca encajonante alterada, apoyan el resultado del estudio de balance de masas de una manera consistente. Es importante destacar que lo que sugieren los resultados de este estudio es que existe una correlación en el comportamiento de los elementos y compuestos con el estudio de balance masas, inclusive sin considerar los grados de correlación geoquímica bivariable.
Los estudios de SEM-EDS en combinación de la microscopía de luz reflejada y luz ultravioleta muestran la presencia de inclusiones minerales de oro nativo, telururos de plata, galena, covelita, esfalerita, molibdenita, scheelita, willemita y turmalina dentro de los cristales de pirita y en vetas de cuarzo (Figuras 10, 11 y 12). Estas inclusiones minerales concilian la existencia de los elementos enriquecidos durante el proceso de alteración hidrotermal, determinados a partir de los estudios geoquímicos de balance de masa y del análisis de correlación geoquímica del Au y Ag. Sin embargo, las inclusiones minerales no explicarían en su totalidad la presencia de algunos elementos que muestran un enriquecimiento según el balance de masas (p.e., $\mathrm{Tl}, \mathrm{V}$, $\mathrm{Be}, \mathrm{Sn}, \mathrm{Se}$ ), y que aún siguen sin explicarse en la paragénesis mineral de las vetas de oro orogénico en el COOC. Por otra parte, algunos autores (Groves et al., 1998) sugieren que ciertos elementos contenidos en la mineralización y alteración orogénica pueden ser inexplicables, por lo que sugieren que estos elementos se encuentran sujetos a la disponibilidad en la corteza local y que son lixiviados durante el ascenso de los fluidos hidrotermales orogénicos.

En conclusión, los resultados obtenidos en este estudio sugieren que los fluidos que generaron la alteración hidrotermal en las rocas encajonantes de las vetas auríferas presentes en el Cinturón de Oro Orogénico Caborca (COOC) son muy homogéneos a lo largo del NW de Sonora. Esta homogeneidad es propuesta a pesar de las grandes distancias de centenares de kilómetros entre las muestras estudiadas (Figura 1) y sugiere que los fluidos posiblemente tuvieron un mismo origen de formación (metamorfismo) y también un mismo periodo de emplazamiento (coetaneidad). Todo esto indica que el evento mineralizante en el COOC tuvo lugar durante el periodo compresivo asociado a la orogenia Larámide del Cretácico tardío-Terciario temprano como ya ha sido sugerido anteriormente (Pérez-Segura et al., 1996; Iriondo y Atkinson, 2000; Iriondo, 2001; Poulsen et al., 2008; Quintanar-Ruíz, 2008). Este estudio también permite proponer que el COOC es un cinturón metalogenético de oro orogénico que es comparable, en su dimensión areal y en características geológicas con otras ocurrencias existentes alrededor del mundo como en Australia (Groves et al., 1998), Alaska y California (Goldfarb et al., 1991, 2008; Marsh et al., 2008). De igual forma, la geometría elongada del COOC (orientación general NW-SE) sugiere que debió existir una disposición estructural regional previa para la canalización y acenso de los fluidos (p.e., la coincidencia espacial del COOC con los límites de la provincia de basamento paleoproterozoica Yavapai) como lo sugieren Iriondo y Premo (2010). Cabe destacar que los elementos $\left(\mathrm{K}_{2} \mathrm{O}, \mathrm{W}, \mathrm{Cu}, \mathrm{Pb}, \mathrm{Mo}, \mathrm{Tl}, \mathrm{Be}, \mathrm{Zn}, \mathrm{V}, \mathrm{Sb}, \mathrm{Ag}, \mathrm{Sn}, \mathrm{SiO}_{2}, \mathrm{Se}, \mathrm{Ni}\right.$ y $\mathrm{FeO}$ ) que se introdujeron a partir del fluido mineralizante en las rocas encajonates de este estudio (COOC) podrían emplearse como guía para la exploración mineral de $\mathrm{Au}$ en la región, incluyendo partes del SW de Arizona y SE de California. Por último, destacar que esta homogeneidad propuesta para los fluidos mineralizantes debería esperase 
también en futuros estudios regionales de isotopía estable $(\mathrm{H}, \mathrm{O}, \mathrm{S}$ y $\mathrm{C})$ y radiogénicos $(\mathrm{Pb}-\mathrm{Pb}$ y $\mathrm{Rb}-\mathrm{Sr})$ a realizarse en minerales de la paragénesis del COOC (p.e., cuarzo, sericita o mica blanca, calcita, siderita, ankerita, pirita, galena, clorita, epidota).

\section{Agradecimientos}

Primeramente, agradecemos a las instituciones que otorgaron los proyectos de investigación PAPIIT/UNAM (clave IN-116709) y CONACYT (claves CB-82518 y CB-129370) por aportar parte del financiamiento para la campaña de campo de este estudio. También se agradece a la Coordinación de Estudios de Posgrado de la UNAM por su ayuda económica para realizar esta campaña de campo. Se agradece al CONACYT por otorgarle al primer autor una beca para una estancia de investigación en el U.S. Geological Survey, Denver, Colorado. Gracias al Servicio Geológico Mexicano (SGM), Gerencia Hermosillo, en Sonora, en especial a Francisco Cendejas-Cruz, Basilio Cervantes-López y Jaime Castro-Escarrega, por el apoyo logístico otorgado durante la campaña de campo y en el manejo de las muestras. Se agradece a Javier Hernández-Rojas, geólogo del SGM, por su compañía profesional durante el muestreo. Queremos expresar nuestros agradecimientos a Thierry Calmus y Pablo Peñaflor por permitir el acceso a los laboratorios de molienda y pulverizado de rocas del Instituto de Geología de la UNAM en la Estación Regional Noroeste en Hermosillo, Sonora. También se da las gracias a Montserrat Hernández-Ramírez por la ayuda brindada durante la molienda y pulverizado de las muestras. Agradecimientos a Luis Miguel MartínezTorres de la Universidad del País Vasco, España, por elaborar desinteresadamente las secciones delgadas para el estudio petrográfico. Gracias a Shannon Mahan del U.S. Geological Survey, Denver, por el préstamo de contenedores de alúmina para el pulverizado de las muestras; así mismo se agradece a Dan Miggins (U.S. Geological Survey en Denver) y Francisco Paz-Moreno (Universidad de Sonora) por organizar el transporte de dichos contenedores. Agradecemos a Erin Marsh y Heather Lowers por facilitar y asesorar en el uso del microscopio electrónico de barrido (SEM) en el U.S. Geological Survey en Denver. También se agradece a José Solorio Munguía y Gilles Levresse por su ayuda en la obtención de imágenes de vetas de cuarzo con luz ultravioleta. Por último, se agradece a los revisores del manuscrito Ruth Esther Villanueva Estrada y Efrén Pérez Segura, así como a los editores del Boletín de la Sociedad Geológica Mexicana, Antoni Camprubí i Cano y Carles Canet Miquel, por sus comentarios críticos, constructivos y sugerencias que contribuyeron a mejorar y enriquecer el presente trabajo.

\section{Referencias}

Albinson, T.F., 1989, Vetas mesotermales auríferas del sector norte del Estado de Sonora, Memorias Técnicas, XVIII Convención Nacional AIMMGM, Acapulco, Guerrero, México, Asociación de Ingenieros de Minas, Metalurgistas y Geólogos de México, 20-40.

Araiza-Martínez, H., 1998, Geology and Mineralization of the San Francisco Gold Deposit, en Clark. K.F., (ed.), Gold Deposits of Northern Sonora, México: Society of Economic Geologists, Guidebook Series, 30, 49-58.

Araux-Sánchez, E., 2000, Geología y yacimientos minerales de la Sierra Pinta, municipio de Puerto Peñasco, Sonora: Departamento de Geología, Universidad de Sonora, tesis de maestría, $121 \mathrm{p}$.

Baumgartner, L.P., Olsen, S.N., 1995, A least-squares approach to mass transport calculations using the isocon method: Economic Geology, 90, 1261-1270.

Branham, A.D., 1988, Gold mineralization in low angle faults American Girl Valley, Cargo Muchacho Mountains, California: Department of Geology, Washington State University, tesis de maestría, 144 p.

Changkuon, L., 1990, Genesis of gold mineralization: San Francisco Mine, Sonora, Mexico: New Mexico Institute of Mining and Technology, Socorro, New Mexico, tesis de maestría, 129 p.

Coelho, J., 2006, GEOISO-A Windows program to calculate and plot mass balances and volume changes occurring in a variety of geologic processes: Computers and Geosciences, 32, 1523-1528.

Davis, J.C., 1986, Statistics and Data Analysis in Geology: Jonh Wiley \& Sons Inc., New York, 2646 p.

Durgin, D.C., Terán, P.I., 1996, La Choya Au deposit, NW Sonora, Mexico, en Coyner, A.R., Fahey, P.L., (eds.), Geology and ore deposits of the American Cordillera: Geological Society of Nevada Symposium, Proceedings, Reno/Sparks, Nevada, 1369-1373.

Goldfarb, R.J., Newberry, R.J., Pickthorn, W.J., Gent, C.A., 1991, Oxygen, hydrogen and sulfur isotope studies in the Juneau gold belt, southeastern Alaska: Constraints on the origin of hydrothermal fluids: Economic Geology, 86, 66-88.

Goldfarb, R.J., Hart, C.J., Marsh, E.E., 2008, Orogenic gold and evolution of the Cordilleran orogen, en Spencer, J.E., Titley S.R. (eds.), Ores and orogenesis: Circum-Pacific tectonics, geologic evolution, and ore deposits: Arizona Geological Society Digest, 22, 311-323.

Grant, J.A., 1986, The isocon diagram-a simple solution to Gresens' ecuation for metasomatic alteration: Economic Geology, 81, 1976-1982.

Grant, J.A., 2005, Isocon analysis: A brief review of the method and applications: Physics and Chemistry of the Earth, 30, 997-1004.

Gresens, R.L., 1967, Composition-volume relationships of metasomatism: Chemical Geology, 2, 47-65.

Groves, D.I., Goldfarb, R.J., Grebre-Meriam, M., Hagemann, S.G., Robert, F., 1998, Orogenic gold deposits: A proposed classification in the context of their crustal distribution and relationship to other gold deposit types: Ore Geology Reviews, 13, 7-27.

Iriondo, A., 2001, Proterozoic basements and their laramide juxtaposition in NW Sonora, Mexico: Tectonic constraints on the SW margin of Laurentia: Boulder, Colorado, University of Colorado, tesis de doctorado, $222 \mathrm{p}$.

Iriondo, A., Atkinson, W.W., Jr., 2000, Orogenic gold mineralization along the proposed trace of the Mojave-Sonora megashear: Evidence for the Laramide Orogeny in NW Sonora, Mexico: Geological Society of America, Abstracts with Programs, 32, 393 p.

Iriondo, A., Premo, W.R., 2010, Las rocas cristalinas proterozoicas de Sonora y su importancia para la reconstrucción del margen continental SW de Laurencia-la pieza mexicana del rompecabezas de Rodinia, en Calmus, T., (ed.), Panorama sobre la geología de Sonora, México: Universidad Nacional Autónoma de México, Instituto de Geología, Boletín, 118, 25-55.

Lentz, D.R., 2005, Mass-balance analysis of mineralized skarn systems: Implications for eplacement processes, carbonate mobility, and permeability evolution, en Mao, J., Bierlein, F.P., (eds.), Mineral Deposit Research: Meeting the Global Challenge, Proceedings of the Biennial SGA Meeting, Beijing, China, 4, 421-424. 
Marsh, E.E., Goldfarb, R.J., Kunk, M.J., Groves, D.I., Bierlein, F.P., Creaser R.A., 2008, New constraints on the timing of gold formation in the Sierra Foothills province, central California, en Spencer, J.E., Titley S.R. (eds.), Ores and orogenesis: Circum-Pacific tectonics, geologic evolution, and ore deposits: Arizona Geological Society Digest, 22, 369-388.

Mernagh, T.P., Bierlein, F.P., 2008, Transport and precipitation of gold in Phanerozoic metamorphic terranes from chemical modeling of fluid-rock interaction: Economic Geology, 103, 1613-1640.

Noriega-Martínez, O., 2006, Evidencias de dos etapas de mineralización de oro mesotermal en las áreas de Tajitos, Juárez-San Francisco, en la región de Caborca, Sonora México: Hermosillo, Sonora, Departamento de Geología, Universidad de Sonora, tesis de maestría, $85 \mathrm{p}$.

Ornelas-Macías, A., Verdugo-Noriega, G., 2009, Caracterización geológica, estructural y de mineralización en el área Karina, municipio de Caborca, Sonora, México: Hermosillo, Sonora, Departamento de Geología, Universidad de Sonora, tesis de licenciatura, $110 \mathrm{p}$.

Pérez-Segura, E., Cheilletz, A., Herrera-Urbina, S., Hanes, Y.J., 1996, Geología, mineralización, alteración hidrotermal y edad del yacimiento de oro de San Francisco, Sonora-Un depósito mesotermal en el Noroeste de México: Revista Mexicana de Ciencias Geológicas, 13, 65-89.

Pitcairn, I.K., Teagle, D.A., Craw, D., Olivo, G.R., Kerrich, R., Brewer, T.S., 2006, Sources of metals and fluids in orogenic gold deposits: Insights from the Ontago and Alpine Schists, New Zealand: Economic Geology, 101, 1525-1546.
Poulsen, K.H., Mortensen J.K., Walford, P.C., 2008, San Francisco gold deposit, Santa Ana region, Sonora, Mexico: Laramide orogenic, intrusion-related mineralization?, en Spencer, J.E., Titley S.R. (eds.), Ores and orogenesis: Circum-Pacific tectonics, geologic evolution, and ore deposits: Arizona Geological Society Digest, 22, 547-559.

Quintanar-Ruíz, F.J., 2008, La Herradura ore deposit: An orogenic gold deposit in northwestern Mexico: Tucson, Arizona, University of Arizona, tesis de maestría $97 \mathrm{p}$.

Silberman, M.L., Staude, J.M., Cox, D.P., 1987, Reconnaissance of gold prospects in northern Sonora, Mexico: U.S. Geological Survey, Administrative Report, $23 \mathrm{p}$.

Silberman, M.L., Giles D.A., Graubard, C., 1988, Characteristics of gold deposits in Northern Sonora, Mexico: A preliminary report: Economic Geology, 83, 1966-1974.

Wei, J.H., Liu, C.Q., Li, Z.D., Zhao, Y.X., 2001, Simulation of rock mass balance of two typical altered rocks in Wulong gold deposit of Liaoning, China: Journal of Central South University of Technology, China, 8, 197-202

Manuscrito recibido: Agosto 30, 2011.

Manuscrito corregido recibido: Enero 27, 2012.

Manuscrito aceptado: Enero 31, 2012. 


\section{Apéndice}

Tabla A1. Elementos mayores y trazas de las rocas encajonantes frescas (Ef) y alteradas (Ea) del Cinturón de Oro Orogénico Caborca,

NW de Sonora, México.

\begin{tabular}{|c|c|c|c|c|c|c|c|c|c|}
\hline Muestra & Niv. det. & Alamo1Ef & Alamo1Ea & Carolina1Ef & Carolina1Ea & Carretera2Ef & Carretera2Ea & Costa4Ef & Costa4Ea \\
\hline \multirow{2}{*}{ Coordenadas } & & $112^{\circ} 0^{\prime} 59.8^{\prime \prime}$ & & $112^{\circ} 44^{\prime} 2.5^{\prime \prime}$ & & $110^{\circ} 57^{\prime} 3.2^{\prime \prime}$ & & $112^{\circ} 56^{\prime} 52.5^{\prime \prime}$ & \\
\hline & & $30^{\circ} 50^{\prime} 13.1^{\prime \prime}$ & & $31^{\circ} 9^{\prime} 12.8^{\prime \prime}$ & & $30^{\circ} 18^{\prime} 14.4^{\prime \prime}$ & & $30^{\circ} 48^{\prime} 33.2^{\prime \prime}$ & \\
\hline \multicolumn{10}{|c|}{ Elementos mayores } \\
\hline $\mathrm{SiO}_{2}$ & 0.001 & 58.62 & 57.46 & 56.35 & 59.20 & 72.87 & 73.27 & 73.59 & 71.20 \\
\hline $\mathrm{TiO}_{2}$ & 0.001 & 0.73 & 0.60 & 1.27 & 1.43 & 0.14 & 0.16 & 0.10 & 0.13 \\
\hline $\mathrm{Al}_{2} \mathbf{O}_{3}$ & 0.001 & 15.98 & 16.81 & 14.68 & 15.71 & 13.60 & 14.10 & 14.23 & 14.79 \\
\hline $\mathrm{FeO}$ & 0.001 & 0.72 & 1.43 & 2.79 & 3.80 & N.D. & 0.19 & N.D. & 0.14 \\
\hline $\mathrm{Fe}_{2} \mathrm{O}_{3}$ & 0.001 & 5.68 & 3.43 & 5.62 & 5.20 & 1.11 & 1.41 & 1.08 & 1.08 \\
\hline MnO & 0.001 & 0.10 & 0.11 & 0.16 & 0.09 & 0.07 & 0.02 & 0.04 & 0.04 \\
\hline MgO & 0.001 & 3.10 & 3.54 & 1.99 & 2.12 & 0.35 & 0.36 & 0.24 & 0.28 \\
\hline $\mathrm{CaO}$ & 0.001 & 5.03 & 6.15 & 3.14 & 1.17 & 0.78 & 0.18 & 1.68 & 1.07 \\
\hline $\mathrm{Na}_{2} \mathrm{O}$ & 0.001 & 3.11 & 2.52 & 1.69 & 0.12 & 3.68 & 2.71 & 3.63 & 3.85 \\
\hline $\mathrm{K}_{2} \mathrm{O}$ & 0.001 & 1.62 & 1.64 & 3.92 & 4.85 & 3.78 & 4.45 & 3.15 & 3.62 \\
\hline $\mathbf{P}_{2} \mathrm{O}_{5}$ & 0.001 & 0.20 & 0.21 & 0.52 & 0.55 & 0.05 & 0.06 & 0.03 & 0.04 \\
\hline PXC & 0.010 & 3.68 & 3.96 & 4.08 & 3.45 & 0.79 & 1.42 & 0.74 & 1.42 \\
\hline Total & & 98.57 & 97.86 & 96.21 & 97.69 & 97.22 & 98.33 & 98.51 & 97.66 \\
\hline \multicolumn{10}{|c|}{ Elementos trazas } \\
\hline Ag & 0.100 & N.D. & 0.20 & N.D. & N.D. & 0.60 & N.D. & N.D. & 1.10 \\
\hline Al & 1.000 & 85720.00 & 84758.00 & 76504.00 & 83523.00 & 72202.00 & 74355.00 & 76652.00 & 76103.00 \\
\hline As & 1.000 & 23.00 & 7.00 & 5.00 & 20.00 & 7.00 & 58.00 & 5.00 & 9.00 \\
\hline Au & 0.001 & N.D. & N.D. & 0.03 & N.D. & N.D. & N.D. & 0.01 & N.D. \\
\hline $\mathbf{B a}$ & 1.000 & 660.00 & 621.00 & 1693.00 & 1037.00 & 559.00 & 544.00 & 901.00 & 1044.00 \\
\hline $\mathrm{Be}$ & 1.000 & N.D. & N.D. & N.D. & N.D. & 1.00 & 2.00 & 1.00 & 1.00 \\
\hline $\mathbf{B i}$ & 1.000 & N.D. & N.D. & N.D. & N.D. & N.D. & N.D. & N.D. & N.D. \\
\hline Cd & 1.000 & N.D. & N.D. & N.D. & N.D. & N.D. & N.D. & N.D. & N.D. \\
\hline $\mathrm{Ce}$ & 0.100 & 51.30 & 70.00 & 173.00 & 193.10 & 34.50 & 31.40 & 29.10 & 30.80 \\
\hline Co & 1.000 & 22.00 & 19.00 & 19.00 & 23.00 & 3.00 & 2.00 & 2.00 & 1.00 \\
\hline $\mathrm{Cr}$ & 1.000 & 36.00 & 26.00 & 21.00 & 23.00 & 5.00 & 7.00 & 6.00 & 6.00 \\
\hline $\mathrm{Cu}$ & 1.000 & 26.00 & 90.00 & 24.00 & 26.00 & 5.00 & 36.00 & 29.00 & 8.00 \\
\hline Dy & 0.100 & 3.60 & 2.90 & 9.50 & 10.50 & 1.30 & 1.20 & 3.00 & 1.80 \\
\hline $\mathbf{E r}$ & 0.100 & 1.90 & 1.50 & 5.10 & 5.60 & 0.60 & 0.60 & 1.90 & 0.90 \\
\hline Eu & 0.100 & 1.70 & 1.40 & 4.30 & 4.80 & 0.60 & 0.50 & 1.00 & 0.90 \\
\hline Gd & 0.100 & 5.30 & 5.30 & 15.60 & 17.30 & 2.80 & 2.50 & 3.10 & 2.80 \\
\hline Но & 0.100 & 0.60 & 0.50 & 1.70 & 1.90 & 0.20 & 0.20 & 0.60 & 0.30 \\
\hline Ir & 0.100 & 0.10 & 0.20 & N.D. & N.D. & N.D. & N.D. & N.D. & N.D. \\
\hline $\mathbf{K}$ & 1.000 & 13562.00 & 13528.00 & 32271.00 & 40464.00 & 30931.00 & 36100.00 & 25926.00 & 30033.00 \\
\hline La & 0.100 & 25.90 & 36.30 & 70.40 & 81.50 & 16.00 & 15.00 & 14.80 & 15.20 \\
\hline Lu & 0.100 & 0.20 & 0.10 & 0.50 & 0.50 & 0.10 & 0.10 & 0.20 & 0.10 \\
\hline Mg & 1.000 & 17370.00 & 19587.00 & 11195.00 & 11754.00 & 2124.00 & 2174.00 & 1465.00 & 1636.00 \\
\hline Mn & 1.000 & 731.00 & 797.00 & 1196.00 & 621.00 & 517.00 & 185.00 & 314.00 & 271.00 \\
\hline Mo & 1.000 & N.D. & N.D. & 1.00 & 1.00 & N.D. & 1.00 & N.D. & 1.00 \\
\hline $\mathrm{Na}$ & 1.000 & 23157.00 & 18823.00 & 12590.00 & 855.00 & 27667.00 & 20359.00 & 26351.00 & 28156.00 \\
\hline Nd & 0.100 & 26.10 & 28.60 & 82.60 & 92.60 & 14.10 & 12.70 & 13.20 & 13.20 \\
\hline $\mathrm{Ni}$ & 1.000 & 41.00 & 40.00 & 22.00 & 28.00 & 9.00 & 16.00 & 7.00 & 8.00 \\
\hline Os & 0.100 & 0.40 & 2.80 & N.D. & N.D. & N.D. & N.D. & N.D. & N.D. \\
\hline $\mathbf{P}$ & 1.000 & 890.00 & 930.00 & 2290.00 & 2499.00 & 275.00 & 289.00 & 181.00 & 143.00 \\
\hline $\mathbf{P b}$ & 1.000 & 12.00 & 20.00 & 24.00 & 1.00 & 20.00 & 76.00 & 24.00 & 25.00 \\
\hline Pd & 0.100 & 1.80 & 1.50 & 0.40 & 0.50 & 0.60 & 0.50 & 0.30 & 0.20 \\
\hline Pr & 0.100 & 6.30 & 7.70 & 19.30 & 21.70 & 3.90 & 3.50 & 3.40 & 3.40 \\
\hline Pt & 0.100 & 0.10 & 0.10 & N.D. & N.D. & 0.20 & 0.20 & N.D. & 0.20 \\
\hline Rh & 0.100 & N.D. & N.D. & N.D. & N.D. & N.D. & N.D. & N.D. & N.D. \\
\hline Ru & 0.100 & 0.10 & 0.10 & N.D. & N.D. & N.D. & N.D. & N.D. & N.D. \\
\hline Sb & 1.000 & N.D. & N.D. & N.D. & N.D. & N.D. & 4.00 & N.D. & N.D. \\
\hline Sc & 0.100 & 13.00 & 8.50 & 20.90 & 22.20 & 6.30 & 6.00 & 3.90 & 2.30 \\
\hline Se & 1.000 & N.D. & N.D. & N.D. & N.D. & N.D. & N.D. & 8.00 & N.D. \\
\hline Sm & 0.100 & 5.00 & 4.80 & 15.10 & 16.50 & 3.10 & 2.60 & 2.90 & 2.70 \\
\hline Sn & 1.000 & N.D. & N.D. & N.D. & N.D. & 1.00 & 2.00 & 2.00 & 1.00 \\
\hline Sr & 1.000 & 803.00 & 1077.00 & 132.00 & 32.00 & 91.00 & 56.00 & 315.00 & 272.00 \\
\hline Tb & 0.100 & 0.70 & 0.60 & 1.90 & 2.10 & 0.30 & 0.30 & 0.50 & 0.30 \\
\hline $\mathrm{Te}$ & 1.000 & 10.00 & 6.00 & 13.00 & 16.00 & 4.00 & N.D. & N.D. & 1.00 \\
\hline Th & 0.100 & 5.80 & 13.60 & 7.30 & 8.50 & 11.10 & 9.80 & 5.80 & 4.90 \\
\hline $\mathrm{Ti}$ & 0.010 & 4104.00 & 3400.00 & 5919.00 & 7720.00 & 787.00 & 753.00 & 734.00 & 649.00 \\
\hline TI & 0.100 & N.D. & N.D. & N.D. & N.D. & 5.00 & 4.00 & 3.00 & 6.00 \\
\hline $\mathbf{T m}$ & 0.100 & 0.20 & 0.20 & 0.60 & 0.60 & 0.10 & 0.10 & 0.30 & 0.10 \\
\hline $\mathbf{U}$ & 1.000 & 1.00 & 2.60 & 2.00 & 2.40 & 1.20 & 4.30 & 1.40 & 1.00 \\
\hline V & 0.100 & 103.00 & 120.00 & 62.00 & 63.00 & 14.00 & 20.00 & 10.00 & 10.00 \\
\hline W & 1.000 & ND & 2.00 & 4.00 & 3.00 & ND & 8.00 & 1.00 & 1.00 \\
\hline $\mathbf{Y}$ & 0.001 & 16.60 & 13.40 & 44.20 & 47.40 & 5.50 & 5.60 & 17.20 & 7.90 \\
\hline Yb & 0.100 & 1.40 & 1.20 & 3.90 & 4.20 & 0.70 & 0.60 & 2.00 & 0.90 \\
\hline Zn & 1.000 & 79.00 & 95.00 & 180.00 & 95.00 & 30.00 & 29.00 & 50.00 & 57.00 \\
\hline
\end{tabular}


Tabla A1. Continuación

\begin{tabular}{|c|c|c|c|c|c|c|c|c|}
\hline Muestra & Km100Ef & Km100Ea & Quitovac2Ef & Quitovac2Ea & Quitovac3Ef & Quitovac3Ea & Quitovac5Ef & Quitovac5Ea \\
\hline \multirow[t]{2}{*}{ Coordenadas } & $111^{\circ} 6^{\prime} 36.8^{\prime \prime}$ & & $112^{\circ} 43^{\prime} 38.1^{\prime \prime}$ & & $112^{\circ} 41^{\prime} 51.1^{\prime \prime}$ & & $112^{\circ} 50^{\prime} 23.6^{\prime \prime}$ & \\
\hline & $29^{\circ} 58^{\prime} 40.6^{\prime \prime}$ & & $31^{\circ} 26^{\prime} 5.9^{\prime \prime}$ & & $31^{\circ} 25^{\prime} 6.6^{\prime \prime}$ & & $31^{\circ} 30^{\prime} 34.2^{\prime \prime}$ & \\
\hline \multicolumn{9}{|c|}{ Elementos mayores } \\
\hline $\mathrm{SiO}_{2}$ & 58.45 & 74.45 & 65.93 & 68.74 & 64.42 & 75.90 & 54.02 & 55.28 \\
\hline $\mathrm{TiO}_{2}$ & 1.18 & 0.34 & 0.38 & 0.38 & 0.50 & 0.14 & 0.89 & 0.92 \\
\hline $\mathrm{Al}_{2} \mathbf{O}_{3}$ & 16.06 & 11.53 & 15.30 & 15.64 & 15.64 & 12.08 & 17.59 & 17.58 \\
\hline $\mathrm{FeO}$ & 4.58 & 0.14 & 0.26 & 0.19 & 1.09 & 0.00 & 0.58 & 1.43 \\
\hline $\mathrm{Fe}_{2} \mathrm{O}_{3}$ & 3.28 & 1.52 & 3.45 & 2.52 & 3.18 & 0.80 & 6.80 & 4.57 \\
\hline MnO & 0.15 & 0.01 & 0.04 & 0.02 & 0.09 & 0.01 & 0.09 & 0.07 \\
\hline MgO & 1.79 & 0.53 & 0.97 & 0.46 & 1.56 & 0.16 & 4.01 & 3.51 \\
\hline $\mathrm{CaO}$ & 3.86 & 0.04 & 1.97 & 0.63 & 3.62 & 0.40 & 6.55 & 2.86 \\
\hline $\mathrm{Na}_{2} \mathrm{O}$ & 3.57 & 0.12 & 4.24 & 3.42 & 3.46 & 2.10 & 4.08 & 3.43 \\
\hline $\mathrm{K}_{2} \mathrm{O}$ & 3.67 & 6.20 & 3.59 & 4.09 & 3.71 & 5.21 & 2.06 & 3.24 \\
\hline $\mathrm{P}_{2} \mathrm{O}_{5}$ & 0.42 & 0.07 & 0.13 & 0.12 & 0.18 & 0.02 & 0.25 & 0.25 \\
\hline PXC & 1.11 & 2.11 & 1.45 & 2.08 & 1.24 & 1.23 & 1.07 & 4.77 \\
\hline Total & 98.12 & 97.06 & 97.71 & 98.29 & 98.69 & 98.05 & 97.99 & 97.91 \\
\hline \multicolumn{9}{|c|}{ Elementos trazas } \\
\hline Ag & N.D. & 8.80 & N.D. & N.D. & N.D. & 0.10 & 0.90 & 0.80 \\
\hline Al & 85184.00 & 61591.00 & 78619.00 & 85605.00 & 83664.00 & 63914.00 & 94075.00 & 94257.00 \\
\hline As & 7.00 & 4.00 & 15.00 & N.D. & N.D. & N.D. & 17.00 & 5.00 \\
\hline Au & N.D. & N.D. & N.D. & N.D. & 4.57 & N.D. & 0.02 & N.D. \\
\hline Ba & 1421.00 & 927.00 & 1477.00 & 1671.00 & 1188.00 & 372.00 & 923.00 & 940.00 \\
\hline $\mathrm{Be}$ & N.D. & N.D. & N.D. & N.D. & N.D. & N.D. & N.D. & N.D. \\
\hline $\mathbf{B i}$ & N.D. & N.D. & N.D. & N.D. & N.D. & N.D. & N.D. & N.D. \\
\hline Cd & N.D. & N.D. & N.D. & N.D. & N.D. & N.D. & N.D. & 1.00 \\
\hline $\mathrm{Ce}$ & 138.70 & 163.60 & 58.80 & 49.20 & 91.30 & 76.80 & 44.20 & 44.60 \\
\hline Co & 24.00 & 3.00 & 8.00 & 6.00 & 12.00 & 2.00 & 29.00 & 24.00 \\
\hline $\mathrm{Cr}$ & 17.00 & 6.00 & 5.00 & 6.00 & 8.00 & 5.00 & 52.00 & 49.00 \\
\hline $\mathrm{Cu}$ & 26.00 & 44.00 & 19.00 & 73.00 & 34.00 & 30.00 & 104.00 & 385.00 \\
\hline Dy & 10.00 & 2.30 & 2.80 & 2.70 & 4.00 & 1.90 & 2.20 & 1.80 \\
\hline Er & 5.50 & 1.10 & 1.70 & 1.70 & 2.50 & 1.30 & 1.10 & 0.90 \\
\hline Eu & 3.60 & 1.40 & 1.60 & 1.70 & 1.80 & 0.60 & 1.60 & 1.50 \\
\hline Gd & 15.10 & 8.50 & 4.60 & 4.10 & 6.70 & 4.30 & 4.40 & 4.00 \\
\hline Но & 1.80 & 0.30 & 0.50 & 0.50 & 0.80 & 0.40 & 0.40 & 0.30 \\
\hline Ir & N.D. & 0.10 & N.D. & N.D. & N.D. & N.D. & N.D. & N.D. \\
\hline $\mathbf{K}$ & 30350.00 & 51317.00 & 29253.00 & 33333.00 & 3331.00 & 43139.00 & 17015.00 & 26453.00 \\
\hline La & 61.70 & 69.90 & 30.40 & 27.60 & 47.80 & 41.80 & 21.10 & 20.90 \\
\hline Lu & 0.60 & 0.10 & 0.20 & 0.20 & 0.30 & 0.20 & 0.10 & 0.10 \\
\hline Mg & 10122.00 & 3222.00 & 5527.00 & 2752.00 & 8718.00 & 976.00 & 22555.00 & 19708.00 \\
\hline Mn & 1087.00 & 88.00 & 310.00 & 125.00 & 616.00 & 113.00 & 678.00 & 525.00 \\
\hline Mo & 1.00 & 1.00 & N.D. & N.D. & 1.00 & 1.00 & N.D. & N.D. \\
\hline $\mathbf{N a}$ & 26410.00 & 860.00 & 30788.00 & 25366.00 & 25232.00 & 15556.00 & 30088.00 & 24956.00 \\
\hline Nd & 77.20 & 57.60 & 23.10 & 20.80 & 35.60 & 24.50 & 23.20 & 22.20 \\
\hline $\mathbf{N i}$ & 23.00 & 18.00 & 14.00 & 13.00 & 10.00 & 11.00 & 37.00 & 36.00 \\
\hline Os & 0.20 & 2.90 & N.D. & N.D. & N.D. & N.D. & N.D. & N.D. \\
\hline $\mathbf{P}$ & 1893.00 & 306.00 & 565.00 & 445.00 & 785.00 & 94.00 & 1048.00 & 1033.00 \\
\hline $\mathbf{P b}$ & 29.00 & 769.00 & 11.00 & 10.00 & 11.00 & 20.00 & 10.00 & 49.00 \\
\hline Pd & 0.80 & 0.50 & 0.90 & 0.50 & 0.60 & 0.50 & 0.60 & 0.50 \\
\hline Pr & 17.50 & 16.30 & 6.10 & 5.80 & 9.60 & 7.50 & 5.50 & 5.30 \\
\hline $\mathbf{P t}$ & 0.20 & 0.10 & 0.10 & N.D. & 0.30 & 0.10 & N.D. & N.D. \\
\hline $\mathbf{R h}$ & N.D. & N.D. & N.D. & N.D. & N.D. & N.D. & N.D. & N.D. \\
\hline $\mathbf{R u}$ & N.D. & N.D. & N.D. & N.D. & N.D. & N.D. & N.D. & N.D. \\
\hline Sb & N.D. & 1.00 & N.D. & N.D. & N.D. & N.D. & N.D. & N.D. \\
\hline $\mathrm{Sc}$ & 18.80 & 8.00 & 8.40 & 8.30 & 9.80 & 2.40 & 13.80 & 13.40 \\
\hline $\mathrm{Se}$ & N.D. & N.D. & 3.00 & N.D. & N.D. & N.D. & N.D. & N.D. \\
\hline Sm & 14.80 & 8.40 & 4.00 & 3.60 & 5.90 & 3.80 & 4.40 & 4.00 \\
\hline Sn & N.D. & 1.00 & N.D. & N.D. & N.D. & N.D. & N.D. & N.D. \\
\hline $\mathrm{Sr}$ & 251.00 & 45.00 & 247.00 & 178.00 & 355.00 & 81.00 & 751.00 & 198.00 \\
\hline Tb & 1.90 & 0.70 & 0.50 & 0.50 & 0.80 & 0.40 & 0.50 & 0.40 \\
\hline $\mathrm{Te}$ & 13.00 & 6.00 & 4.00 & 3.00 & 4.00 & N.D. & 13.00 & 9.00 \\
\hline Th & 10.20 & 10.40 & 9.30 & 12.90 & 18.00 & 31.20 & 3.60 & 3.30 \\
\hline $\mathbf{T i}$ & 6784.00 & 1648.00 & 2096.00 & 1916.00 & 2956.00 & 657.00 & 5080.00 & 3146.00 \\
\hline Tl & N.D. & 7.00 & N.D. & 1.00 & 5.00 & 9.00 & N.D. & 1.00 \\
\hline $\mathbf{T m}$ & 0.60 & 0.10 & 0.20 & 0.20 & 0.30 & 0.20 & 0.10 & 0.10 \\
\hline $\mathbf{U}$ & 2.80 & 0.70 & 1.40 & 2.50 & 4.40 & 2.40 & 1.20 & 0.90 \\
\hline $\mathbf{V}$ & 68.00 & 24.00 & 32.00 & 34.00 & 65.00 & 16.00 & 146.00 & 145.00 \\
\hline $\mathbf{W}$ & 1.00 & 16.00 & 2.00 & 3.00 & 1.00 & 6.00 & 1.00 & 8.00 \\
\hline $\mathbf{Y}$ & 47.40 & 8.30 & 13.90 & 13.00 & 22.10 & 11.10 & 10.10 & 8.00 \\
\hline $\mathbf{Y b}$ & 4.40 & 0.70 & 1.50 & 1.60 & 2.40 & 1.40 & 0.90 & 0.70 \\
\hline Zn & 211.00 & 46.00 & 79.00 & 36.00 & 56.00 & 26.00 & 111.00 & 122.00 \\
\hline
\end{tabular}


Tabla A1. Continuación

\begin{tabular}{|c|c|c|c|c|c|c|c|c|}
\hline Muestra & Quitovac6Ef & Quitovac6Ea & Sanfran1Ef & Sanfran1Ea & Sanfran3Ef & Sanfran3Ea & Sanfran4Ef & Sanfran4Ea \\
\hline \multirow[t]{2}{*}{ Coordenadas } & $112^{\circ} 51^{\prime} 55.3^{\prime \prime}$ & & $113^{\circ} 3^{\prime} 56.0^{\prime \prime}$ & & $113^{\circ} 4^{\prime} 44.1^{\prime \prime}$ & & $113^{\circ} 6^{\prime} 42.4^{\prime \prime}$ & \\
\hline & $31^{\circ} 29^{\prime} 54.2^{\prime \prime}$ & & $31^{\circ} 32^{\prime} 22.6^{\prime \prime}$ & & $31^{\circ} 31^{\prime} 21.7^{\prime \prime}$ & & $31^{\circ} 37^{\prime} 37.0^{\prime \prime}$ & \\
\hline \multicolumn{9}{|c|}{ Elementos mayores } \\
\hline $\mathrm{SiO}_{2}$ & 71.92 & 68.93 & 68.48 & 63.40 & 74.02 & 72.50 & 72.31 & 71.31 \\
\hline $\mathrm{TiO}_{2}$ & 0.19 & 0.21 & 0.34 & 0.62 & 0.28 & 0.07 & 0.04 & 0.06 \\
\hline $\mathrm{Al}_{2} \mathbf{O}_{3}$ & 15.09 & 16.33 & 14.98 & 19.23 & 11.81 & 13.77 & 14.20 & 15.39 \\
\hline $\mathrm{FeO}$ & 0.00 & 0.26 & 0.15 & 0.15 & 0.19 & 0.14 & 0.00 & N.D. \\
\hline $\mathrm{Fe}_{2} \mathrm{O}_{3}$ & 1.33 & 1.95 & 2.24 & 3.46 & 2.59 & 0.65 & 0.67 & 0.75 \\
\hline MnO & 0.03 & 0.03 & 0.04 & 0.01 & 0.02 & 0.01 & 0.01 & 0.01 \\
\hline MgO & 0.32 & 0.35 & 0.97 & 1.47 & 0.26 & 0.15 & 0.08 & 0.11 \\
\hline $\mathrm{CaO}$ & 1.57 & 0.04 & 2.60 & 0.30 & 1.55 & 0.19 & 0.70 & 0.20 \\
\hline $\mathrm{Na}_{2} \mathrm{O}$ & 3.99 & 0.16 & 4.31 & 0.09 & 2.18 & 1.06 & 4.07 & 1.59 \\
\hline $\mathrm{K}_{2} \mathrm{O}$ & 3.67 & 6.89 & 2.86 & 6.86 & 3.74 & 8.82 & 4.68 & 8.99 \\
\hline $\mathbf{P}_{2} \mathrm{O}_{5}$ & 0.05 & 0.07 & 0.14 & 0.15 & 0.04 & 0.00 & 0.01 & 0.06 \\
\hline PXC & 0.78 & 3.46 & 0.87 & 3.56 & 0.49 & 0.56 & 0.37 & 0.77 \\
\hline Total & 98.94 & 98.68 & 97.98 & 99.30 & 97.17 & 97.92 & 97.14 & 99.24 \\
\hline \multicolumn{9}{|c|}{ Elementos trazas } \\
\hline Ag & 0.50 & 0.40 & 0.40 & 3.90 & N.D. & N.D. & 0.40 & 2.10 \\
\hline Al & 80237.00 & 87660.00 & 77980.00 & 102801.00 & 62770.00 & 73602.00 & 75959.00 & 80844.00 \\
\hline As & 4.00 & 4.00 & 13.00 & 3.00 & N.D. & N.D. & ND & 7.00 \\
\hline $\mathbf{A u}$ & N.D. & N.D. & N.D. & N.D. & N.D. & N.D. & N.D. & 0.06 \\
\hline $\mathbf{B a}$ & 1456.00 & 1396.00 & 486.00 & 785.00 & 1605.00 & 3826.00 & 910.00 & 2424.00 \\
\hline Be & N.D. & 2.00 & N.D. & 11.00 & ND & 1.00 & 6.00 & 3.00 \\
\hline $\mathbf{B i}$ & N.D. & N.D. & N.D. & N.D. & N.D. & N.D. & N.D. & 1.00 \\
\hline Cd & N.D. & N.D. & N.D. & N.D. & N.D. & N.D. & N.D. & N.D. \\
\hline $\mathrm{Ce}$ & 67.40 & 42.60 & 36.20 & 74.20 & 71.50 & 15.60 & 8.90 & 22.20 \\
\hline Co & 2.00 & 1.00 & 8.00 & 7.00 & 5.00 & N.D. & N.D. & N.D. \\
\hline $\mathrm{Cr}$ & 4.00 & 8.00 & 10.00 & 14.00 & 8.00 & 6.00 & 6.00 & 6.00 \\
\hline $\mathrm{Cu}$ & 29.00 & 42.00 & 24.00 & 829.00 & 26.00 & 531.00 & 11.00 & 333.00 \\
\hline Dy & 1.60 & 0.20 & 1.00 & 0.80 & 1.40 & 1.00 & 0.90 & 1.10 \\
\hline $\mathbf{E r}$ & 0.70 & 0.10 & 0.50 & 0.40 & 0.60 & 0.70 & 0.80 & 0.70 \\
\hline Eu & 1.60 & 0.80 & 0.80 & 1.30 & 2.50 & 1.90 & 0.60 & 1.30 \\
\hline Gd & 4.40 & 1.60 & 2.40 & 4.00 & 4.30 & 1.40 & 0.80 & 2.20 \\
\hline Ho & 0.20 & N.D. & 0.20 & 0.10 & 0.20 & 0.20 & 0.20 & 0.20 \\
\hline Ir & 0.10 & N.D. & N.D. & N.D. & N.D. & N.D. & N.D. & 0.10 \\
\hline $\mathbf{K}$ & 30404.00 & 57143.00 & 23290.00 & 55025.00 & 30665.00 & 73247.00 & 38723.00 & 76983.00 \\
\hline La & 35.00 & 22.90 & 18.10 & 38.90 & 39.50 & 9.40 & 5.50 & 11.20 \\
\hline $\mathbf{L u}$ & 0.10 & N.D. & 0.10 & N.D. & 0.10 & 0.10 & 0.20 & 0.10 \\
\hline Mg & 1994.00 & 2105.00 & 5484.00 & 8197.00 & 1618.00 & 894.00 & 495.00 & 611.00 \\
\hline Mn & 200.00 & 197.00 & 267.00 & 74.00 & 177.00 & 66.00 & 106.00 & 41.00 \\
\hline Мo & N.D. & 7.00 & N.D. & 1.00 & N.D. & 41.00 & N.D. & 26.00 \\
\hline $\mathrm{Na}$ & 29329.00 & 1179.00 & 31844.00 & 650.00 & 16366.00 & 7859.00 & 29955.00 & 11422.00 \\
\hline Nd & 26.10 & 10.90 & 15.30 & 27.70 & 28.70 & 5.70 & 2.70 & 12.30 \\
\hline $\mathrm{Ni}$ & 15.00 & 5.00 & 17.00 & 22.00 & 7.00 & 6.00 & 13.00 & 11.00 \\
\hline Os & 2.10 & N.D. & N.D. & N.D. & N.D. & N.D. & N.D. & 3.30 \\
\hline $\mathbf{P}$ & 242.00 & 309.00 & 608.00 & 565.00 & 181.00 & 142.00 & 43.00 & 190.00 \\
\hline $\mathbf{P b}$ & 28.00 & 331.00 & 21.00 & 110.00 & 27.00 & 51.00 & 74.00 & 479.00 \\
\hline Pd & 0.40 & 0.30 & 0.30 & 0.30 & 0.20 & 0.20 & 1.10 & 0.70 \\
\hline Pr & 7.40 & 3.70 & 4.10 & 7.90 & 7.50 & 1.60 & 0.90 & 3.00 \\
\hline Pt & N.D. & N.D. & 0.20 & N.D. & N.D. & N.D. & N.D. & N.D. \\
\hline $\mathbf{R h}$ & N.D. & N.D. & N.D. & N.D. & N.D. & N.D. & N.D. & N.D. \\
\hline Ru & N.D. & N.D. & N.D. & N.D. & N.D. & N.D. & N.D. & N.D. \\
\hline Sb & N.D. & 5.00 & N.D. & 1.00 & N.D. & 2.00 & N.D. & N.D. \\
\hline Sc & 3.30 & 3.10 & 2.80 & 7.50 & 2.60 & 2.30 & 1.00 & 2.00 \\
\hline $\mathrm{Se}$ & N.D. & N.D. & N.D. & N.D. & 4.00 & N.D. & N.D. & 2.00 \\
\hline $\mathrm{Sm}$ & 4.20 & 1.30 & 2.40 & 3.90 & 4.00 & 0.90 & 0.50 & 2.30 \\
\hline Sn & 1.00 & N.D. & N.D. & N.D. & N.D. & N.D. & 2.00 & 1.00 \\
\hline $\mathrm{Sr}$ & 433.00 & 188.00 & 527.00 & 54.00 & 154.00 & 331.00 & 352.00 & 320.00 \\
\hline Tb & 0.40 & 0.10 & 0.20 & 0.30 & 0.40 & 0.20 & 0.10 & 0.30 \\
\hline $\mathrm{Te}$ & 1.00 & 2.00 & 2.00 & 3.00 & 6.00 & N.D. & N.D. & N.D. \\
\hline Th & 19.10 & 6.20 & 8.90 & 8.40 & 9.30 & 1.10 & 5.30 & 4.40 \\
\hline $\mathbf{T i}$ & 1174.00 & 851.00 & 2019.00 & 3342.00 & 1646.00 & 400.00 & 228.00 & 274.00 \\
\hline Tl & 11.00 & 3.00 & 3.00 & 2.00 & 9.00 & 6.00 & 7.00 & 13.00 \\
\hline $\mathbf{T m}$ & 0.10 & N.D. & 0.10 & N.D. & 0.10 & 0.10 & 0.10 & 0.10 \\
\hline $\mathbf{U}$ & 4.10 & 0.50 & 3.40 & 8.10 & 0.50 & 0.70 & 4.90 & 2.10 \\
\hline $\mathbf{V}$ & 15.00 & 15.00 & 35.00 & 91.00 & 21.00 & 22.00 & 16.00 & 18.00 \\
\hline $\mathbf{W}$ & 1.00 & 12.00 & ND & 11.00 & ND & 1.00 & ND & 33.00 \\
\hline $\mathbf{Y}$ & 6.30 & 0.70 & 4.40 & 2.60 & 5.70 & 5.40 & 5.90 & 6.20 \\
\hline $\mathbf{Y b}$ & 0.50 & 0.10 & 0.40 & 0.20 & 0.40 & 0.70 & 1.10 & 0.60 \\
\hline Zn & 70.00 & 71.00 & 60.00 & 147.00 & 39.00 & 40.00 & 12.00 & 2212.00 \\
\hline
\end{tabular}


Tabla A1. Continuación

\begin{tabular}{|c|c|c|c|c|c|c|c|c|}
\hline Muestra & Sanfran5Ef & Sanfran5Ea & Sanfran8Ef & Sanfran8Ea & Sanfran14Ef & Sanfran14Ea & Sanluisito2Ef & Sanluisito2Ea \\
\hline \multirow{2}{*}{ Coordenadas } & $113^{\circ} 6^{\prime} 51.3^{\prime \prime}$ & & $113^{\circ} 8^{\prime} 11.4^{\prime \prime}$ & & $113^{\circ} 7^{\prime} 56.7^{\prime \prime}$ & & $112^{\circ} 37^{\prime} 31.0^{\prime \prime}$ & \\
\hline & $31^{\circ} 37^{\prime} 25.4^{\prime \prime}$ & & $31^{\circ} 40^{\prime} 19.8^{\prime \prime}$ & & $31^{\circ} 39^{\prime} 53.0^{\prime \prime}$ & & $31^{\circ} 17^{\prime} 2.0^{\prime \prime}$ & \\
\hline \multicolumn{9}{|c|}{ Elementos mayores } \\
\hline $\mathrm{SiO}_{2}$ & 61.46 & 66.38 & 69.31 & 70.06 & 52.26 & 46.53 & 69.74 & 68.35 \\
\hline $\mathrm{TiO}_{2}$ & 0.82 & 0.75 & 0.35 & 0.08 & 0.90 & 0.64 & 0.26 & 0.27 \\
\hline $\mathrm{Al}_{2} \mathbf{O}_{3}$ & 16.26 & 16.32 & 13.06 & 16.24 & 14.52 & 11.81 & 14.26 & 16.43 \\
\hline $\mathrm{FeO}$ & 5.00 & 1.00 & 0.15 & 0.26 & 5.72 & 7.17 & 0.19 & 0.14 \\
\hline $\mathrm{Fe}_{2} \mathrm{O}_{3}$ & 2.62 & 3.81 & 3.88 & 0.86 & 3.49 & 4.66 & 2.43 & 1.81 \\
\hline MnO & 0.07 & 0.04 & 0.06 & 0.02 & 0.16 & 0.22 & 0.06 & 0.02 \\
\hline MgO & 3.03 & 1.48 & 2.56 & 1.04 & 7.16 & 11.38 & 0.96 & 0.94 \\
\hline $\mathrm{CaO}$ & 1.05 & 0.22 & 3.39 & 0.26 & 7.26 & 9.30 & 2.52 & 0.43 \\
\hline $\mathrm{Na}_{2} \mathrm{O}$ & 1.11 & 0.42 & 3.24 & 1.72 & 2.65 & 1.27 & 3.45 & 0.09 \\
\hline $\mathrm{K}_{2} \mathrm{O}$ & 3.70 & 4.75 & 1.33 & 3.36 & 2.32 & 2.11 & 3.42 & 6.07 \\
\hline $\mathrm{P}_{2} \mathrm{O}_{5}$ & 0.05 & 0.03 & 0.08 & 0.02 & 0.26 & 0.12 & 0.08 & 0.06 \\
\hline PXC & 2.61 & 3.11 & 0.96 & 3.97 & 2.63 & 3.77 & 0.62 & 2.71 \\
\hline Total & 97.78 & 98.31 & 98.37 & 97.89 & 99.33 & 98.98 & 97.99 & 97.32 \\
\hline \multicolumn{9}{|c|}{ Elementos trazas } \\
\hline Ag & N.D. & 0.20 & 0.40 & 1.40 & 0.80 & 1.40 & 0.10 & 1.00 \\
\hline Al & 84390.00 & 85858.00 & 66296.00 & 83778.00 & 73788.00 & 60624.00 & 75928.00 & 84882.00 \\
\hline As & 10.00 & 13.00 & 18.00 & 12.00 & 11.00 & N.D. & 2.00 & 4.00 \\
\hline Au & N.D. & $\mathbf{0 . 0 2}$ & N.D. & 0.02 & 0.01 & N.D. & N.D. & N.D. \\
\hline Ba & 1131.00 & 1250.00 & 752.00 & 766.00 & 807.00 & 351.00 & 731.00 & 391.00 \\
\hline $\mathrm{Be}$ & N.D. & N.D. & N.D. & 7.00 & N.D. & N.D. & N.D. & 3.00 \\
\hline $\mathbf{B i}$ & N.D. & N.D. & N.D. & N.D. & N.D. & N.D. & N.D. & N.D. \\
\hline Cd & N.D. & N.D. & N.D. & N.D. & N.D. & N.D. & N.D. & 1.00 \\
\hline $\mathrm{Ce}$ & 109.60 & 111.90 & 62.70 & 8.90 & 44.20 & 29.20 & 88.00 & 41.00 \\
\hline Co & 25.00 & 23.00 & 14.00 & 1.00 & 40.00 & 52.00 & 8.00 & 5.00 \\
\hline $\mathrm{Cr}$ & 99.00 & 100.00 & 51.00 & 8.00 & 279.00 & 678.00 & 8.00 & 8.00 \\
\hline $\mathrm{Cu}$ & 32.00 & 94.00 & 23.00 & 144.00 & 19.00 & 7.00 & 12.00 & 16.00 \\
\hline Dy & 5.60 & 4.80 & 4.10 & 0.20 & 10.30 & 8.70 & 2.50 & 0.70 \\
\hline $\mathbf{E r}$ & 2.60 & 2.20 & 2.40 & 0.10 & 6.30 & 5.90 & 1.70 & 0.40 \\
\hline Eu & 2.00 & 2.00 & 1.90 & 0.50 & 1.90 & 1.50 & 1.00 & 0.70 \\
\hline Gd & 9.00 & 8.70 & 5.70 & 0.70 & 8.90 & 6.80 & 4.40 & 2.50 \\
\hline Ho & 1.00 & 0.80 & 0.80 & N.D. & 2.00 & 1.90 & 0.50 & 0.10 \\
\hline Ir & N.D. & N.D. & N.D. & N.D. & N.D. & 0.10 & N.D. & N.D. \\
\hline $\mathbf{K}$ & 30104.00 & 39288.00 & 11390.00 & 27483.00 & 19128.00 & 17539.00 & 28300.00 & 50111.00 \\
\hline La & 54.90 & 52.70 & 31.60 & 5.30 & 17.20 & 11.40 & 51.70 & 20.70 \\
\hline Lu & 0.30 & 0.30 & 0.30 & N.D. & 0.90 & 0.90 & 0.30 & N.D. \\
\hline Mg & 17926.00 & 8391.00 & 14355.00 & 5938.00 & 38676.00 & 67634.00 & 5472.00 & 5543.00 \\
\hline Mn & 545.00 & 280.00 & 417.00 & 129.00 & 1110.00 & 1505.00 & 453.00 & 143.00 \\
\hline Mo & 1.00 & 2.00 & N.D. & 7.00 & N.D. & N.D. & 1.00 & 2.00 \\
\hline $\mathrm{Na}$ & 8175.00 & 3174.00 & 23105.00 & 12647.00 & 18769.00 & 8817.00 & 25379.00 & 745.00 \\
\hline Nd & 45.40 & 45.20 & 28.50 & 3.60 & 29.80 & 21.90 & 24.30 & 16.00 \\
\hline $\mathbf{N i}$ & 60.00 & 54.00 & 81.00 & 14.00 & 161.00 & 182.00 & 10.00 & 10.00 \\
\hline Os & N.D. & N.D. & N.D. & N.D. & N.D. & 0.10 & N.D. & N.D. \\
\hline $\mathbf{P}$ & 207.00 & 138.00 & 344.00 & 87.00 & 1125.00 & 472.00 & 353.00 & 270.00 \\
\hline $\mathbf{P b}$ & 20.00 & 57.00 & 2.00 & 411.00 & 11.00 & 0.00 & 15.00 & 55.00 \\
\hline Pd & 0.20 & 0.30 & 0.30 & 0.10 & 0.70 & 0.70 & 0.30 & 0.10 \\
\hline Pr & 12.60 & 12.40 & 7.40 & 1.00 & 6.50 & 4.60 & 8.10 & 4.50 \\
\hline Pt & N.D. & N.D. & 1.20 & N.D. & N.D. & N.D. & N.D. & N.D. \\
\hline Rh & N.D. & N.D. & N.D. & N.D. & N.D. & N.D. & N.D. & N.D. \\
\hline Ru & N.D. & N.D. & N.D. & N.D. & N.D. & N.D. & N.D. & N.D. \\
\hline Sb & N.D. & N.D. & N.D. & N.D. & N.D. & 6.00 & N.D. & 3.00 \\
\hline Sc & 17.60 & 16.10 & 9.90 & 3.20 & 30.60 & 49.90 & 5.80 & 3.10 \\
\hline Se & N.D. & N.D. & N.D. & 1.00 & N.D. & N.D. & N.D. & 2.00 \\
\hline Sm & 8.10 & 8.30 & 5.00 & 0.60 & 7.80 & 6.10 & 3.40 & 2.60 \\
\hline Sn & N.D. & N.D. & N.D. & 1.00 & N.D. & N.D. & N.D. & N.D. \\
\hline $\mathrm{Sr}$ & 127.00 & 47.00 & 401.00 & 185.00 & 342.00 & 145.00 & 268.00 & 19.00 \\
\hline Tb & 1.10 & 1.00 & 0.80 & N.D. & 1.60 & 1.30 & 0.50 & 0.20 \\
\hline Te & 13.00 & 6.00 & 1.00 & N.D. & 13.00 & 13.00 & N.D. & N.D. \\
\hline Th & 15.20 & 16.40 & 8.20 & 0.80 & 0.40 & 0.80 & 59.80 & 11.00 \\
\hline $\mathbf{T i}$ & 4936.00 & 3974.00 & 2086.00 & 345.00 & 5058.00 & 3540.00 & 1649.00 & 1481.00 \\
\hline Tl & N.D. & 4.00 & 8.00 & 12.00 & N.D. & N.D. & 6.00 & 11.00 \\
\hline $\mathbf{T m}$ & 0.30 & 0.30 & 0.30 & N.D. & 0.90 & 0.90 & 0.20 & N.D. \\
\hline $\mathbf{U}$ & 1.60 & 6.70 & 0.80 & 0.40 & 0.40 & 0.40 & 11.30 & 2.00 \\
\hline $\mathbf{V}$ & 108.00 & 107.00 & 40.00 & 35.00 & 133.00 & 202.00 & 43.00 & 36.00 \\
\hline W & 1.00 & 26.00 & 1.00 & 17.00 & 1.00 & 1.00 & 2.00 & 19.00 \\
\hline $\mathbf{Y}$ & 22.20 & 18.50 & 19.00 & 0.60 & 49.40 & 46.20 & 13.50 & 2.40 \\
\hline $\mathbf{Y b}$ & 2.20 & 1.90 & 2.10 & 0.10 & 6.00 & 6.20 & 1.80 & 0.30 \\
\hline$\underline{\mathrm{Zn}}$ & 141.00 & 199.00 & 118.00 & 2221.00 & 137.00 & 318.00 & 71.00 & 177.00 \\
\hline
\end{tabular}


Tabla A1. Continuación

\begin{tabular}{|c|c|c|c|c|c|c|c|c|}
\hline Muestra & Sanluisito3Ef & Sanluisito3Ea & Sonoyta5Ef & Sonoyta5Ea & Trin11Ef & Trin11Ea & Vidrios1Ef & Vidrios1Ea \\
\hline \multirow{2}{*}{ Coordenadas } & $112^{\circ} 29^{\prime} 18.1^{\prime \prime}$ & & $112^{\circ} 52^{\prime} 3.5^{\prime \prime}$ & & $111^{\circ} 40^{\prime} 57.8^{\prime \prime}$ & & $113^{\circ} 40^{\prime} 45.2^{\prime \prime}$ & \\
\hline & $31^{\circ} 22^{\prime} 57.0^{\prime \prime}$ & & $31^{\circ} 49^{\prime} 3.5^{\prime \prime}$ & & $30^{\circ} 11^{\prime} 2.1^{\prime \prime}$ & & $32^{\circ} 5^{\prime} 6.8^{\prime \prime}$ & \\
\hline \multicolumn{9}{|c|}{ Elementos mayores } \\
\hline $\mathrm{SiO}_{2}$ & 60.07 & 62.90 & 73.27 & 71.35 & 68.24 & 70.17 & 64.61 & 60.76 \\
\hline $\mathrm{TiO}_{2}$ & 0.59 & 0.59 & 0.09 & 0.16 & 0.52 & 0.39 & 0.71 & 0.70 \\
\hline $\mathbf{A l}_{2} \mathbf{O}_{3}$ & 16.36 & 15.79 & 14.85 & 16.50 & 14.14 & 13.41 & 15.86 & 17.59 \\
\hline $\mathrm{FeO}$ & 0.84 & 1.00 & 0.00 & 0.14 & 0.27 & 0.26 & 0.28 & 0.27 \\
\hline $\mathrm{Fe}_{2} \mathrm{O}_{3}$ & 4.49 & 3.90 & 0.78 & 1.21 & 3.62 & 3.34 & 3.84 & 3.42 \\
\hline MnO & 0.10 & 0.14 & 0.02 & 0.02 & 0.04 & 0.01 & 0.07 & 0.07 \\
\hline MgO & 2.62 & 2.50 & 0.15 & 0.39 & 1.17 & 0.82 & 1.31 & 1.13 \\
\hline $\mathrm{CaO}$ & 4.76 & 3.11 & 1.15 & 0.10 & 0.89 & 0.54 & 2.69 & 2.10 \\
\hline $\mathrm{Na}_{2} \mathrm{O}$ & 3.35 & 2.09 & 3.84 & 0.22 & 2.66 & 5.29 & 2.98 & 3.77 \\
\hline $\mathbf{K}_{2} \mathbf{O}$ & 2.78 & 4.12 & 3.39 & 6.16 & 4.32 & 1.24 & 4.95 & 7.33 \\
\hline $\mathbf{P}_{2} \mathbf{O}_{5}$ & 0.16 & 0.07 & 0.04 & 0.04 & 0.13 & 0.10 & 0.30 & 0.27 \\
\hline PXC & 2.12 & 2.47 & 0.46 & 2.08 & 1.15 & 2.48 & 1.03 & 1.32 \\
\hline Total & 98.24 & 98.68 & 98.04 & 98.37 & 97.15 & 98.05 & 98.63 & 98.73 \\
\hline \multicolumn{9}{|c|}{ Elementos trazas } \\
\hline Ag & 5.50 & 5.80 & 0.40 & 7.00 & 0.10 & 0.90 & N.D. & N.D. \\
\hline Al & 84806.00 & 80283.00 & 80670.00 & 88271.00 & 76609.00 & 69590.00 & 85081.00 & 91594.00 \\
\hline As & 12.00 & 6.00 & 9.00 & 4.00 & $\mathrm{ND}$ & 22.00 & 6.00 & 5.00 \\
\hline Au & N.D. & N.D. & N.D. & N.D. & N.D. & 0.06 & N.D. & N.D. \\
\hline $\mathbf{B a}$ & 935.00 & 1163.00 & 1423.00 & 823.00 & 974.00 & 134.00 & 2711.00 & 2634.00 \\
\hline $\mathrm{Be}$ & N.D. & N.D. & N.D. & 3.00 & N.D. & N.D. & N.D. & N.D. \\
\hline $\mathbf{B i}$ & N.D. & N.D. & N.D. & N.D. & N.D. & N.D. & N.D. & N.D. \\
\hline Cd & 5.00 & 3.00 & N.D. & N.D. & N.D. & N.D. & N.D. & N.D. \\
\hline $\mathrm{Ce}$ & 95.10 & 85.40 & 52.10 & 66.10 & 214.40 & 147.90 & 250.00 & 301.90 \\
\hline Co & 19.00 & 21.00 & 1.00 & 2.00 & 11.00 & 8.00 & 15.00 & 6.00 \\
\hline $\mathrm{Cr}$ & 30.00 & 33.00 & 7.00 & 5.00 & 24.00 & 22.00 & 12.00 & 8.00 \\
\hline $\mathrm{Cu}$ & 28.00 & 1935.00 & 18.00 & 7.00 & 60.00 & 432.00 & 12.00 & 12.00 \\
\hline Dy & 4.10 & 4.30 & 1.60 & 1.60 & 7.50 & 4.00 & 11.20 & 10.60 \\
\hline Er & 2.30 & 2.30 & 0.70 & 0.60 & 2.50 & 1.90 & 6.60 & 6.10 \\
\hline Eu & 2.00 & 2.10 & 1.30 & 0.90 & 3.30 & 1.20 & 5.30 & 4.90 \\
\hline Gd & 6.90 & 6.70 & 3.40 & 4.00 & 16.70 & 11.00 & 18.80 & 19.70 \\
\hline Ho & 0.70 & 0.80 & 0.30 & 0.20 & 1.00 & 0.60 & 2.10 & 1.90 \\
\hline Ir & N.D. & N.D. & N.D. & N.D. & N.D. & N.D. & N.D. & N.D. \\
\hline $\mathbf{K}$ & 22907.00 & 34208.00 & 28107.00 & 51002.00 & 35874.00 & 10381.00 & 40787.00 & 60477.00 \\
\hline La & 51.00 & 44.70 & 26.10 & 33.40 & 89.20 & 62.10 & 111.40 & 140.70 \\
\hline Lu & 0.30 & 0.30 & 0.10 & N.D. & 0.20 & 0.20 & 0.90 & 0.80 \\
\hline Mg & 14995.00 & 14984.00 & 939.00 & 2360.00 & 6827.00 & 4780.00 & 7919.00 & 6807.00 \\
\hline Mn & 736.00 & 1046.00 & 124.00 & 120.00 & 315.00 & 101.00 & 561.00 & 538.00 \\
\hline Mo & N.D. & N.D. & 1.00 & N.D. & 1.00 & 1.00 & 3.00 & 24.00 \\
\hline $\mathrm{Na}$ & 24167.00 & 15214.00 & 28831.00 & 1648.00 & 19378.00 & 38946.00 & 21690.00 & 27027.00 \\
\hline Nd & 35.50 & 33.20 & 18.90 & 24.10 & 87.60 & 78.30 & 111.60 & 117.90 \\
\hline $\mathbf{N i}$ & 24.00 & 25.00 & 29.00 & 8.00 & 36.00 & 44.00 & 14.00 & 14.00 \\
\hline Os & N.D. & N.D. & N.D. & N.D. & N.D. & N.D. & N.D. & N.D. \\
\hline $\mathbf{P}$ & 717.00 & 314.00 & 170.00 & 190.00 & 558.00 & 450.00 & 1347.00 & 1115.00 \\
\hline $\mathbf{P b}$ & 246.00 & 773.00 & 74.00 & 12.00 & 15.00 & 66.00 & 54.00 & 41.00 \\
\hline Pd & 0.50 & 0.50 & 0.20 & 0.40 & 0.20 & 0.40 & 0.80 & 0.50 \\
\hline Pr & 10.30 & 9.30 & 5.60 & 7.10 & 23.10 & 21.60 & 30.30 & 33.20 \\
\hline Pt & N.D. & N.D. & N.D. & N.D. & N.D. & N.D. & N.D. & N.D. \\
\hline $\mathbf{R h}$ & N.D. & 0.10 & N.D. & N.D. & N.D. & N.D. & N.D. & N.D. \\
\hline Ru & N.D. & N.D. & N.D. & N.D. & N.D. & N.D. & N.D. & N.D. \\
\hline Sb & N.D. & N.D. & 2.00 & N.D. & N.D. & N.D. & N.D. & N.D. \\
\hline Sc & 13.60 & 11.90 & 2.20 & 3.40 & 9.00 & 10.10 & 12.50 & 14.50 \\
\hline Se & N.D. & N.D. & N.D. & 6.00 & N.D. & N.D. & N.D. & N.D. \\
\hline Sm & 5.90 & 5.90 & 3.10 & 3.90 & 17.20 & 11.10 & 18.40 & 18.10 \\
\hline Sn & N.D. & N.D. & N.D. & 1.00 & N.D. & N.D. & N.D. & N.D. \\
\hline $\mathbf{S r}$ & 464.00 & 383.00 & 413.00 & 45.00 & 123.00 & 117.00 & 607.00 & 426.00 \\
\hline Tb & 0.80 & 0.80 & 0.40 & 0.40 & 1.90 & 1.10 & 2.30 & 2.30 \\
\hline $\mathrm{Te}$ & 4.00 & 4.00 & N.D. & 1.00 & 4.00 & 2.00 & 7.00 & 7.00 \\
\hline Th & 19.90 & 17.60 & 12.30 & 16.40 & 49.60 & 53.00 & 30.60 & 29.50 \\
\hline $\mathbf{T i}$ & 3565.00 & 3461.00 & 628.00 & 798.00 & 3071.00 & 2069.00 & 4349.00 & 3217.00 \\
\hline TI & N.D. & 9.00 & 8.00 & 13.00 & 1.00 & 8.00 & 3.00 & 6.00 \\
\hline $\mathbf{T m}$ & 0.30 & 0.30 & 0.10 & 0.10 & 0.20 & 0.20 & 0.90 & 0.80 \\
\hline $\mathbf{U}$ & 5.10 & 4.60 & 1.50 & 1.10 & 2.70 & 3.10 & 5.40 & 5.40 \\
\hline V & 87.00 & 85.00 & 7.00 & 9.00 & 37.00 & 26.00 & 63.00 & 65.00 \\
\hline W & 2.00 & ND & 1.00 & 2.00 & $\mathrm{ND}$ & 1.00 & 1.00 & 2.00 \\
\hline $\mathbf{Y}$ & 18.80 & 20.40 & 6.60 & 5.70 & 21.00 & 12.50 & 52.80 & 48.90 \\
\hline $\mathbf{Y b}$ & 2.00 & 2.00 & 0.60 & 0.40 & 1.70 & 1.40 & 6.00 & 5.50 \\
\hline Zn & 234.00 & 6848.00 & 40.00 & 122.00 & 33.00 & 27.00 & 83.00 & 145.00 \\
\hline
\end{tabular}




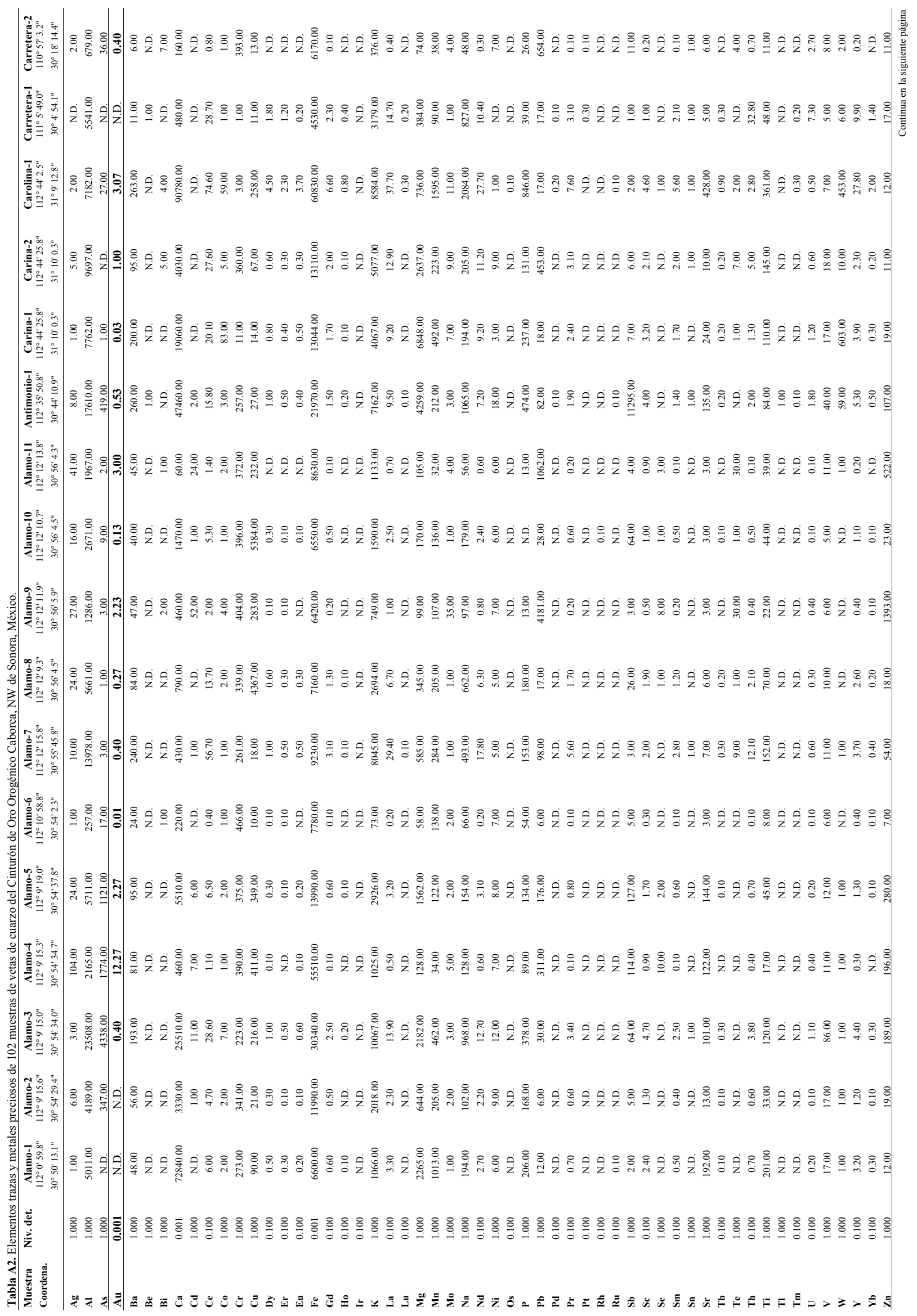




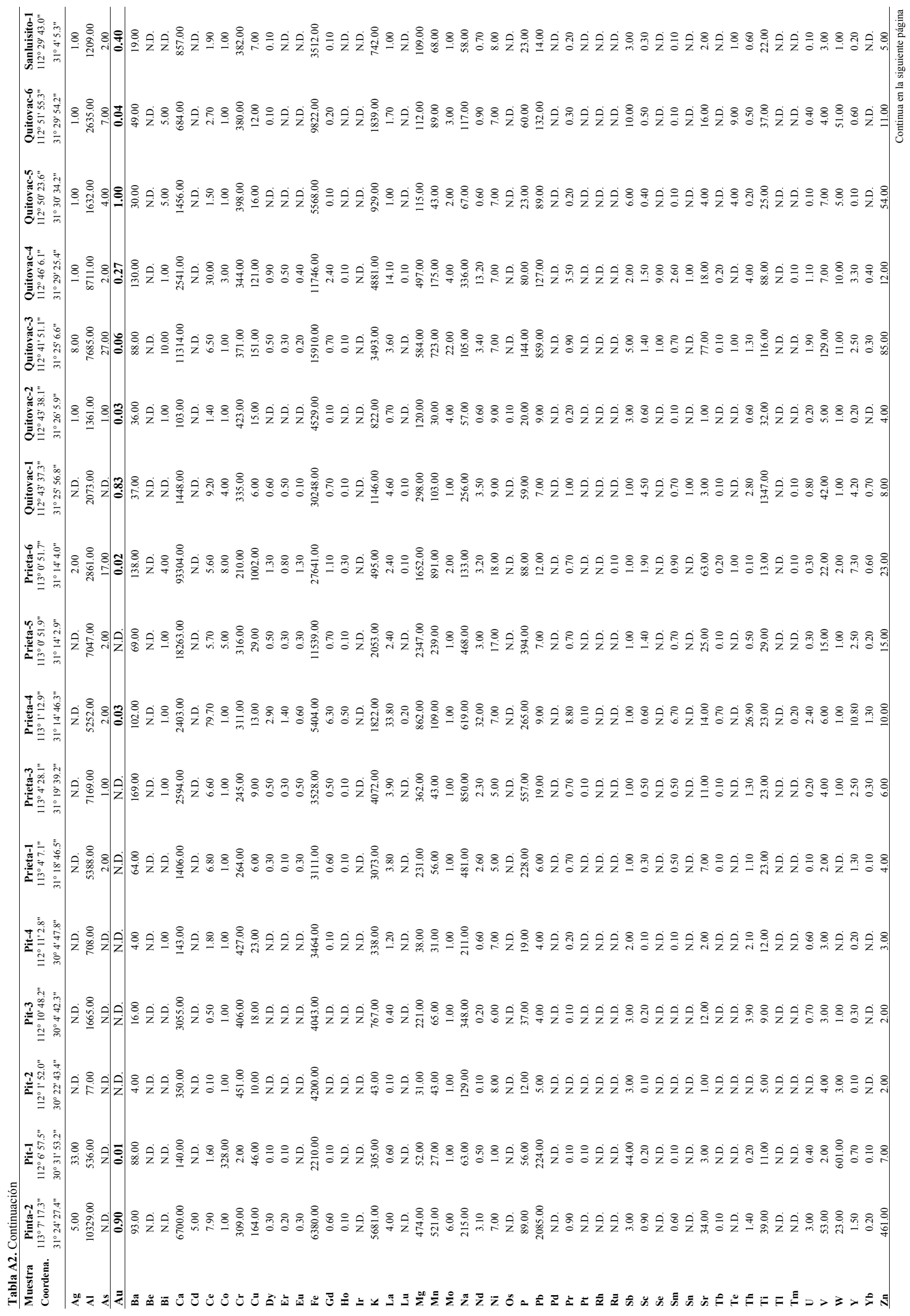




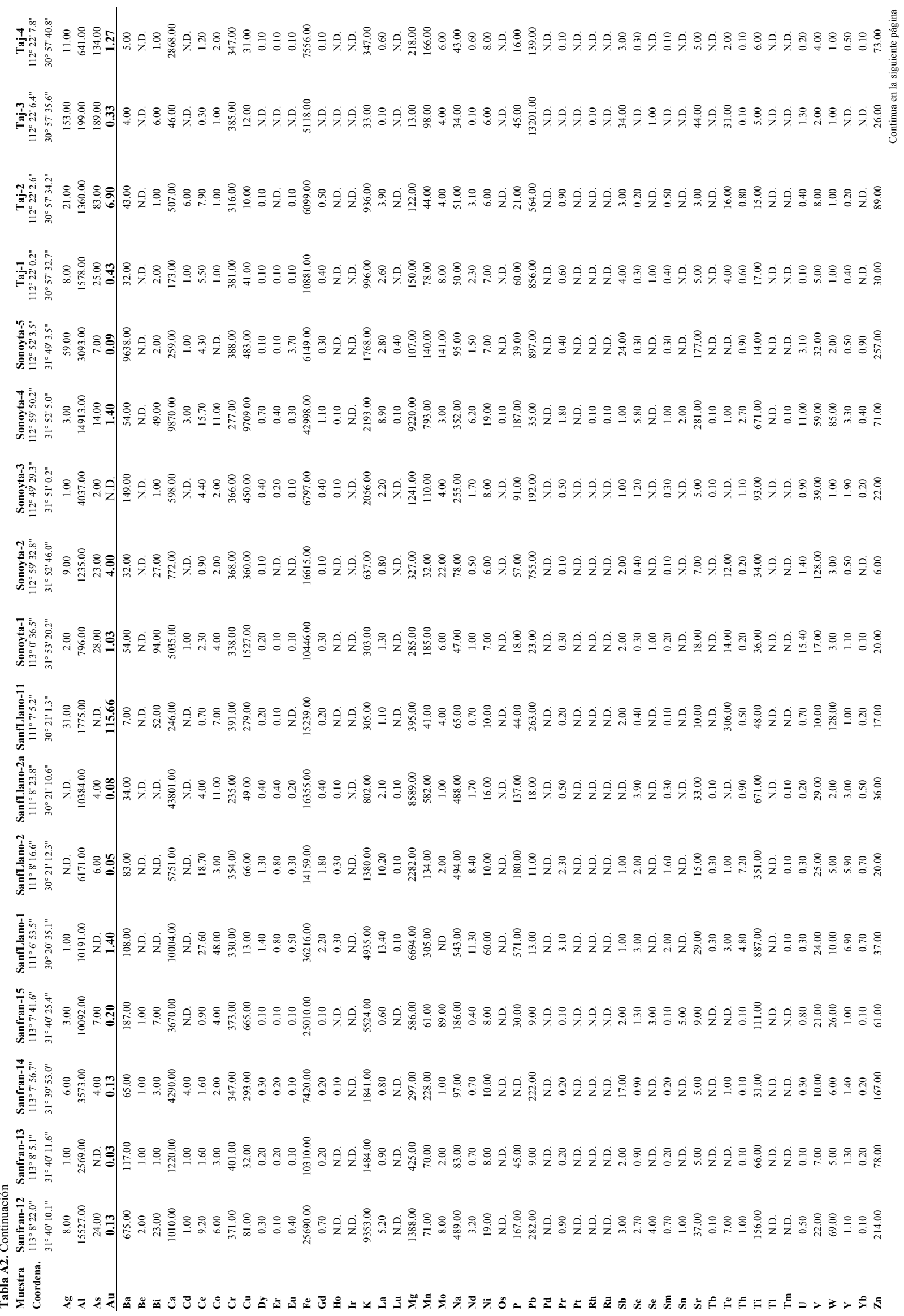


Tabla A3. Resultados del balance de masas de las rocas encajonantes frescas y alteradas de la mineralización del Cinturón de Oro Orogénico Caborca, NW de Sonora, México.

\begin{tabular}{|c|c|c|c|c|c|c|c|c|c|c|}
\hline \multirow[t]{2}{*}{ Elemento } & \multicolumn{2}{|l|}{ Alamo-1 } & \multicolumn{2}{|l|}{ Carolina-1 } & \multicolumn{2}{|l|}{ Carretera-2 } & \multicolumn{2}{|l|}{ Costa-4 } & \multicolumn{2}{|l|}{ Km100 } \\
\hline & $\Delta$ conc & $\Delta$ conc $-C^{A}$ & $\Delta$ conc & $\Delta$ conc $-C^{A}$ & $\Delta$ conc & $\Delta$ conc $-C^{A}$ & $\Delta$ conc & $\Delta$ conc $-C^{A}$ & $\Delta$ conc & $\Delta$ conc $-C^{A}$ \\
\hline Ag & 0.14 & 2.80 & 0.00 & 0.00 & 0.00 & -0.04 & 1.01 & 20.17 & 15.46 & 309.10 \\
\hline $\mathbf{A l}_{2} \mathbf{O}_{3}$ & 0.00 & 0.00 & 1.03 & 0.07 & 0.00 & 0.00 & 0.00 & 0.00 & 4.26 & 0.27 \\
\hline As & -16.35 & -0.71 & 15.00 & 3.00 & 48.94 & 6.99 & 3.66 & 0.73 & 0.05 & 0.01 \\
\hline Au & 0.00 & -0.05 & -0.03 & -0.98 & 0.00 & -0.04 & -0.01 & -0.95 & 0.00 & 0.00 \\
\hline Ba & -69.66 & -0.11 & -656.00 & -0.39 & -34.29 & -0.06 & 103.47 & 0.12 & 212.29 & 0.15 \\
\hline $\mathrm{Be}$ & -0.03 & -0.05 & 0.00 & 0.00 & 0.93 & 0.93 & -0.04 & -0.04 & 0.38 & 0.76 \\
\hline $\mathbf{B i}$ & -0.03 & -0.05 & 0.00 & 0.00 & -0.02 & -0.04 & -0.02 & -0.04 & 0.38 & 0.76 \\
\hline $\mathrm{CaO}$ & 0.82 & 0.16 & -1.97 & -0.63 & -0.61 & -0.78 & -0.65 & -0.39 & -3.79 & -0.98 \\
\hline Cd & -0.03 & -0.05 & 0.00 & 0.00 & -0.02 & -0.04 & -0.02 & -0.04 & 0.38 & 0.76 \\
\hline $\mathrm{Ce}$ & 15.24 & 0.30 & 20.10 & 0.12 & -4.21 & -0.12 & 0.53 & 0.02 & 149.55 & 1.08 \\
\hline Co & -3.94 & -0.18 & 4.00 & 0.21 & -1.07 & -0.36 & -1.04 & -0.52 & -18.71 & -0.78 \\
\hline $\mathrm{Cr}$ & -11.28 & -0.31 & 2.00 & 0.10 & 1.75 & 0.35 & -0.23 & -0.04 & -6.43 & -0.38 \\
\hline $\mathrm{Cu}$ & 59.56 & 2.29 & 2.00 & 0.08 & 29.72 & 5.95 & -21.30 & -0.74 & 51.52 & 1.98 \\
\hline Dy & -0.84 & -0.23 & 1.00 & 0.11 & -0.14 & -0.11 & -1.27 & -0.42 & -5.95 & -0.60 \\
\hline $\mathbf{E r}$ & -0.47 & -0.25 & 0.50 & 0.10 & -0.02 & -0.04 & -1.03 & -0.54 & -3.56 & -0.65 \\
\hline $\mathbf{E u}$ & -0.37 & -0.22 & 0.50 & 0.12 & -0.12 & -0.20 & -0.13 & -0.13 & -1.13 & -0.32 \\
\hline $\mathrm{FeO}$ & 0.64 & 0.89 & 1.01 & 0.36 & 0.18 & 365.53 & 0.13 & 268.40 & -4.33 & -0.95 \\
\hline $\mathrm{Fe}_{2} \mathrm{O}_{3}$ & -2.42 & -0.43 & -0.42 & -0.08 & 0.25 & 0.23 & -0.04 & -0.04 & -0.60 & -0.18 \\
\hline Gd & -0.26 & -0.05 & 1.70 & 0.11 & -0.39 & -0.14 & -0.41 & -0.13 & -0.12 & -0.01 \\
\hline Но & -0.13 & -0.21 & 0.20 & 0.12 & -0.01 & -0.04 & -0.31 & -0.52 & -1.27 & -0.71 \\
\hline Ir & 0.09 & 0.90 & 0.00 & 0.00 & 0.00 & -0.04 & 0.00 & -0.04 & 0.13 & 2.52 \\
\hline $\mathrm{K}_{2} \mathrm{O}$ & -0.06 & -0.04 & 0.93 & 0.24 & 0.51 & 0.14 & 0.33 & 0.11 & 7.25 & 1.98 \\
\hline La & 8.61 & 0.33 & 11.10 & 0.16 & -1.53 & -0.10 & -0.18 & -0.01 & 61.46 & 1.00 \\
\hline $\mathbf{L u}$ & -0.11 & -0.53 & 0.00 & 0.00 & 0.00 & -0.04 & -0.10 & -0.52 & -0.42 & -0.71 \\
\hline MgO & 0.27 & 0.09 & 0.13 & 0.07 & 0.00 & -0.01 & 0.03 & 0.12 & -0.86 & -0.48 \\
\hline MnO & 0.01 & 0.05 & -0.07 & -0.44 & -0.05 & -0.72 & 0.00 & -0.04 & -0.13 & -0.88 \\
\hline Mo & -0.03 & -0.05 & 0.00 & 0.00 & 0.47 & 0.93 & 0.46 & 0.92 & 0.76 & 0.76 \\
\hline $\mathbf{N a}$ & -5263.39 & -0.23 & -1.57 & -0.93 & -1.07 & -0.29 & 0.07 & 0.02 & -3.36 & -0.94 \\
\hline Nd & 1.09 & 0.04 & 10.00 & 0.12 & -1.85 & -0.13 & -0.50 & -0.04 & 24.29 & 0.32 \\
\hline $\mathbf{N i}$ & -2.98 & -0.07 & 6.00 & 0.27 & 6.43 & 0.72 & 0.70 & 0.10 & 8.71 & 0.38 \\
\hline Os & 0.00 & 0.00 & 0.00 & 0.00 & 0.00 & -0.04 & 0.00 & -0.04 & 0.00 & 0.00 \\
\hline $\mathbf{P b}$ & 7.01 & 0.58 & -23.00 & -0.96 & 53.31 & 2.67 & 0.05 & 0.00 & 1325.91 & 45.72 \\
\hline Pd & -0.37 & -0.21 & 0.10 & 0.25 & -0.12 & -0.20 & -0.11 & -0.36 & 0.08 & 0.10 \\
\hline Pr & 1.02 & 0.16 & 2.40 & 0.12 & -0.52 & -0.13 & -0.13 & -0.04 & 11.22 & 0.64 \\
\hline Pt & -0.01 & -0.05 & 0.00 & 0.00 & -0.01 & -0.04 & 0.14 & 2.85 & -0.02 & -0.12 \\
\hline $\mathbf{P}_{2} \mathrm{O}_{5}$ & 0.00 & 0.00 & 0.03 & 0.06 & 0.01 & 0.16 & 0.01 & 0.28 & -0.30 & -0.71 \\
\hline $\mathbf{R h}$ & 0.00 & -0.05 & 0.00 & 0.00 & 0.00 & -0.04 & 0.00 & -0.04 & 0.04 & 0.76 \\
\hline $\mathbf{R u}$ & -0.01 & -0.05 & 0.00 & 0.00 & 0.00 & -0.04 & 0.00 & -0.04 & 0.04 & 0.76 \\
\hline Sb & -0.03 & -0.05 & 0.00 & 0.00 & 3.36 & 6.72 & -0.02 & -0.04 & 1.26 & 2.52 \\
\hline Sc & -4.92 & -0.38 & 1.30 & 0.06 & -0.51 & -0.08 & -1.69 & -0.43 & -4.71 & -0.25 \\
\hline Se & -0.03 & -0.05 & 0.00 & 0.00 & -0.02 & -0.04 & -7.52 & -0.94 & 0.38 & 0.76 \\
\hline $\mathrm{SiO}_{2}$ & -4.00 & -0.07 & 2.85 & 0.05 & -2.20 & -0.03 & -5.09 & -0.07 & 72.72 & 1.24 \\
\hline Sm & -0.44 & -0.09 & 1.40 & 0.09 & -0.59 & -0.19 & -0.30 & -0.10 & 0.00 & 0.00 \\
\hline Sn & -0.03 & -0.05 & 0.00 & 0.00 & 0.93 & 0.93 & -1.04 & -0.52 & 1.26 & 2.52 \\
\hline $\mathrm{Sr}$ & 220.82 & 0.28 & -100.00 & -0.76 & -36.99 & -0.41 & -53.30 & -0.17 & -171.71 & -0.68 \\
\hline $\mathbf{T b}$ & -0.13 & -0.19 & 0.20 & 0.11 & -0.01 & -0.04 & -0.21 & -0.42 & -0.67 & -0.35 \\
\hline Te & -4.30 & -0.43 & 3.00 & 0.23 & -3.52 & -0.88 & 0.46 & 0.92 & -2.43 & -0.19 \\
\hline Th & 7.13 & 1.23 & 1.20 & 0.16 & -1.65 & -0.15 & -1.09 & -0.19 & 8.12 & 0.80 \\
\hline $\mathrm{TiO}_{2}$ & -0.16 & -0.22 & 0.16 & 0.13 & 0.01 & 0.10 & 0.03 & 0.25 & -0.58 & -0.49 \\
\hline TI & 0.00 & -0.05 & 0.00 & 0.00 & -1.14 & -0.23 & 2.77 & 0.92 & 12.28 & 245.67 \\
\hline $\mathbf{T m}$ & -0.01 & -0.05 & 0.00 & 0.00 & 0.00 & -0.04 & -0.20 & -0.68 & -0.42 & -0.71 \\
\hline $\mathbf{U}$ & 1.47 & 1.47 & 0.40 & 0.20 & 2.95 & 2.46 & -0.44 & -0.31 & -1.57 & -0.56 \\
\hline $\mathbf{V}$ & 11.08 & 0.11 & 1.00 & 0.02 & 5.29 & 0.38 & -0.38 & -0.04 & -25.71 & -0.38 \\
\hline $\mathbf{W}$ & 1.40 & 2.80 & -1.00 & -0.25 & 7.22 & 14.43 & -0.04 & -0.04 & 27.19 & 27.19 \\
\hline $\mathbf{Y}$ & -3.86 & -0.23 & 3.20 & 0.07 & -0.10 & -0.02 & -9.60 & -0.56 & -32.78 & -0.69 \\
\hline $\mathbf{Y b}$ & -0.26 & -0.19 & 0.30 & 0.08 & -0.12 & -0.17 & -1.13 & -0.57 & -3.17 & -0.72 \\
\hline $\mathrm{Zn}$ & 11.31 & 0.14 & -85.00 & -0.47 & -2.03 & -0.07 & 4.84 & 0.10 & -129.95 & -0.62 \\
\hline PXC & 0.08 & 0.02 & -0.63 & -0.15 & 0.58 & 0.73 & 0.63 & 0.85 & 2.61 & 2.35 \\
\hline Isocona & $\mathrm{Al}_{2} \mathrm{O}_{3}, \mathrm{TiO}_{2}, \mathrm{Yb}$ & & $\mathrm{Lu}, \mathrm{La}, \mathrm{Ho}$ & & $\mathrm{Al}_{2} \mathrm{O}_{3}, \mathrm{Lu}, \mathrm{Ho}$ & & $\mathrm{Al}_{2} \mathrm{O}_{3}, \mathrm{Lu}, \mathrm{Pd}$ & & $\mathrm{Sm}, \mathrm{Pd}, \mathrm{As}$ & \\
\hline Correlación & 1.00 & & 1.00 & & 1.00 & & 1.00 & & 1.00 & \\
\hline Error & 0.081 & & 0.007 & & 0.003 & & 0.003 & & 0.001 & \\
\hline$\Delta$ Masa & -4.9 & & 0.0 & & -3.5 & & -3.8 & & 76.2 & \\
\hline
\end{tabular}


Tabla A3. Continuación

\begin{tabular}{|c|c|c|c|c|c|c|c|c|c|c|}
\hline \multirow[t]{2}{*}{ Elemento } & \multicolumn{2}{|l|}{ Quitovac 2} & \multicolumn{2}{|l|}{ Quitovac 3 } & \multicolumn{2}{|l|}{ Quitovac 5 } & \multicolumn{2}{|l|}{ Quitovac 6 } & \multicolumn{2}{|l|}{ Sanfran-1 } \\
\hline & $\Delta$ conc & $\Delta$ conc $-C^{A}$ & $\Delta$ conc & $\Delta$ conc- $C^{A}$ & $\Delta$ conc & $\Delta$ conc- $C^{A}$ & $\Delta$ conc & $\Delta$ conc $-C^{A}$ & $\Delta$ conc & $\Delta$ conc $-C^{A}$ \\
\hline Ag & 0.00 & -0.02 & 0.11 & 2.11 & -0.10 & -0.11 & -0.13 & -0.26 & 2.64 & 6.60 \\
\hline $\mathbf{A l}_{2} \mathbf{O}_{3}$ & 0.00 & 0.00 & 3.12 & 0.20 & 0.00 & 0.00 & 0.00 & 0.00 & 0.00 & 0.00 \\
\hline As & -14.51 & -0.97 & 0.28 & 0.55 & -12.00 & -0.71 & -0.30 & -0.08 & -10.66 & -0.82 \\
\hline Au & 0.00 & -0.02 & -4.57 & -1.00 & -0.01 & -0.97 & 0.00 & -0.08 & 0.00 & -0.22 \\
\hline Ba & 157.67 & 0.11 & -610.42 & -0.51 & 17.54 & 0.02 & -166.00 & -0.11 & 125.51 & 0.26 \\
\hline $\mathbf{B e}$ & -0.01 & -0.02 & 0.28 & 0.55 & 0.00 & 0.00 & 1.35 & 2.70 & 8.07 & 16.14 \\
\hline Bi & -0.01 & -0.02 & 0.28 & 0.55 & 0.00 & 0.00 & -0.04 & -0.08 & -0.11 & -0.22 \\
\hline $\mathrm{CaO}$ & -1.35 & -0.69 & -3.00 & -0.83 & -3.69 & -0.56 & -1.53 & -0.98 & -2.37 & -0.91 \\
\hline Cd & -0.01 & -0.02 & 0.28 & 0.55 & 0.50 & 1.00 & -0.04 & -0.08 & -0.11 & -0.22 \\
\hline $\mathrm{Ce}$ & -10.67 & -0.18 & 27.94 & 0.31 & 0.43 & 0.01 & -28.04 & -0.42 & 21.60 & 0.60 \\
\hline Co & -2.13 & -0.27 & -8.90 & -0.74 & -4.99 & -0.17 & -1.08 & -0.54 & -2.55 & -0.32 \\
\hline $\mathrm{Cr}$ & 0.87 & 0.17 & -0.24 & -0.03 & -2.97 & -0.06 & 3.39 & 0.85 & 0.91 & 0.09 \\
\hline $\mathrm{Cu}$ & 52.41 & 2.76 & 12.58 & 0.37 & 281.22 & 2.70 & 9.81 & 0.34 & 621.78 & 25.91 \\
\hline Dy & -0.16 & -0.06 & -1.05 & -0.26 & -0.40 & -0.18 & -1.42 & -0.88 & -0.38 & -0.38 \\
\hline $\mathbf{E r}$ & -0.04 & -0.02 & -0.48 & -0.19 & -0.20 & -0.18 & -0.61 & -0.87 & -0.19 & -0.38 \\
\hline Eu & 0.06 & 0.04 & -0.87 & -0.48 & -0.10 & -0.06 & -0.86 & -0.54 & 0.21 & 0.27 \\
\hline $\mathrm{FeO}$ & -0.07 & -0.29 & -1.09 & -1.00 & 0.85 & 1.47 & 0.24 & 479.51 & -0.03 & -0.22 \\
\hline $\mathrm{Fe}_{2} \mathrm{O}_{3}$ & -0.99 & -0.29 & -1.94 & -0.61 & -2.23 & -0.33 & 0.47 & 0.36 & 0.46 & 0.20 \\
\hline Gd & -0.59 & -0.13 & -0.02 & 0.00 & -0.40 & -0.09 & -2.92 & -0.66 & 0.72 & 0.30 \\
\hline Ho & -0.01 & -0.02 & -0.18 & -0.22 & -0.10 & -0.25 & -0.15 & -0.77 & -0.12 & -0.61 \\
\hline Ir & 0.00 & -0.02 & 0.03 & 0.55 & 0.00 & 0.00 & -0.05 & -0.54 & -0.01 & -0.22 \\
\hline $\mathrm{K}_{2} \mathrm{O}$ & 0.41 & 0.12 & 4.38 & 1.18 & 1.18 & 0.57 & 2.70 & 0.74 & 2.48 & 0.87 \\
\hline La & -3.40 & -0.11 & 17.10 & 0.36 & -0.19 & -0.01 & -13.84 & -0.40 & 12.20 & 0.67 \\
\hline $\mathbf{L u}$ & 0.00 & -0.02 & 0.01 & 0.04 & 0.00 & 0.00 & -0.05 & -0.54 & -0.06 & -0.61 \\
\hline MgO & -0.52 & -0.54 & -1.31 & -0.84 & -0.50 & -0.12 & 0.00 & 0.01 & 0.18 & 0.18 \\
\hline $\mathrm{MnO}$ & -0.02 & -0.51 & -0.07 & -0.83 & -0.02 & -0.22 & 0.00 & -0.08 & -0.03 & -0.81 \\
\hline Mo & -0.01 & -0.02 & 0.55 & 0.55 & 0.00 & 0.00 & 5.97 & 11.94 & 0.28 & 0.56 \\
\hline $\mathrm{Na}$ & -0.89 & -0.21 & -0.20 & -0.06 & -0.65 & -0.16 & -3.84 & -0.96 & -4.24 & -0.98 \\
\hline Nd & -2.75 & -0.12 & 2.44 & 0.07 & -0.99 & -0.04 & -16.03 & -0.61 & 6.28 & 0.41 \\
\hline $\mathbf{N i}$ & -1.28 & -0.09 & 7.08 & 0.71 & -0.98 & -0.03 & -10.38 & -0.69 & 0.14 & 0.01 \\
\hline Os & 0.00 & -0.02 & 0.00 & 0.55 & 0.00 & 0.00 & 0.00 & -0.98 & 0.00 & -0.22 \\
\hline $\mathbf{P b}$ & -1.22 & -0.11 & 20.05 & 1.82 & 39.03 & 3.90 & 277.87 & 9.92 & 64.69 & 3.08 \\
\hline Pd & -0.41 & -0.46 & 0.18 & 0.29 & -0.10 & -0.17 & -0.12 & -0.31 & -0.07 & -0.22 \\
\hline $\operatorname{Pr}$ & -0.43 & -0.07 & 2.05 & 0.21 & -0.20 & -0.04 & -3.98 & -0.54 & 2.05 & 0.50 \\
\hline Pt & -0.05 & -0.51 & -0.15 & -0.48 & 0.00 & 0.00 & 0.00 & -0.08 & -0.16 & -0.81 \\
\hline $\mathrm{P}_{2} \mathrm{O}_{5}$ & -0.01 & -0.10 & -0.15 & -0.83 & 0.00 & 0.00 & 0.02 & 0.29 & -0.02 & -0.17 \\
\hline $\mathbf{R h}$ & 0.00 & -0.02 & 0.03 & 0.55 & 0.00 & 0.00 & 0.00 & -0.08 & -0.01 & -0.22 \\
\hline Ru & 0.00 & -0.02 & 0.03 & 0.55 & 0.00 & 0.00 & 0.00 & -0.08 & -0.01 & -0.22 \\
\hline Sb & -0.01 & -0.02 & 0.28 & 0.55 & 0.00 & 0.00 & 4.12 & 8.24 & 0.28 & 0.56 \\
\hline Sc & -0.28 & -0.03 & -6.07 & -0.62 & -0.39 & -0.03 & -0.44 & -0.13 & 3.04 & 1.09 \\
\hline Se & -2.51 & -0.84 & 0.28 & 0.55 & 0.00 & 0.00 & -0.04 & -0.08 & -0.11 & -0.22 \\
\hline $\mathrm{SiO}_{2}$ & 1.32 & 0.02 & 53.43 & 0.83 & 1.29 & 0.02 & -8.22 & -0.11 & -19.09 & -0.28 \\
\hline Sm & -0.48 & -0.12 & 0.00 & 0.00 & -0.40 & -0.09 & -3.00 & -0.71 & 0.64 & 0.27 \\
\hline Sn & -0.01 & -0.02 & 0.28 & 0.55 & 0.00 & 0.00 & -0.54 & -0.54 & -0.11 & -0.22 \\
\hline $\mathrm{Sr}$ & -72.87 & -0.30 & -229.24 & -0.65 & -552.89 & -0.74 & -259.28 & -0.60 & -484.93 & -0.92 \\
\hline $\mathbf{T b}$ & -0.01 & -0.02 & -0.18 & -0.22 & -0.10 & -0.20 & -0.31 & -0.77 & 0.03 & 0.17 \\
\hline Te & -1.07 & -0.27 & -3.22 & -0.81 & -4.00 & -0.31 & 0.85 & 0.85 & 0.34 & 0.17 \\
\hline Th & 3.32 & 0.36 & 30.44 & 1.69 & -0.30 & -0.08 & -13.37 & -0.70 & -2.36 & -0.27 \\
\hline $\mathrm{TiO}_{2}$ & -0.01 & -0.02 & -0.28 & -0.57 & 0.03 & 0.03 & 0.00 & 0.02 & 0.14 & 0.42 \\
\hline TI & 0.93 & 18.57 & 8.97 & 1.80 & 0.95 & 19.01 & -8.23 & -0.75 & -1.44 & -0.48 \\
\hline Tm & 0.00 & -0.02 & 0.01 & 0.04 & 0.00 & 0.00 & -0.05 & -0.54 & -0.06 & -0.61 \\
\hline $\mathbf{U}$ & 1.05 & 0.75 & -0.67 & -0.15 & -0.30 & -0.25 & -3.64 & -0.89 & 2.91 & 0.86 \\
\hline $\mathbf{V}$ & 1.26 & 0.04 & -40.16 & -0.62 & -0.92 & -0.01 & -1.14 & -0.08 & 35.89 & 1.03 \\
\hline $\mathbf{W}$ & 0.94 & 0.47 & 8.32 & 8.32 & 7.01 & 7.01 & 10.09 & 10.09 & 8.07 & 16.14 \\
\hline $\mathbf{Y}$ & -1.18 & -0.09 & -4.87 & -0.22 & -2.10 & -0.21 & -5.65 & -0.90 & -2.38 & -0.54 \\
\hline $\mathbf{Y b}$ & 0.07 & 0.04 & -0.23 & -0.09 & -0.20 & -0.22 & -0.41 & -0.82 & -0.24 & -0.61 \\
\hline $\mathrm{Zn}$ & -43.78 & -0.55 & -15.63 & -0.28 & 11.07 & 0.10 & -4.39 & -0.06 & 54.51 & 0.91 \\
\hline PXC & 0.59 & 0.40 & -0.15 & -0.83 & 3.70 & 3.46 & 2.42 & 3.10 & 1.90 & 2.19 \\
\hline Isocona & $\mathrm{Al}_{2} \mathrm{O}_{3}, \mathrm{Lu}, \mathrm{Ho}$ & & Sm, Gd, Pd & & $\mathrm{Al}_{2} \mathrm{O}_{3}, \mathrm{Pd}, \mathrm{Ho}$ & & $\mathrm{Al}_{2} \mathrm{O}_{3}, \mathrm{Ho}, \mathrm{Pd}$ & & $\mathrm{Al}_{2} \mathrm{O}_{3}, \mathrm{Pd}, \mathrm{Sn}$ & \\
\hline Correlación & 1.00 & & 1.00 & & 1.00 & & 1.00 & & 1.00 & \\
\hline Error & 0.005 & & 0.001 & & 0.001 & & 0.022 & & 0.041 & \\
\hline$\Delta$ Masa & -2.2 & & 55.3 & & 0.6 & & -7.6 & & -21.3 & \\
\hline
\end{tabular}


Tabla A3. Continuación

\begin{tabular}{|c|c|c|c|c|c|c|c|c|c|c|}
\hline Elemento & Sanfran-3 & & Sanfran-4 & & Sanfran-5 & & Sanfran-8 & & Sanfran-14 & \\
\hline & $\Delta$ conc & $\Delta$ conc- $C^{A}$ & $\Delta$ conc & $\Delta$ conc- $C^{A}$ & $\Delta$ conc & $\Delta$ conc- $C^{A}$ & $\Delta$ conc & $\Delta$ conc $-C^{A}$ & $\Delta$ conc & $\Delta$ conc $-C^{A}$ \\
\hline Ag & -0.01 & -0.14 & 1.54 & 3.84 & 0.16 & 3.17 & 1.00 & 2.50 & 0.92 & 1.15 \\
\hline $\mathrm{Al}_{2} \mathbf{O}_{3}$ & 0.00 & 0.00 & 0.00 & 0.00 & 0.74 & 0.05 & 3.18 & 0.24 & 0.00 & 0.00 \\
\hline As & -0.07 & -0.14 & 5.96 & 11.92 & 3.54 & 0.35 & -6.00 & -0.33 & -10.39 & -0.94 \\
\hline Au & 0.00 & -0.14 & 0.05 & 106.03 & 0.02 & 44.84 & 0.02 & 47.00 & -0.01 & -0.92 \\
\hline Ba & 1676.41 & 1.04 & 1326.57 & 1.46 & 171.18 & 0.15 & 14.00 & 0.02 & -375.46 & -0.47 \\
\hline $\mathrm{Be}$ & 0.36 & 0.72 & -3.23 & -0.54 & 0.02 & 0.04 & 6.50 & 13.00 & 0.12 & 0.23 \\
\hline Bi & -0.07 & -0.14 & 0.42 & 0.85 & 0.02 & 0.04 & 0.00 & 0.00 & 0.12 & 0.23 \\
\hline $\mathrm{CaO}$ & -1.39 & -0.90 & -0.52 & -0.74 & -0.82 & -0.78 & -3.13 & -0.92 & 4.17 & 0.58 \\
\hline $\mathrm{Cd}$ & -0.07 & -0.14 & -0.04 & -0.08 & 0.02 & 0.04 & 0.00 & 0.00 & 0.12 & 0.23 \\
\hline $\mathrm{Ce}$ & -58.12 & -0.81 & 11.58 & 1.30 & 6.97 & 0.06 & -53.80 & -0.86 & -8.30 & -0.19 \\
\hline Co & -4.57 & -0.91 & -0.04 & -0.08 & -1.04 & -0.04 & -13.00 & -0.93 & 23.93 & 0.60 \\
\hline $\mathrm{Cr}$ & -2.85 & -0.36 & -0.46 & -0.08 & 5.18 & 0.05 & -43.00 & -0.84 & 554.58 & 1.99 \\
\hline $\mathbf{C u}$ & 429.42 & 16.52 & 296.25 & 26.93 & 65.92 & 2.06 & 121.00 & 5.26 & -10.39 & -0.55 \\
\hline Dy & -0.54 & -0.39 & 0.12 & 0.13 & -0.60 & -0.11 & -3.90 & -0.95 & 0.40 & 0.04 \\
\hline $\mathbf{E r}$ & 0.00 & 0.00 & -0.15 & -0.19 & -0.31 & -0.12 & -2.30 & -0.96 & 0.95 & 0.15 \\
\hline Eu & -0.87 & -0.35 & 0.60 & 1.00 & 0.08 & 0.04 & -1.40 & -0.74 & -0.06 & -0.03 \\
\hline $\mathrm{FeO}$ & -0.07 & -0.37 & 0.00 & 0.00 & -3.96 & -0.79 & 0.11 & 0.73 & 3.10 & 0.54 \\
\hline $\mathrm{Fe}_{2} \mathrm{O}_{3}$ & -2.03 & -0.79 & 0.02 & 0.03 & 1.35 & 0.52 & -3.02 & -0.78 & 2.24 & 0.64 \\
\hline Gd & -3.10 & -0.72 & 1.23 & 1.54 & 0.06 & 0.01 & -5.00 & -0.88 & -0.54 & -0.06 \\
\hline Но & -0.03 & -0.14 & -0.02 & -0.08 & -0.17 & -0.17 & -0.75 & -0.94 & 0.34 & 0.17 \\
\hline Ir & -0.01 & -0.14 & 0.04 & 0.85 & 0.00 & 0.04 & 0.00 & 0.00 & 0.07 & 1.46 \\
\hline $\mathrm{K}_{2} \mathrm{O}$ & 3.83 & 1.02 & 3.62 & 0.77 & 1.25 & 0.34 & 2.03 & 1.53 & 0.27 & 0.12 \\
\hline La & -31.44 & -0.80 & 4.83 & 0.88 & 0.00 & 0.00 & -26.30 & -0.83 & -3.18 & -0.19 \\
\hline Lu & -0.01 & -0.14 & -0.11 & -0.54 & 0.01 & 0.04 & -0.25 & -0.83 & 0.21 & 0.23 \\
\hline MgO & -0.13 & -0.51 & 0.02 & 0.27 & -1.49 & -0.49 & -1.52 & -0.59 & 6.83 & 0.95 \\
\hline MnO & -0.01 & -0.57 & 0.00 & -0.08 & -0.03 & -0.41 & -0.04 & -0.67 & 0.11 & 0.69 \\
\hline Mo & 34.66 & 69.33 & 23.49 & 46.98 & 1.08 & 1.08 & 6.50 & 13.00 & 0.12 & 0.23 \\
\hline $\mathrm{Na}$ & -1.27 & -0.58 & -2.60 & -0.64 & -0.67 & -0.61 & -1.52 & -0.47 & -1.09 & -0.41 \\
\hline Nd & -23.81 & -0.83 & 8.65 & 3.20 & 1.69 & 0.04 & -24.90 & -0.87 & -2.88 & -0.10 \\
\hline $\mathrm{Ni}$ & -1.85 & -0.27 & -2.85 & -0.22 & -3.75 & -0.06 & -67.00 & -0.83 & 62.76 & 0.39 \\
\hline Os & 0.00 & -0.14 & 0.00 & 59.90 & 0.00 & 0.04 & 0.00 & 0.00 & 0.00 & 1.46 \\
\hline $\mathbf{P b}$ & 16.74 & 0.62 & 367.96 & 4.97 & 39.38 & 1.97 & 409.00 & 204.50 & -11.00 & -1.00 \\
\hline Pd & -0.03 & -0.14 & -0.45 & -0.41 & 0.11 & 0.56 & -0.20 & -0.67 & 0.16 & 0.23 \\
\hline Pr & -6.13 & -0.82 & 1.87 & 2.08 & 0.32 & 0.03 & -6.40 & -0.87 & -0.84 & -0.13 \\
\hline Pt & -0.01 & -0.14 & 0.00 & -0.08 & 0.00 & 0.04 & -1.15 & -0.96 & 0.01 & 0.23 \\
\hline $\mathbf{P}_{2} \mathbf{O}_{5}$ & -0.04 & -1.00 & 0.05 & 4.54 & -0.02 & -0.38 & -0.06 & -0.75 & -0.11 & -0.43 \\
\hline Rh & -0.01 & -0.14 & 0.00 & -0.08 & 0.00 & 0.04 & 0.00 & 0.00 & 0.01 & 0.23 \\
\hline Ru & -0.01 & -0.14 & 0.00 & -0.08 & 0.00 & 0.04 & 0.00 & 0.00 & 0.01 & 0.23 \\
\hline Sb & 1.22 & 2.43 & -0.04 & -0.08 & 0.02 & 0.04 & 0.00 & 0.00 & 6.88 & 13.75 \\
\hline Sc & -0.63 & -0.24 & 0.85 & 0.85 & -0.83 & -0.05 & -6.70 & -0.68 & 30.75 & 1.01 \\
\hline Se & -3.57 & -0.89 & 1.35 & 2.69 & 0.02 & 0.04 & 0.50 & 1.00 & 0.12 & 0.23 \\
\hline $\mathrm{SiO}_{2}$ & -11.84 & -0.16 & -6.51 & -0.09 & 7.69 & 0.13 & 0.75 & 0.01 & 4.95 & 0.10 \\
\hline Sm & -3.23 & -0.81 & 1.62 & 3.24 & 0.55 & 0.07 & -4.40 & -0.88 & -0.30 & -0.04 \\
\hline Sn & -0.07 & -0.14 & -1.08 & -0.54 & 0.02 & 0.04 & 0.50 & 1.00 & 0.12 & 0.23 \\
\hline $\mathbf{S r}$ & 129.89 & 0.84 & -56.74 & -0.16 & -78.04 & -0.61 & -216.00 & -0.54 & -163.73 & -0.48 \\
\hline Tb & -0.23 & -0.57 & 0.18 & 1.77 & -0.06 & -0.05 & -0.75 & -0.94 & 0.00 & 0.00 \\
\hline Te & -5.57 & -0.93 & -0.04 & -0.08 & -6.75 & -0.52 & -0.50 & -0.50 & 2.98 & 0.23 \\
\hline Th & -8.36 & -0.90 & -1.24 & -0.23 & 1.89 & 0.12 & -7.40 & -0.90 & 0.58 & 1.46 \\
\hline $\mathrm{TiO}_{2}$ & -0.22 & -0.79 & 0.02 & 0.38 & -0.04 & -0.05 & -0.27 & -0.77 & -0.11 & -0.13 \\
\hline TI & -3.85 & -0.43 & 5.00 & 0.71 & 4.12 & 82.34 & 4.00 & 0.50 & 0.01 & 0.23 \\
\hline Tm & -0.01 & -0.14 & -0.01 & -0.08 & 0.01 & 0.04 & -0.25 & -0.83 & 0.21 & 0.23 \\
\hline U & 0.10 & 0.20 & -2.96 & -0.61 & 5.38 & 3.36 & -0.40 & -0.50 & 0.09 & 0.23 \\
\hline V & -2.13 & -0.10 & 0.61 & 0.04 & 3.47 & 0.03 & -5.00 & -0.13 & 115.35 & 0.87 \\
\hline W & 0.36 & 0.72 & 29.95 & 59.90 & 26.09 & 26.09 & 16.00 & 16.00 & 0.23 & 0.23 \\
\hline Y & -1.07 & -0.19 & -0.18 & -0.03 & -2.93 & -0.13 & -18.40 & -0.97 & 7.40 & 0.15 \\
\hline Yb & 0.20 & 0.50 & -0.55 & -0.50 & -0.22 & -0.10 & -2.00 & -0.95 & 1.62 & 0.27 \\
\hline $\mathbf{Z n}$ & -4.69 & -0.12 & 2028.96 & 169.08 & 66.31 & 0.47 & 2103.00 & 17.82 & 253.97 & 1.85 \\
\hline PXC & -0.01 & -0.02 & 0.34 & 0.92 & 0.63 & 0.24 & 3.01 & 3.14 & 2.01 & 0.76 \\
\hline Isocona & $\mathrm{Al}_{2} \mathrm{O}_{3}, \mathrm{Lu}, \mathrm{Pd}$ & & $\mathrm{Al}_{2} \mathrm{O}_{3}, \mathrm{FeO}, \mathrm{Ho}$ & & $\mathrm{La}, \mathrm{Pd}, \mathrm{Gd}$ & & $\mathrm{Ru}, \mathrm{SiO}_{2}, \mathrm{Sb}$ & & $\mathrm{Al}_{2} \mathrm{O}_{3}, \mathrm{Lu}, \mathrm{Ho}$ & \\
\hline Correlación & 1.00 & & 1.00 & & 1.00 & & 1.00 & & 1.00 & \\
\hline Error & 0.012 & & 0.012 & & 0.023 & & 0.0003 & & 0.087 & \\
\hline$\Delta$ Masa & -14.2 & & -7.7 & & 4.2 & & 0.0 & & 22.9 & \\
\hline
\end{tabular}


Tabla A3. Continuación

\begin{tabular}{|c|c|c|c|c|c|c|c|c|c|c|}
\hline Elemento & Sanluisito-2 & & Sanluisito-3 & & Sonoyta-5 & & Trin-11 & & Vidrios-1 & \\
\hline & $\Delta$ conc & $\Delta$ conc $-C^{A}$ & $\Delta$ conc & $\Delta$ conc $-C^{A}$ & $\Delta$ conc & $\Delta$ conc $-C^{A}$ & $\Delta$ conc & $\Delta$ conc $-C^{A}$ & $\Delta$ conc & $\Delta$ conc $-C^{A}$ \\
\hline Ag & 1.26 & 12.57 & 0.51 & 0.09 & 6.60 & 16.50 & 0.85 & 8.49 & 0.00 & 0.01 \\
\hline $\mathbf{A l}_{2} \mathbf{O}_{3}$ & 8.04 & 0.56 & 0.00 & 0.00 & 1.65 & 0.11 & 0.00 & 0.00 & 1.98 & 0.13 \\
\hline As & 3.43 & 1.71 & -5.78 & -0.48 & -5.00 & -0.56 & 22.70 & 45.40 & -0.93 & -0.16 \\
\hline Au & 0.00 & 0.36 & 0.00 & 0.04 & 0.00 & 0.00 & 0.06 & 119.21 & 0.00 & 0.01 \\
\hline Ba & -200.36 & -0.27 & 269.98 & 0.29 & -600.00 & -0.42 & -832.71 & -0.86 & -39.37 & -0.02 \\
\hline Be & 3.57 & 7.14 & 0.02 & 0.04 & 2.50 & 5.00 & 0.03 & 0.05 & 0.01 & 0.01 \\
\hline $\mathbf{B i}$ & 0.18 & 0.36 & 0.02 & 0.04 & 0.00 & 0.00 & 0.03 & 0.05 & 0.01 & 0.01 \\
\hline $\mathrm{CaO}$ & -1.94 & -0.77 & -1.54 & -0.32 & -1.05 & -0.91 & -0.32 & -0.36 & -0.56 & -0.21 \\
\hline Cd & 0.86 & 1.71 & -1.89 & -0.38 & 0.00 & 0.00 & 0.03 & 0.05 & 0.01 & 0.01 \\
\hline $\mathrm{Ce}$ & -32.36 & -0.37 & -6.62 & -0.07 & 14.00 & 0.27 & -58.45 & -0.27 & 56.21 & 0.23 \\
\hline Co & -1.21 & -0.15 & 2.76 & 0.15 & 1.00 & 1.00 & -2.57 & -0.23 & -8.91 & -0.59 \\
\hline $\mathrm{Cr}$ & 2.86 & 0.36 & 4.19 & 0.14 & -2.00 & -0.29 & -0.80 & -0.03 & -3.89 & -0.32 \\
\hline $\mathrm{Cu}$ & 9.71 & 0.81 & 1976.85 & 70.60 & -11.00 & -0.61 & 395.52 & 6.59 & 0.17 & 0.01 \\
\hline Dy & -1.55 & -0.62 & 0.36 & 0.09 & 0.00 & 0.00 & -3.28 & -0.44 & -0.45 & -0.04 \\
\hline $\mathbf{E r}$ & -1.16 & -0.68 & 0.08 & 0.04 & -0.10 & -0.14 & -0.50 & -0.20 & -0.41 & -0.06 \\
\hline Eu & -0.05 & -0.05 & 0.18 & 0.09 & -0.40 & -0.31 & -2.04 & -0.62 & -0.33 & -0.06 \\
\hline $\mathrm{FeO}$ & 0.00 & 0.00 & 0.20 & 0.23 & -0.36 & -0.72 & 0.00 & 0.02 & -0.01 & -0.02 \\
\hline $\mathrm{Fe}_{2} \mathrm{O}_{3}$ & 0.03 & 0.01 & -0.45 & -0.10 & 0.43 & 0.55 & -0.10 & -0.03 & -0.37 & -0.10 \\
\hline Gd & -1.01 & -0.23 & 0.04 & 0.01 & 0.60 & 0.18 & -5.10 & -0.31 & 1.18 & 0.06 \\
\hline Ho & -0.36 & -0.73 & 0.13 & 0.18 & -0.10 & -0.33 & -0.37 & -0.37 & -0.17 & -0.08 \\
\hline Ir & 0.02 & 0.36 & 0.00 & 0.04 & 0.00 & 0.00 & 0.00 & 0.05 & 0.00 & 0.01 \\
\hline $\mathbf{K}_{2} \mathbf{O}$ & 4.82 & 1.41 & 1.49 & 0.54 & 2.77 & 0.82 & -3.01 & -0.70 & 2.49 & 0.50 \\
\hline La & -23.61 & -0.46 & -4.69 & -0.09 & 7.30 & 0.28 & -23.72 & -0.27 & 31.31 & 0.28 \\
\hline $\mathbf{L u}$ & -0.23 & -0.77 & 0.01 & 0.04 & -0.05 & -0.50 & 0.01 & 0.05 & -0.09 & -0.10 \\
\hline MgO & 0.32 & 0.33 & -0.03 & -0.01 & 0.24 & 1.60 & -0.31 & -0.26 & -0.16 & -0.13 \\
\hline MnO & -0.03 & -0.55 & 0.05 & 0.45 & 0.00 & 0.00 & -0.03 & -0.74 & 0.00 & 0.01 \\
\hline Mo & 1.71 & 1.71 & 0.02 & 0.04 & -0.50 & -0.50 & 0.05 & 0.05 & 21.34 & 7.11 \\
\hline $\mathrm{Na}$ & -3.33 & -0.97 & -1.19 & -0.35 & -3.62 & -0.94 & 2.92 & 1.10 & 0.84 & 0.28 \\
\hline Nd & -2.59 & -0.11 & -1.10 & -0.03 & 5.20 & 0.28 & -5.04 & -0.06 & 7.98 & 0.07 \\
\hline $\mathbf{N i}$ & 3.57 & 0.36 & 1.90 & 0.08 & -21.00 & -0.72 & 10.40 & 0.29 & 0.20 & 0.01 \\
\hline Os & 0.00 & 0.36 & 0.00 & 0.04 & 0.00 & 0.00 & 0.00 & 0.05 & 0.00 & 0.01 \\
\hline $\mathbf{P b}$ & 59.64 & 3.98 & 554.90 & 2.26 & -62.00 & -0.84 & 54.59 & 3.64 & -12.41 & -0.23 \\
\hline Pd & -0.16 & -0.55 & 0.02 & 0.04 & 0.20 & 1.00 & 0.22 & 1.11 & -0.29 & -0.37 \\
\hline $\operatorname{Pr}$ & -1.99 & -0.25 & -0.66 & -0.06 & 1.50 & 0.27 & -0.32 & -0.01 & 3.37 & 0.11 \\
\hline Pt & 0.02 & 0.36 & 0.00 & 0.04 & 0.00 & 0.00 & 0.00 & 0.05 & 0.00 & 0.01 \\
\hline $\mathbf{P}_{2} \mathbf{O}_{5}$ & 0.00 & 0.02 & -0.09 & -0.55 & 0.00 & 0.00 & -0.03 & -0.19 & -0.03 & -0.09 \\
\hline $\mathbf{R h}$ & 0.02 & 0.36 & 0.05 & 1.07 & 0.00 & 0.00 & 0.00 & 0.05 & 0.00 & 0.01 \\
\hline Ru & 0.02 & 0.36 & 0.00 & 0.04 & 0.00 & 0.00 & 0.00 & 0.05 & 0.00 & 0.01 \\
\hline Sb & 3.57 & 7.14 & 0.02 & 0.04 & -1.50 & -0.75 & 0.03 & 0.05 & 0.01 & 0.01 \\
\hline Sc & -1.59 & -0.28 & -1.27 & -0.09 & 1.20 & 0.55 & 1.65 & 0.18 & 2.21 & 0.18 \\
\hline Se & 2.21 & 4.43 & 0.02 & 0.04 & 5.50 & 11.00 & 0.03 & 0.05 & 0.01 & 0.01 \\
\hline $\mathrm{SiO}_{2}$ & 23.02 & 0.33 & 5.10 & 0.09 & -1.92 & -0.03 & 5.75 & 0.08 & -2.98 & -0.05 \\
\hline Sm & 0.13 & 0.04 & 0.21 & 0.04 & 0.80 & 0.26 & -5.50 & -0.32 & -0.04 & 0.00 \\
\hline Sn & 0.18 & 0.36 & 0.02 & 0.04 & 0.50 & 1.00 & 0.03 & 0.05 & 0.01 & 0.01 \\
\hline $\mathrm{Sr}$ & -242.21 & -0.90 & -67.17 & -0.15 & -368.00 & -0.89 & 0.37 & 0.00 & -174.91 & -0.29 \\
\hline $\mathbf{T b}$ & -0.23 & -0.46 & 0.03 & 0.04 & 0.00 & 0.00 & -0.74 & -0.39 & 0.03 & 0.01 \\
\hline $\mathrm{Te}$ & 0.18 & 0.36 & 0.14 & 0.04 & 0.50 & 1.00 & -1.89 & -0.47 & 0.10 & 0.01 \\
\hline Th & -44.87 & -0.75 & -1.67 & -0.08 & 4.10 & 0.33 & 6.29 & 0.13 & -0.68 & -0.02 \\
\hline $\mathrm{TiO}_{2}$ & 0.11 & 0.41 & 0.02 & 0.04 & 0.07 & 0.78 & -0.11 & -0.21 & 0.00 & 0.00 \\
\hline TI & 8.93 & 1.49 & 9.28 & 185.50 & 5.00 & 0.63 & 7.44 & 7.44 & 3.09 & 1.03 \\
\hline Tm & -0.13 & -0.66 & 0.01 & 0.04 & 0.00 & 0.00 & 0.01 & 0.05 & -0.09 & -0.10 \\
\hline $\mathbf{U}$ & -8.59 & -0.76 & -0.33 & -0.07 & -0.40 & -0.27 & 0.57 & 0.21 & 0.08 & 0.01 \\
\hline $\mathbf{V}$ & 5.86 & 0.14 & 1.07 & 0.01 & 2.00 & 0.29 & -9.59 & -0.26 & 2.93 & 0.05 \\
\hline $\mathbf{W}$ & 23.79 & 11.89 & -1.48 & -0.74 & 1.00 & 1.00 & 0.55 & 1.11 & 1.03 & 1.03 \\
\hline $\mathbf{Y}$ & -10.24 & -0.76 & 2.34 & 0.12 & -0.90 & -0.14 & -7.82 & -0.37 & -3.20 & -0.06 \\
\hline $\mathbf{Y b}$ & -1.39 & -0.77 & 0.07 & 0.04 & -0.20 & -0.33 & -0.22 & -0.13 & -0.42 & -0.07 \\
\hline $\mathrm{Zn}$ & 169.21 & 2.38 & 6861.21 & 29.32 & 82.00 & 2.05 & -4.53 & -0.14 & 64.07 & 0.77 \\
\hline PXC & 3.06 & 4.93 & 0.44 & 0.21 & 1.62 & 3.52 & 1.47 & 1.27 & 0.31 & 0.30 \\
\hline Isocona & $\mathrm{FeO}, \mathrm{Sm}, \mathrm{P}_{2} \mathrm{O}_{5}$ & & $\mathrm{Al}_{2} \mathrm{O}_{3}, \mathrm{Lu}, \mathrm{Pd}$ & & $\mathrm{P}_{2} \mathrm{O}_{5}, \mathrm{SiO}_{2}, \mathrm{~Tb}$ & & $\mathrm{Al}_{2} \mathrm{O}_{3}, \mathrm{Ho}, \mathrm{Yb}$ & & $\mathrm{TiO}_{2}, \mathrm{Gd}, \mathrm{Nd}$ & \\
\hline Correlación & 1.00 & & 1.00 & & 1.00 & & 1.00 & & 1.00 & \\
\hline Error & 0.003 & & 0.005 & & 0.007 & & 0.085 & & 0.091 & \\
\hline$\Delta$ Masa & 35.7 & & 3.6 & & 0.0 & & 5.4 & & 1.4 & \\
\hline
\end{tabular}

$\Delta$ conc: Cambio absoluto en la concentración elemental. $\Delta$ conc- $\mathrm{C}^{\mathrm{A}}$ : Cambio relativo en la concentración elemental expresado en número de veces con respecto a la concentración de la roca fresca. $\Delta$ conc $=\left(\mathrm{M}_{0} / \mathrm{M}_{\mathrm{A}}\right)(\mathrm{Ea} / \mathrm{Ef})-1, \Delta$ conc- $\mathrm{C}^{\mathrm{A}}=\Delta$ conc/Ef. $\left(\mathrm{M}_{0} / \mathrm{M}_{\mathrm{A}}\right)$ : Pendiente de la isocona. $($ Ea/Ef): Pendiente del elemento o compuesto. Ef: Concentración original del elemento o compuesto.

Los resultados de los elementos mayores $\left(\mathrm{Al}_{2} \mathrm{O}_{3}, \mathrm{CaO}, \mathrm{FeO}, \mathrm{Fe}_{2} \mathrm{O}_{3}, \mathrm{~K}_{2} \mathrm{O}, \mathrm{MgO}, \mathrm{MnO}, \mathrm{Na}_{2} \mathrm{O}, \mathrm{P}_{2} \mathrm{O}_{5}, \mathrm{SiO}_{2}, \mathrm{TiO}_{2}\right.$, PXC) están expresadas en \%, el resto de

los valores se expresan ppm. Los valores positivos indican enriquecimiento, los valores negativos indican empobrecimiento y valores en cero indican inmovilidad.

$\triangle$ Masa: Porcentaje de cambio de masa total de la roca; valores positivos indican aumento de masa y valores negativos decremento de masa.

Todos los cálculos se elaboraron con el programa computacional GEOISO (Coelho, 2006).

Isocona: Elementos usados como inertes para el trazo de la línea de isocona. Correlación y error: calculados con algoritmos de GEOISO (Coelho, 2006). 
Tabla A4. Resumen de número de muestras por rango de $\Delta$ conc- $\mathrm{C}^{\mathrm{A}}$ en orden de enriquecimiento y empobrecimiento del estudio balance de masas de las rocas encajonantes frescas y alteradas del Cinturón de Oro Orogénico Caborca, NW de Sonora, México.

\begin{tabular}{|c|c|c|c|c|c|c|c|c|c|}
\hline Elemento & $\begin{array}{l}\text { Rango-1 } \\
\Delta \text { conc- } C^{A} \\
(>-0.5)(x) \\
\end{array}$ & $\begin{array}{c}\text { Rango-2 } \\
\Delta \text { conc- } C^{A} \\
-0.5-(<0)(x) \\
\end{array}$ & $\begin{array}{c}\Delta \text { conc }-C^{A} \\
0 \\
\end{array}$ & $\begin{array}{c}\text { Rango-3 } \\
\Delta \text { conc- } \mathrm{C}^{\mathrm{A}} \\
>0-0.50(\mathrm{x}) \\
\end{array}$ & $\begin{array}{c}\text { Rango-4 } \\
\Delta \text { conc- }-C^{A} \\
>0.50-1(x) \\
\end{array}$ & $\begin{array}{c}\text { Rango-5 } \\
\Delta \text { conc- } \mathrm{C}^{\mathrm{A}} \\
>1-2(\mathrm{x}) \\
\end{array}$ & $\begin{array}{c}\text { Rango-6 } \\
\Delta \text { conc- }-C^{A} \\
>2(x) \\
\end{array}$ & $\begin{array}{c}\text { Promedio } \\
\text { aritmético }(\mathbf{x})^{*} \\
\text { empobrecimiento }\end{array}$ & $\begin{array}{c}\text { Promedio } \\
\text { aritmético }(\mathrm{x})^{*} \\
\text { enriquecimiento }\end{array}$ \\
\hline Ag & & $\mathbf{5}(-0.11)$ & 1 & $2(0.05)$ & & $\mathbf{1}(1.15)$ & $11(35.25)$ & -0.11 & 27.79 \\
\hline $\mathrm{Al}_{2} \mathbf{O}_{3}$ & & & 12 & $7(0.15)$ & $\mathbf{1}(0.56)$ & & & 0.00 & 0.20 \\
\hline As & $6(-0.78)$ & $5(-0.24)$ & & $2(0.18)$ & $2(0.64)$ & $\mathbf{1}(1.71)$ & $4(16.83)$ & -0.54 & 7.85 \\
\hline Au & $5(-0.96)$ & $6(-0.09)$ & 2 & $3(0.14)$ & & & $4(79.27)$ & -0.49 & 45.35 \\
\hline Ba & $2(-0.68)$ & $8(-0.23)$ & & $8(0.14)$ & & $2(1.25)$ & & -0.32 & 0.36 \\
\hline Be & $\mathbf{1}(-0.54)$ & $3(-0.04)$ & 2 & $\mathbf{5}(0.08)$ & $4(0.74)$ & & $\mathbf{5}(8.80)$ & -0.16 & 3.38 \\
\hline $\mathbf{B i}$ & & $7(-0.08)$ & 4 & $6(0.12)$ & $3(0.72)$ & & & -0.08 & 0.32 \\
\hline $\mathrm{CaO}$ & $\mathbf{1 4}(-0.81)$ & $4(-0.32)$ & & $\mathbf{1}(0.16)$ & $\mathbf{1}(0.58)$ & & & -0.70 & 0.37 \\
\hline Cd & & $9(-0.12)$ & 3 & $4(0.08)$ & $3(0.77)$ & $\mathbf{1}(1.71)$ & & -0.12 & 0.55 \\
\hline $\mathrm{Ce}$ & $2(-0.84)$ & $7(-0.23)$ & & $8(0.16)$ & $\mathbf{1}(0.60)$ & $2(1.19)$ & & -0.37 & 0.39 \\
\hline Co & $7(-0.72)$ & $9(-0.20)$ & & $2(0.18)$ & $2(0.80)$ & & & -0.43 & 0.49 \\
\hline $\mathrm{Cr}$ & $\mathbf{1}(-0.84)$ & $\mathbf{1 0}(-0.19)$ & & $7(0.18)$ & $\mathbf{1}(0.85)$ & $\mathbf{1}(1.99)$ & & -0.25 & 0.46 \\
\hline $\mathrm{Cu}$ & $3(-0.63)$ & & & $4(0.20)$ & $\mathbf{1}(0.81)$ & $\mathbf{1}(1.98)$ & $\mathbf{1 1}(15.23)$ & -0.63 & 10.07 \\
\hline Dy & $4(-0.76)$ & 11(-0.24) & 1 & $4(0.09)$ & & & & -0.38 & 0.09 \\
\hline $\mathbf{E r}$ & $5(-0.74)$ & 11(-0.16) & 1 & $3(0.10)$ & & & & -0.34 & 0.10 \\
\hline Eu & $3(-0.63)$ & $11(-0.20)$ & & $\mathbf{5}(0.11)$ & $\mathbf{1}(1.00)$ & & & -0.29 & 0.26 \\
\hline $\mathrm{FeO}$ & $4(-0.86)$ & $3(-0.18)$ & 2 & $4(0.19)$ & $3(0.72)$ & $\mathbf{1}(1.47)$ & $\mathbf{3}(371.13)$ & -0.57 & 101.62 \\
\hline $\mathrm{Fe}_{2} \mathrm{O}_{3}$ & $3(-0.72)$ & $9(-0.17)$ & & $\mathbf{5}(0.17)$ & $\mathbf{3}(0.57)$ & & & -0.31 & 0.32 \\
\hline Gd & $3(-0.75)$ & $\mathbf{9}(-0.13)$ & 1 & $\mathbf{6}(0.11)$ & & $\mathbf{1}(1.54)$ & & -0.28 & 0.31 \\
\hline Ho & $6(-0.71)$ & $11(-0.17)$ & & $3(0.16)$ & & & & -0.36 & 0.16 \\
\hline Ir & $3(-0.72)$ & $9(-0.17)$ & & $\mathbf{5}(0.17)$ & $3(0.57)$ & & & -0.31 & 0.32 \\
\hline $\mathbf{K}_{2} \mathbf{O}$ & $\mathbf{1}(-0.70)$ & $\mathbf{1}(-0.04)$ & & $7(0.22)$ & $6(0.72)$ & $\mathbf{5}(1.42)$ & & -0.37 & 0.72 \\
\hline La & $2(-0.81)$ & $9(-0.18)$ & 1 & $\mathbf{5}(0.28)$ & $\mathbf{3}(0.85)$ & & & -0.30 & 0.49 \\
\hline Lu & $8(-0.63)$ & $5(-0.16)$ & 2 & $\mathbf{5}(0.08)$ & & & & -0.45 & 0.08 \\
\hline MgO & $4(-0.62)$ & $7(-0.21)$ & & $7(0.15)$ & $\mathbf{1}(0.95)$ & $\mathbf{1}(1.60)$ & & -0.36 & 0.40 \\
\hline MnO & $9(-0.70)$ & $6(-0.21)$ & 1 & $3(0.17)$ & $\mathbf{1}(0.69)$ & & & -0.50 & 0.30 \\
\hline Mo & & $3(-0.19)$ & 2 & $3(0.11)$ & $\mathbf{5}(0.75)$ & $2(1.40)$ & $\mathbf{5}(29.69)$ & -0.19 & 10.35 \\
\hline $\mathrm{Na}$ & $9(-0.84)$ & $8(-0.27)$ & & $2(0.15)$ & & $\mathbf{1}(1.10)$ & & -0.57 & 0.47 \\
\hline Nd & $3(-0.77)$ & $8(-0.08)$ & & $8(0.17)$ & & & $\mathbf{1}(3.20)$ & -0.27 & 0.50 \\
\hline $\mathrm{Ni}$ & $3(-0.75)$ & $6(-0.12)$ & & $9(0.21)$ & $2(0.71)$ & & & -0.33 & 0.30 \\
\hline Os & $\mathbf{1}(-0.98)$ & $5(-0.09)$ & 13 & $\mathbf{1}(0.04)$ & & & & -0.24 & 0.04 \\
\hline $\mathbf{P b}$ & $3(-0.93)$ & $2(-0.17)$ & 1 & & $2(0.60)$ & $2(1.90)$ & $10(28.46)$ & -0.63 & 20.69 \\
\hline Pd & $2(-0.19)$ & $9(-0.29)$ & & $\mathbf{6}(0.19)$ & $2(0.78)$ & $\mathbf{1}(1.11)$ & & -0.35 & 0.42 \\
\hline Pr & $3(-0.74)$ & $8(-0.19)$ & & $7(0.20)$ & $\mathbf{1}(0.64)$ & & $\mathbf{1}(2.08)$ & -0.27 & 0.46 \\
\hline Pt & $3(-0.76)$ & $7(-0.14)$ & 3 & $6(0.12)$ & & & $\mathbf{1}(2.85)$ & -0.33 & 0.51 \\
\hline $\mathbf{P}_{2} \mathrm{O}_{5}$ & $5(-0.77)$ & $6(-0.22)$ & 3 & $\mathbf{5}(0.16)$ & & & $\mathbf{1}(4.54)$ & -0.47 & 0.89 \\
\hline $\mathbf{R h}$ & & $8(-0.08)$ & 4 & $\mathbf{5}(0.14)$ & $2(0.92)$ & $\mathbf{1}(1.07)$ & & -0.08 & 0.39 \\
\hline Ru & & $8(-0.08)$ & 4 & $6(0.12)$ & $2(0.66)$ & & & -0.08 & 0.26 \\
\hline Sb & $\mathbf{1}(-0.75)$ & $4(-0.05)$ & 3 & $4(0.04)$ & $2(0.56)$ & & $6(6.80)$ & -0.19 & 3.51 \\
\hline Sc & $2(-0.65)$ & $11(-0.18)$ & & $3(0.14)$ & $2(0.70)$ & $2(1.05)$ & & -0.25 & 0.56 \\
\hline Se & $3(-0.89)$ & $4(-0.10)$ & 2 & $\mathbf{5}(0.08)$ & $3(0.77)$ & & $3(6.04)$ & -0.44 & 1.89 \\
\hline $\mathrm{SiO}_{2}$ & & $9(-0.10)$ & & $9(0.09)$ & $\mathbf{1}(0.83)$ & $\mathbf{1}(1.24)$ & & -0.10 & 0.26 \\
\hline Sm & $3(-0.80)$ & $7(-0.14)$ & 3 & $6(0.13)$ & & & $1(3.24)$ & -0.34 & 0.57 \\
\hline Sn & $3(-0.53)$ & $4(-0.11)$ & 2 & $6(0.12)$ & $4(0.87)$ & & $1(2.52)$ & -0.29 & 0.61 \\
\hline $\mathrm{Sr}$ & $10(-0.73)$ & $7(-0.28)$ & 1 & $\mathbf{1}(0.28)$ & $\mathbf{1}(0.84)$ & & & -0.54 & 0.56 \\
\hline Tb & $3(-0.76)$ & $10(-0.23)$ & 2 & $4(0.08)$ & & $\mathbf{1}(1.77)$ & & -0.36 & 0.42 \\
\hline Te & $4(-0.78)$ & $7(-0.32)$ & & $6(0.17)$ & $3(0.92)$ & & & -0.49 & 0.42 \\
\hline Th & $4(-0.81)$ & $7(-0.15)$ & & $\mathbf{5}(0.22)$ & $\mathbf{1}(0.80)$ & $3(1.46)$ & & -0.39 & 0.70 \\
\hline $\mathrm{TiO}_{2}$ & $3(-0.71)$ & $6(-0.19)$ & 1 & $\mathbf{9}(0.20)$ & $\mathbf{1}(0.78)$ & & & -0.36 & 0.26 \\
\hline TI & $\mathbf{1}(-0.75)$ & $4(-0.30)$ & 1 & $2(0.36)$ & $3(0.75)$ & $3(1.44)$ & 6(93.09) & -0.39 & 40.42 \\
\hline $\mathbf{T m}$ & $6(-0.67)$ & $6(-0.07)$ & 3 & $\mathbf{5}(0.08)$ & & & & -37.00 & 0.08 \\
\hline $\mathbf{U}$ & $4(-0.70)$ & $6(-0.26)$ & & $\mathbf{5}(0.17)$ & $\mathbf{2}(0.80)$ & $\mathbf{1}(1.47)$ & $\mathbf{2}(2.91)$ & -0.44 & 0.97 \\
\hline V & $\mathbf{1}(-0.62)$ & $7(-0.14)$ & & $\mathbf{1 0}(0.11)$ & $\mathbf{1}(0.87)$ & $\mathbf{1}(1.03)$ & & -0.20 & 0.25 \\
\hline $\mathbf{W}$ & $\mathbf{1}(-0.74)$ & $2(-0.14)$ & & $2(0.35)$ & $2(0.86)$ & $2(1.07)$ & 11(18.17) & -0.34 & 12.02 \\
\hline $\mathbf{Y}$ & $6(-0.74)$ & $11(-0.15)$ & & $3(0.12)$ & & & & -0.36 & 0.12 \\
\hline $\mathbf{Y b}$ & $6(-0.74)$ & $9(-0.20)$ & & $\mathbf{5}(0.19)$ & & & & -0.42 & 0.19 \\
\hline $\mathrm{Zn}$ & $2(-0.59)$ & $6(-0.19)$ & & $4(0.20)$ & $2(0.84)$ & $\mathbf{1}(1.85)$ & $\mathbf{5}(44.13)$ & -0.29 & 18.75 \\
\hline PXC & $\mathbf{1}(-0.83)$ & $2(-0.09)$ & & $\mathbf{5}(0.23)$ & $4(0.82)$ & $\mathbf{1}(1.27)$ & $7(3.24)$ & -0.33 & 1.67 \\
\hline
\end{tabular}

$\Delta$ conc-C $C^{\mathrm{A}}$ : Cambio en la concentración elemental expresado en número de veces con respecto a la concentración de la roca fresca.

Ejemplo en la tabla: Arsénico (As): 6(-0.78) $=6$ muestras empobrecidas dentro del intervalo $>0.5$ veces de empobrecimineto (promedio aritmético del intervalo).

Datos con encabezados en azul indican empobrecimiento, y en rojo enriquecimiento.(x): Promedio aritmético de ese intervalo. (x)*: Promedio aritmético de enriquecimiento o empobrecimiento de ese elemento.

Para los cálculos en los elementos mayores $\left(\mathrm{Al}_{2} \mathrm{O}_{3}, \mathrm{CaO}, \mathrm{FeO}, \mathrm{Fe}_{2} \mathrm{O}_{3}, \mathrm{~K}_{2} \mathrm{O}, \mathrm{MgO}, \mathrm{MnO}, \mathrm{Na}_{2} \mathrm{O}, \mathrm{P}_{2} \mathrm{O}_{5}, \mathrm{SiO}_{2}, \mathrm{TiO}_{2}, \mathrm{PXC}\right)$ se emplearon unidades de \% en peso, en el resto de los valores se utilizó ppm. Los valores positivos indican enriquecimiento, los valores negativos indican empobrecimiento y valores en cero indican inmovilidad. 
Tabla A5. Resultados de los rangos 1 y 6 ordenados de menor a mayor incidencia, que se muestran en la Tabla A4 del Apéndice A, y obtenidos a partir del estudio de balance de masas de las rocas encajonantes frescas y alteradas de la mineralización del Cinturón de Oro Orogénico Caborca, Sonora, México.

\begin{tabular}{|c|c|c|c|c|c|}
\hline Elemento & $\begin{array}{c}\text { Rango-1 } \\
\Delta \text { conc- } C^{A} \\
(>-0.5)(x)\end{array}$ & $\begin{array}{c}\text { Promedio } \\
\text { aritmético }(x)^{*} \\
\text { empobrecimiento }\end{array}$ & Elemento & $\begin{array}{c}\text { Rango-6 } \\
\Delta \text { conc- } \mathrm{C}^{\mathrm{A}} \\
>2(\mathrm{x})\end{array}$ & $\begin{array}{c}\text { Promedio } \\
\text { aritmético }(\mathbf{x})^{*} \\
\text { enriquecimiento }\end{array}$ \\
\hline Be & $\mathbf{1}(-0.54)$ & -0.16 & Pr & $\mathbf{1}(2.08)$ & 0.46 \\
\hline $\mathbf{V}$ & $\mathbf{1}(-0.62)$ & -0.20 & Sn & $\mathbf{1}(2.52)$ & 0.61 \\
\hline $\mathbf{K}_{2} \mathbf{O}$ & $\mathbf{1}(-0.70)$ & -0.37 & $\mathbf{P t}$ & $\mathbf{1}(2.85)$ & 0.51 \\
\hline W & $\mathbf{1}(-0.74)$ & -0.34 & Nd & $1(3.20)$ & 0.50 \\
\hline Sb & $\mathbf{1}(-0.75)$ & -0.19 & Sm & $1(3.24)$ & 0.57 \\
\hline Tl & $\mathbf{1}(-0.75)$ & -0.39 & $\mathbf{P}_{2} \mathbf{O}_{5}$ & $\mathbf{1}(4.54)$ & 0.89 \\
\hline PXC & $\mathbf{1}(-0.83)$ & -0.33 & $\mathbf{U}$ & $2(2.91)$ & 0.97 \\
\hline $\mathrm{Cr}$ & $\mathbf{1}(-0.84)$ & -0.25 & $\mathrm{FeO}$ & 3(371.13) & 101.62 \\
\hline Os & $\mathbf{1}(-0.98)$ & -0.24 & Se & $\mathbf{3}(6.04)$ & 1.89 \\
\hline Pd & $2(-0.19)$ & -0.35 & As & $4(16.83)$ & 7.85 \\
\hline $\mathbf{Z n}$ & $2(-0.59)$ & -0.29 & $\mathbf{A u}$ & $4(79.27)$ & 45.35 \\
\hline Sc & $2(-0.65)$ & -0.25 & Mo & $\mathbf{5}(29.69)$ & 10.35 \\
\hline $\mathbf{B a}$ & $2(-0.68)$ & -0.32 & $\mathbf{Z n}$ & $\mathbf{5}(44.13)$ & 18.75 \\
\hline La & $2(-0.81)$ & -0.30 & $\mathrm{Be}$ & $\mathbf{5}(8.80)$ & 3.38 \\
\hline $\mathrm{Ce}$ & $2(-0.84)$ & -0.37 & Sb & $6(6.80)$ & 3.51 \\
\hline Sn & $3(-0.53)$ & -0.29 & Tl & 6(93.09) & 40.42 \\
\hline $\mathrm{Cu}$ & $3(-0.63)$ & -0.63 & PXC & $7(3.24)$ & 1.67 \\
\hline $\mathbf{E u}$ & $3(-0.63)$ & -0.29 & $\mathbf{P b}$ & $\mathbf{1 0}(28.46)$ & 20.69 \\
\hline $\mathrm{TiO}_{2}$ & $3(-0.71)$ & -0.36 & Ag & $11(35.25)$ & 27.79 \\
\hline $\mathrm{Fe}_{2} \mathrm{O}_{3}$ & $3(-0.72)$ & -0.31 & $\mathrm{Cu}$ & 11(15.23) & 10.07 \\
\hline Ir & $3(-0.72)$ & -0.31 & $\mathbf{W}$ & 11(18.17) & 12.02 \\
\hline Pr & $3(-0.74)$ & -0.27 & & & \\
\hline Gd & $3(-0.75)$ & -0.28 & & & \\
\hline $\mathbf{N i}$ & $3(-0.75)$ & -0.33 & & & \\
\hline $\mathbf{P t}$ & $3(-0.76)$ & -0.33 & & & \\
\hline $\mathbf{T b}$ & $3(-0.76)$ & -0.36 & & & \\
\hline Nd & $3(-0.77)$ & -0.27 & & & \\
\hline Sm & $3(-0.80)$ & -0.34 & & & \\
\hline Se & 3(-0.89) & -0.44 & & & \\
\hline $\mathbf{P b}$ & $3(-0.93)$ & -0.63 & & & \\
\hline MgO & $4(-0.62)$ & -0.36 & & & \\
\hline $\mathbf{U}$ & $4(-0.70)$ & -0.44 & & & \\
\hline Dy & $4(-0.76)$ & -0.38 & & & \\
\hline Te & $4(-0.78)$ & -0.49 & & & \\
\hline Th & $\mathbf{4}(-0.81)$ & -0.39 & & & \\
\hline $\mathrm{FeO}$ & $4(-0.86)$ & -0.57 & & & \\
\hline Er & $5(-0.74)$ & -0.34 & & & \\
\hline $\mathbf{P}_{2} \mathbf{O}_{5}$ & $5(-0.77)$ & -0.47 & & & \\
\hline Au & $\mathbf{5}(-0.96)$ & -0.49 & & & \\
\hline Tm & $6(-0.67)$ & -37.00 & & & \\
\hline Но & $6(-0.71)$ & -0.36 & & & \\
\hline Y & $6(-0.74)$ & -0.36 & & & \\
\hline $\mathbf{Y b}$ & $6(-0.74)$ & -0.42 & & & \\
\hline As & $6(-0.78)$ & -0.54 & & & \\
\hline Co & $7(-0.72)$ & -0.43 & & & \\
\hline Lu & $8(-0.63)$ & -0.45 & & & \\
\hline MnO & $9(-0.70)$ & -0.50 & & & \\
\hline $\mathrm{Na}$ & $\mathbf{9}(-0.84)$ & -0.57 & & & \\
\hline $\mathbf{S r}$ & 10(-0.73) & -0.54 & & & \\
\hline $\mathrm{CaO}$ & $\mathbf{1 4}(-0.81)$ & -0.70 & & & \\
\hline
\end{tabular}

$\Delta$ conc- $C^{\mathrm{A}}$ : Cambio en la concentración elemental expresado en número de veces con respecto a la concentración de la roca fresca.

Datos con encabezados en azul indican empobrecimiento, y en rojo enriquecimiento.(x): Promedio aritmético de ese intervalo. $(\mathrm{x})^{*}$ : Promedio aritmético de enriquecimiento o empobrecimiento de ese elemento.

Para los cálculos en los elementos mayores $\left(\mathrm{Al}_{2} \mathrm{O}_{3}, \mathrm{CaO}, \mathrm{FeO}, \mathrm{Fe}_{2} \mathrm{O}_{3}, \mathrm{~K}_{2} \mathrm{O}, \mathrm{MgO}, \mathrm{MnO}, \mathrm{Na}_{2} \mathrm{O}, \mathrm{P}_{2} \mathrm{O}_{5}, \mathrm{SiO}_{2}, \mathrm{TiO}_{2}, \mathrm{PXC}\right)$ se emplearon unidades de \% en peso, en el resto delos valores se utilizó ppm. Los valores positivos indican enriquecimiento, los valores negativos indican empobrecimiento. 
Tabla A6. Correlación bivariable del Au

y Ag en el Cinturón de Oro Orogénico

Caborca, NW Sonora, México.

\begin{tabular}{|c|c|c|c|}
\hline $\begin{array}{l}\text { Elem. } \\
\text { Au }\end{array}$ & *Corr. & $\begin{array}{l}\text { Elem. } \\
\text { Ag }\end{array}$ & *Corr. \\
\hline $\mathbf{P b}$ & 0.604 & $\mathbf{P b}$ & 0.703 \\
\hline Ag & 0.553 & Zn & 0.565 \\
\hline Zn & 0.523 & $\mathbf{A u}$ & 0.553 \\
\hline $\mathbf{F e}$ & 0.510 & Sb & 0.522 \\
\hline As & 0.377 & As & 0.469 \\
\hline $\mathrm{Cu}$ & 0.355 & $\mathrm{Cu}$ & 0.432 \\
\hline $\mathbf{N i}$ & 0.296 & Mo & 0.305 \\
\hline Bi & 0.294 & $\mathrm{Sr}$ & 0.274 \\
\hline $\mathrm{Cr}$ & 0.278 & $\mathrm{Fe}$ & 0.251 \\
\hline Мo & 0.243 & $\mathbf{B i}$ & 0.241 \\
\hline $\mathrm{Sr}$ & 0.236 & Ba & 0.231 \\
\hline Sb & 0.225 & $\mathrm{Cr}$ & 0.219 \\
\hline Sc & 0.178 & $\mathbf{V}$ & 0.145 \\
\hline $\mathbf{V}$ & 0.175 & $\mathbf{N i}$ & 0.140 \\
\hline Co & 0.148 & Eu & 0.124 \\
\hline $\mathbf{T i}$ & 0.148 & $\mathbf{U}$ & 0.116 \\
\hline Nd & 0.146 & $\mathbf{W}$ & 0.107 \\
\hline $\mathbf{B a}$ & 0.143 & Pr & 0.083 \\
\hline $\mathbf{L a}$ & 0.143 & $\mathbf{K}$ & 0.051 \\
\hline $\mathbf{U}$ & 0.142 & Al & 0.039 \\
\hline $\mathrm{Ce}$ & 0.137 & Nd & 0.028 \\
\hline $\mathbf{K}$ & 0.128 & $\mathrm{Ce}$ & 0.025 \\
\hline Al & 0.126 & $\mathbf{P}$ & 0.014 \\
\hline Mg & 0.103 & Sc & 0.007 \\
\hline Gd & 0.097 & La & 0.006 \\
\hline Sm & 0.091 & Co & 0.005 \\
\hline Mn & 0.090 & Sm & -0.004 \\
\hline $\mathbf{E u}$ & 0.076 & Gd & -0.012 \\
\hline Th & 0.072 & Mn & -0.036 \\
\hline $\mathbf{P}$ & 0.042 & Th & -0.061 \\
\hline $\mathbf{W}$ & 0.038 & Mg & -0.080 \\
\hline $\mathbf{C a}$ & 0.017 & $\mathbf{T i}$ & -0.124 \\
\hline Dy & 0.001 & Dy & -0.129 \\
\hline Pr & -0.022 & $\mathbf{Y b}$ & -0.135 \\
\hline $\mathbf{E r}$ & -0.044 & $\mathbf{Y}$ & -0.153 \\
\hline $\mathbf{Y b}$ & -0.063 & $\mathbf{C a}$ & -0.173 \\
\hline $\mathbf{Y}$ & -0.066 & $\mathbf{N a}$ & -0.173 \\
\hline $\mathrm{Na}$ & -0.073 & $\mathbf{E r}$ & -0.240 \\
\hline
\end{tabular}

*Correlación de 102 muestras de cuarzo auríferas.

Los coeficientes de correlación $r$ varían entre $-1 \mathrm{y}+1$. Cuando $r=0$ significa una completa independencia entre dos elementos analizados; $r=+1$ indica una relación funcional directa y cuando $r=-1$ indica una correlación funcional inversa (p.ej., Davis, 1986). Elem. $=$ Elemento, Corr $=$ Coeficiente de correlación "r". 